\title{
Measurement in education
}

Citation for published version (APA):

Hirsch, S. (2017). Measurement in education: test scores and beyond. [Doctoral Thesis, Maastricht University]. Maastricht University. https://doi.org/10.26481/dis.20170111sh

Document status and date:

Published: 01/01/2017

DOI:

10.26481/dis.20170111sh

Document Version:

Publisher's PDF, also known as Version of record

Document license:

Unspecified

\section{Please check the document version of this publication:}

- A submitted manuscript is the version of the article upon submission and before peer-review. There can be important differences between the submitted version and the official published version of record.

People interested in the research are advised to contact the author for the final version of the publication, or visit the DOI to the publisher's website.

- The final author version and the galley proof are versions of the publication after peer review.

- The final published version features the final layout of the paper including the volume, issue and page numbers.

Link to publication

\footnotetext{
General rights rights.

- You may freely distribute the URL identifying the publication in the public portal. please follow below link for the End User Agreement:

www.umlib.nl/taverne-license

Take down policy

If you believe that this document breaches copyright please contact us at:

repository@maastrichtuniversity.nl

providing details and we will investigate your claim.
}

Copyright and moral rights for the publications made accessible in the public portal are retained by the authors and/or other copyright owners and it is a condition of accessing publications that users recognise and abide by the legal requirements associated with these

- Users may download and print one copy of any publication from the public portal for the purpose of private study or research.

- You may not further distribute the material or use it for any profit-making activity or commercial gain

If the publication is distributed under the terms of Article $25 \mathrm{fa}$ of the Dutch Copyright Act, indicated by the "Taverne" license above, 


\section{Measurement in Education - Test Scores and Beyond}


(C) Stefa Hirsch, Maastricht, 2017

All rights reserved. No part of this publication may be reproduced, stored in a retrieval system or transmitted in any form, or by any means, electronic, mechanical, photocopying, recording, or otherwise, without the prior permission in writing, from the author.

Cover picture: Prof. Dr. Uwe Hameyer

Cover layout: Martin Hallmann

Published by Maastricht University, Florijnruwe 111-06, 6218 CZ Maastricht Printed in the Netherlands by Datawyse - Universitaire Pers Maastricht

ISBN 9789461596536

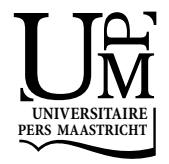




\title{
Measurement in Education - Test Scores and Beyond
}

\author{
Dissertation \\ To obtain the degree of Doctor at \\ Maastricht University \\ On the authority of the Rector Magnificus, \\ Prof. dr. Rianne M. Letschert \\ In accordance with the decision of the Board of Deans, \\ To be defended in public on \\ Wednesday, January 11, 2017 at 16:00 hours \\ By
}

Stefanie Hirsch 


\section{Supervisor}

Prof. Dr. Lex Borghans

\section{Co-Supervisor}

Dr. Trudie Schils

\section{Assessment Committee}

Prof. Dr. Hans Heijke (chairman)

Dr. Barbara Belfi

Dr. Ilja Cornelisz, Vrije Universiteit Amsterdam

Prof. Dr. Ulrich Trautwein, University of Tübingen (DE) 


\section{Acknowledgements}

One dissertation, two supervisors, three years, four offices, five office mates. The result are four studies compiled in this thesis. Many people have helped me, directly or indirectly, in writing this thesis. Therefore, the following appellations are by no means complete.

Throughout the course of writing this thesis my supervisors Lex Borghans, and Trudie Schils have provided me with invaluable support. Lex, your feedback has always been precise as well as result-oriented. Your guidance on how to move within the academic community has allowed me to attend many conferences and meet with several experts in research, policy-making and practice. Trudie, you always provided immediate, and very valuable feedback on all my academic projects and had an open ear whenever I needed it. I am particularly thankful that both of you welcomed my manifold interests rather than considering them distractions.

Many people have given their views, and ideas on the studies in this thesis. I thank them in the beginning of the chapters. The work on each chapter has also been shaped by the different coauthors. I thank all of them for fruitful, and inspiring collaboration. Roxanne Korthals has provided valuable comments for the thesis as a whole in the last phase of the research. In this respect, I also thank the members of the assessment committee.

All studies of this thesis are based on data collected within the OnderwijsMonitor Limburg. I thank everyone involved in this ongoing project. Some of them deserve special attention: Karien Coppens introduced me to the project, and the separate datasets. Tyas Prevoo, and Raoul Haenbeukers many times patiently answered my questions regarding the data collection, and preparation. Leo Kockelkorn let me profit from his long practical experience in school, and Paul Jungbluth from his extensive knowledge of the regional circumstances.

Finally, I am grateful to my family, my mother, my father, and my second father Manfred. All of them provided me with a good foundation to build upon. I thank my family of choice, Hannah, Martin, Dagma, Ella, and Quinn, for continuous moral support as well as for challenging me and helping me to keep a wide perspective.

\section{Stefa Hirsch}

Maastricht, December 2016 



\section{Table of Contents}

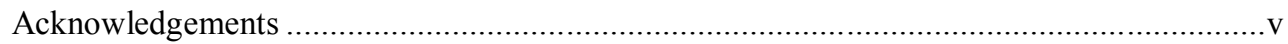

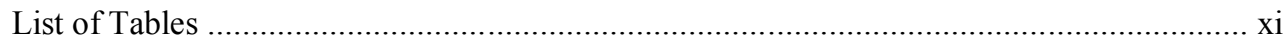

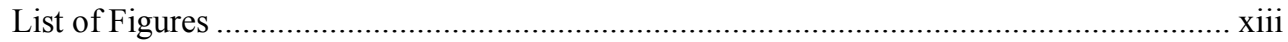

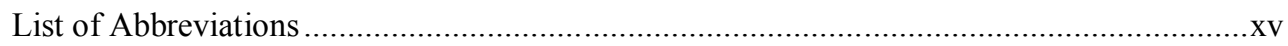

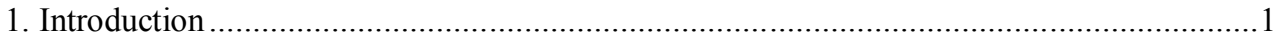

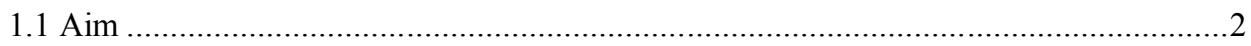

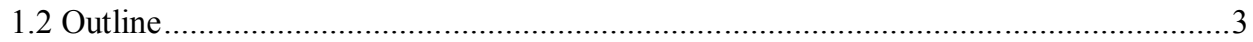

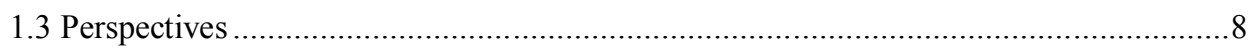

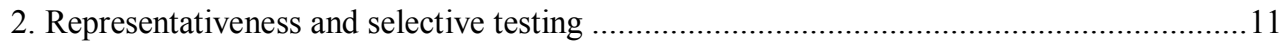

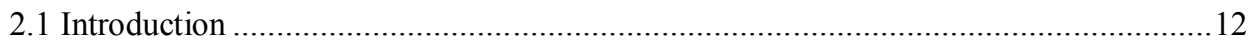

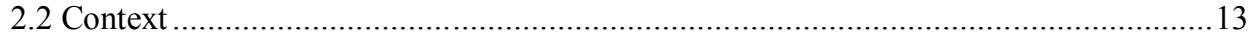

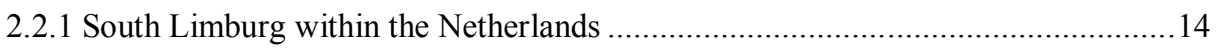

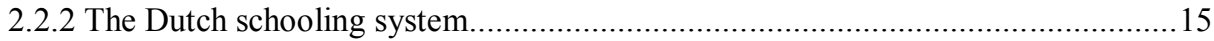

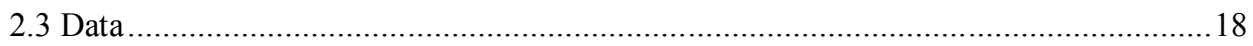

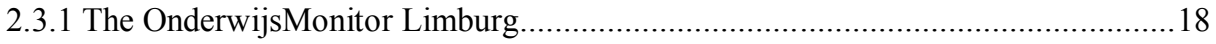

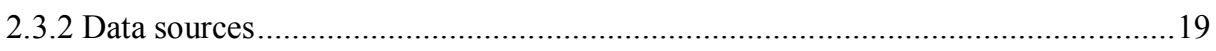

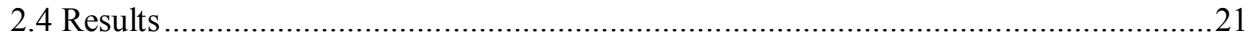

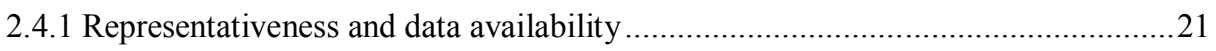

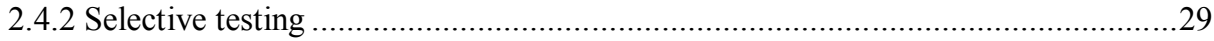

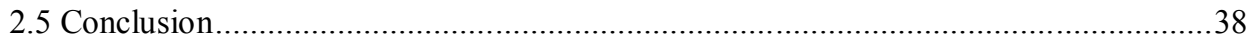

3. Are Estimates of Intergenerational Mobility Biased by Non-Response? ..........................41

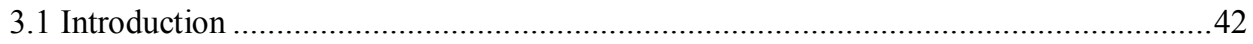

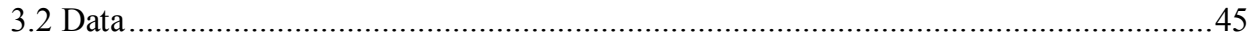

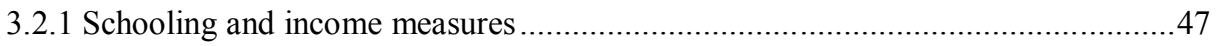

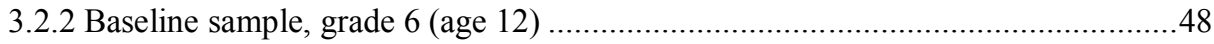

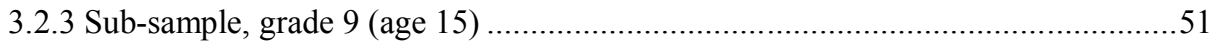




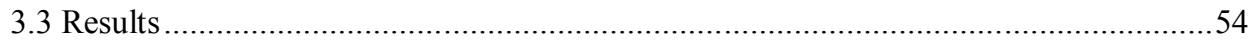

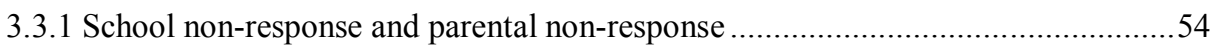

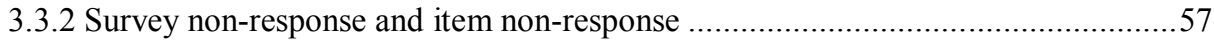

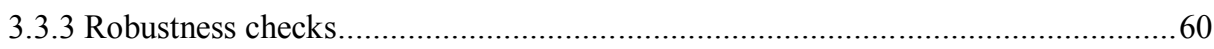

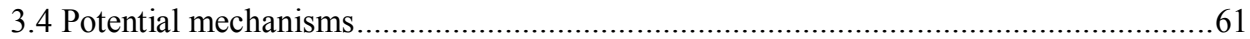

3.4.1 Selection into school survey non-response.....................................................61

3.4.2 Selection into parental survey non-response ..................................................62

3.4.3. Selection into parental item non-response.......................................................63

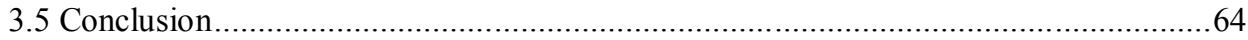

4. Measurement error and intergenerational mobility ...................................................67

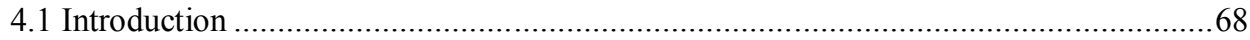

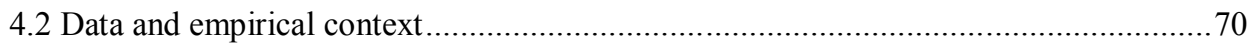

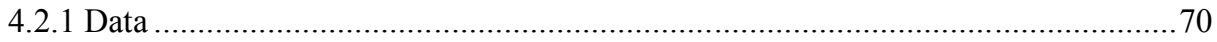

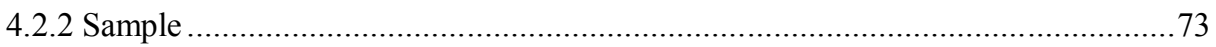

4.3 The raw correlation between parental education and achievement tests .....................74

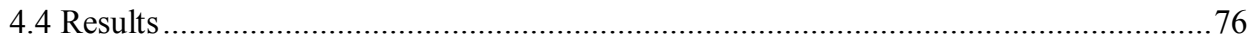

4.4.1 Current test scores as predictors of future test scores .......................................77

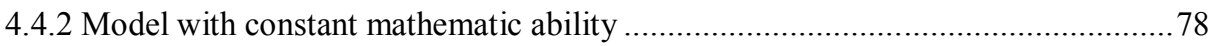

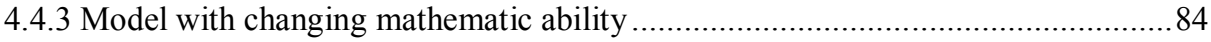

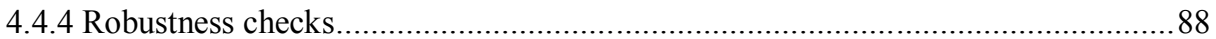

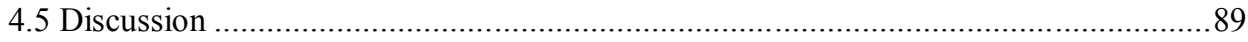

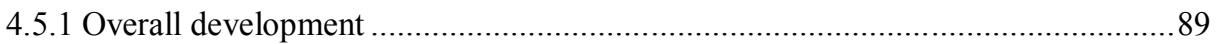

4.5.2 Within-year patterns and the role of the Cito test ......................................... 90

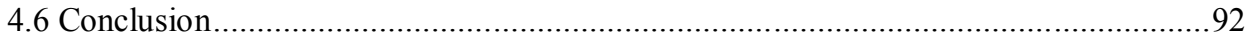

5. Basic numeric competencies - its Measurement and Predictive Value ...........................93

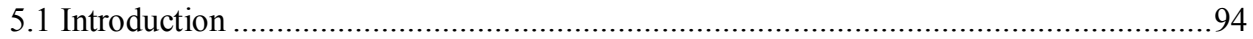

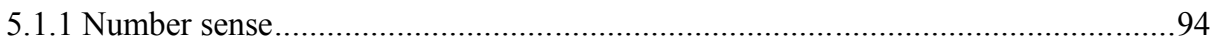

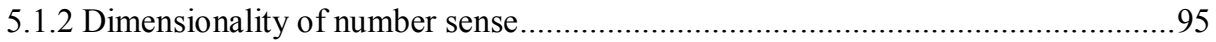

5.1.3 Prediction of later mathematic performance ................................................. 96 


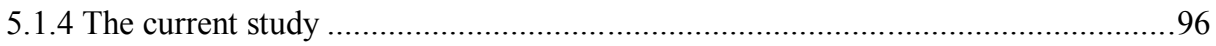

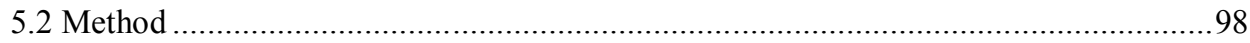

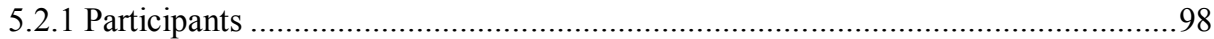

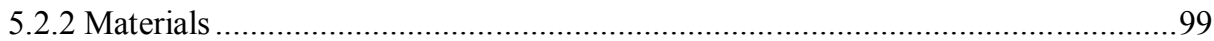

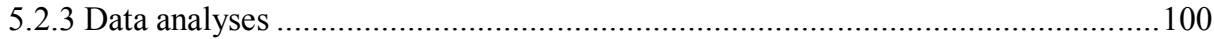

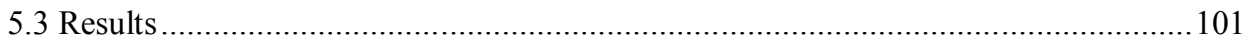

5.3.1 Step 1: Empirical evaluation of the proposed number sense structure .................101

5.3.2 Step 2: Confirming long-term relevance of basic numerical competencies...........103

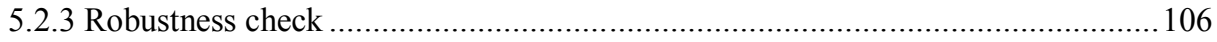

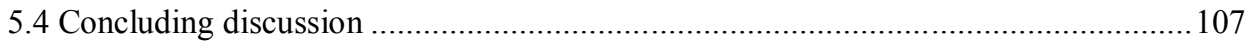

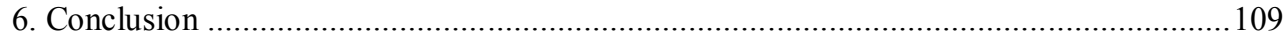

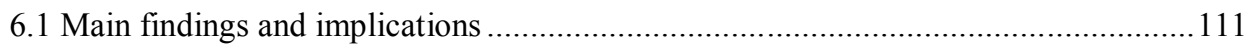

6.1.1 Representativeness and selective testing in education data................................111

6.1.2 Non-response and intergenerational mobility.................................................... 112

6.1.3 Measurement error and intergenerational mobility .......................................... 113

6.1.4 Number sense and its prediction of mathematic achievement.............................. 114

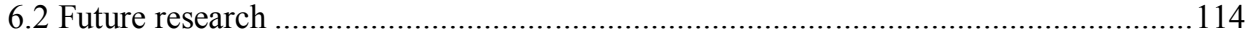

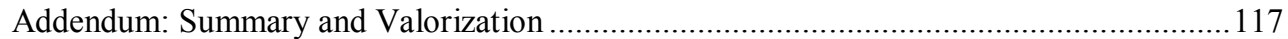

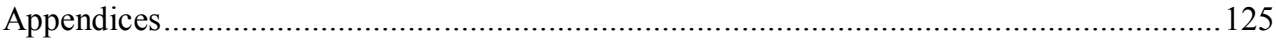

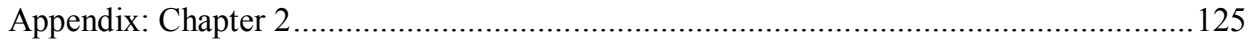

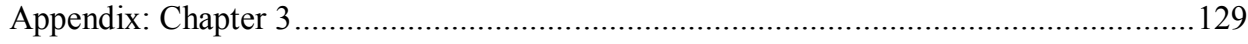

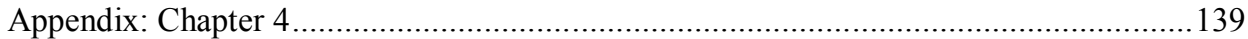

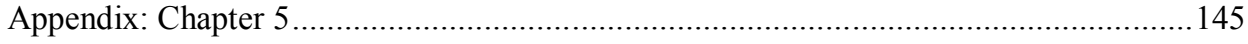

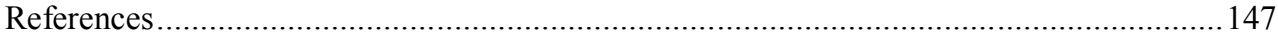

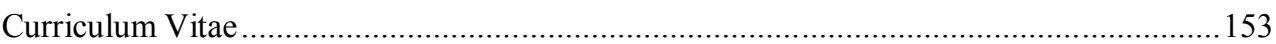





\section{List of Tables}

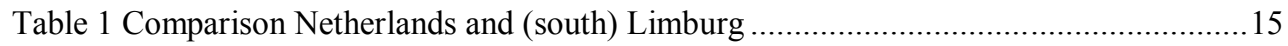

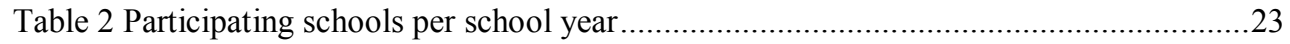

Table 3 Descriptive statistics of individual students, by data availability...........................27

Table 4 Location and denomination of school attended, grouped by data availability ............28

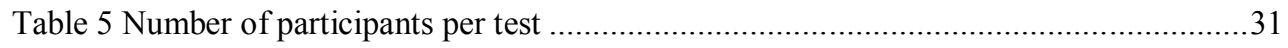

Table 6 Fraction of students tested per school, by school year...........................................32

Table 7 School characteristics, by fraction of all students tested per school and year.............33

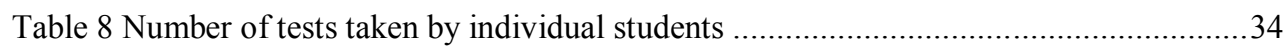

Table 9 Descriptive statistics for students, grouped by the number of tests taken ..................35

Table 10 Extensity of testing, by location and denomination of school.................................37

Table 11 Descriptive statistics by survey response status, baseline sample grade 6 (age 12)..49

Table 12 Parental survey participation by income quintile, baseline sample grade 6 (age 12) 51

Table 13 Descriptive statistics by survey response status, sub-sample grade 9 (age 15)........52

Table 14 Parental survey participation by income quintile, sub-sample in grade 9 (age 15)...53

Table 15 Parental income coefficients explaining test scores, by survey response (grade 6) ..56

Table 16 Parental income coefficients explaining test scores, by survey response (grade 9) ..59

Table 17 Descriptive statistics, by test score availability and parental survey participation ...72

Table 18 Articles with operationalization of number sense including similar competencies ..97

Table 19 Descriptive statistics and correlations between all measures ............................... 101

Table 20 Fit indices of the confirmatory factor analysis ................................................. 103

Table 21 Regression results, longitudinal sample ............................................................... 104

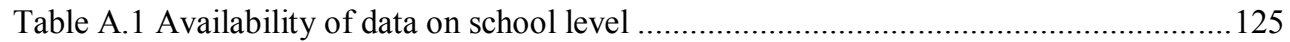

Table A.2 Availability of data on school-year level ........................................................ 126

Table A.3 Availability of data on individual student level..............................................127

Table A.4 Descriptive statistics for students without administrative data.......................... 129

Table A.5 Regression results for full sample with interactions, baseline sample grade 6 .....130

Table A.6 Regression results for full sample with interactions, sub-sample grade 9 ...........131

Table A.7 Regression of school survey response on aggregate characteristics .................... 132

Table A.8 Regression of parental survey response on individual characteristics ................. 133

Table A.9 Regression of parental item response on individual characteristics ....................134

Table A.10 Correlations of parental education level with Cito and PIAAC test ...................139

Table A.11 Descriptive statistics for tests, based on unbalanced sample.............................139

Table A.12 Variance-covariance matrix of test scores and socio-economic background......143 



\section{List of Figures}

Figure 1 Limburg in the Netherlands and sub-regions in south Limburg ............................. 14

Figure 2 Schematic depiction of the Dutch education system .......................................... 16

Figure 3 Data collected by domain, grade and project .................................................. 19

Figure 4 Number of observations depending on data sources required ................................22

Figure 5 Participation of schools in different domains....................................................24

Figure 6 Students' Cito score distributions, by the number of tests taken in primary school ..36

Figure 7 Data collection and approximate response rates in both samples ...........................46

Figure 8 Cito score distributions, by survey response, baseline sample grade 6 ....................50

Figure 9 Box plots of Cito scores, by survey response and income, baseline sample grade 6.55

Figure 10 Box plots of language scores, by survey response and income, sample grade 9 ....58

Figure 11 Correlation between mathematics scores and highest parental education level ......75

Figure 12 Correlations of scores in consecutive mathematics tests ...................................77

Figure 13 Coefficients of structural equation model, mathematic ability as latent variable ....80

Figure 14 Development of normalized PE coefficients (detail from Figure 13) ....................81

Figure 15 Normalized PE coefficients for different test score quartiles ..............................83

Figure 16 Coefficients of rolling structural equation model............................................... 85

Figure 17 Normalized PE coefficients based on rolling sem (detail from Figure 16) ............86

Figure 18 Decomposition of test score variance ........................................................... 87

Figure 19 Normalized PE coefficients for test score quartiles, based on rolling sem.............88

Figure 20 Confirmatory factor analysis for five factor model of number sense ................... 102

Figure 21 Comparing predictive power of early numeracy test and curricular test ...............106

Figure A.1 Language test distributions by survey response status, sub-sample grade $9 \ldots \ldots . .135$

Figure A.2 Mathematics test distributions by survey response status, sub-sample grade $9 \ldots 136$

Figure A.3 Box plots of mathematics test by survey response and income, sample grade 9.137

Figure A.4 Average Cito mathematics score for changing part of the unbalanced sample....140

Figure A.5 Coefficients of separate regressions, mathematic ability from Cito test .............141

Figure A.6 Coefficients of separate regressions, mathematic ability from sem .................. 141

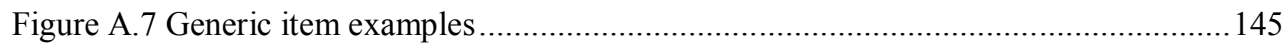





\section{List of Abbreviations}

CFI

Cito

Cito test

CNT

$\mathrm{COOL}^{5-18}$

DUO

gen. cogn. ability

HAVO

HBO

INR

IR

ISCED

$\mathrm{kg}$

LOVS

LVS

MATH

MBO
Comparative Fit Index

Centraal Instituut voor Toetsontwikkeling

[Central Institute for Test Development]

Cito Eindtoets

[Cito Endtest]

counting

Cohortonderzoek Onderwijsloopbanen onder leerlingen van 5 tot 18 [Cohort Study Educational Careers on students from 5 to 18]

Dienst Uitvoering Onderwijs

[Office of Education]

general cognitive ability

hoger algemeen voortgezet onderwijs

[higher general secondary education]

hoger beroepsonderwijs

[higher vocational edcuation]

item non-responding (parents)

item responding (parents)

International Standard Classification of Education

kindergarten

Cito Leerling Onderwijs Volgsysteem

[literally: Cito Pupil Education Monitoring System]

Cito Leerling Volgsysteem

[literally: Cito Pupil Monitoring System]

mathematic ability

middelbaar beroepsonderwijs

[mid-level vocational education] 
multiple choice

NSNK

OECD

OML

PE

PER

PIAAC

PISA

RMSEA

sem

SER

ses

SLO

SNK

SNR

SR

TLI

VMBO

VWO

WO non-symbolic number knowledge

Organization for Economic Co-operation and Development

OnderwijsMonitor Limburg

[Education Monitor Limburg]

highest parental education level

perceptual matching

Programme for the International Assessment of Adult Competencies

Programme for International Student Assessment

Root Mean Squared Error of Approximation

structural equation model

seriation

socio-economic status

Stichting Leerplanontwikkeling Nederland

[Foundation Curriculum Development Netherlands]

symbolic number knowledge

survey non-responding (parents)

survey responding (parents)

Tucker-Lewis Index

voorbereidend middelbaar beroepsonderwijs

[pre-mid-level vocational education]

voorbereidend wetenschappelijk onderwijs

[pre-university education]

wetenschappelijk onderwijs

[university education] 
Introduction 


\section{Chapter 1: Introduction}

\subsection{Aim}

The perfect data do not exist. No survey covers the full population. No measurement is without error. No dataset is complete, in the sense that always some useful information has not been assessed. This holds generally, hence also for measurement in education. Working empirically means dealing with imperfections. Researchers have to make compromises, choosing one of several non-optimal cases. In the field of education, this is further complicated because researchers depend on the collaboration of many different actors, such as parents, teachers and schools.

The aim of this thesis is to understand nuisances and specific features in education data better, as a means to improve empirical research. The first goal is to improve the understanding of how distortions in survey data, administrative data, and measurement methods influence research findings. The second goal is to provide insight into how to minimize such distortions, to reach sound answers to research questions and ultimately valid policy implications.

Four separate studies assess the consequences of selective data collection and selective testing (Chapter 2), non-response bias (Chapter 3), measurement error (Chapter4) and aggregated test scores (Chapter 5). The studies are exemplary, each of them analyzes one of those data-related imperfections with respect to a specific focus or relationship: the representativeness of a dataset (Chapter 2), the assessment (Chapter 3) and development (Chapter 4) of intergenerational mobility, and the understanding of skill development (Chapter 5).

The thesis combines basic methodological analyses in order to improve future empirical educational research without increasing resource requirements. The contribution is threefold: Firstly, each chapter provides an estimation of how much a specific nuisance in the data matters in that exemplary context, raising awareness. Secondly, and mainly, the results yield some insights in which questions to ask oneself regarding the data collection, choice of data, and methodology. Different suggestions are provided regarding how to minimize the impact of data imperfections. Thirdly, the proposed methodologies, such as the combination of administrative and survey data in Chapter 3, can be applied in other contexts to replicate the studies, as well as to transfer it to other research questions.

The context remains the same throughout the thesis, while the focus changes between different data-related challenges. All studies use data collected within a comprehensive educational monitor in the south of the Netherlands. Chapter 2 introduces the education monitor and analyzes how representative the sample is with respect to the different data sources compiled. 
Chapter 3 focusses on survey non-response and how it influences estimates of intergenerational mobility. Connected to that, Chapter 4 investigates the role of measurement error in the observed development of intergenerational mobility, over the course of primary school. Lastly, Chapter 5 zooms in to the item level of a test, analyzing whether test results per question increases the predictive power for later achievement tests, compared to simple sum scores. A more detailed outline is provided in Section 1.2.

Each of the Chapters 2 to 5 is an independent study on specific methodological or data-related challenges, with respect to a specific empirical research question in education. Yet, they complement each other: All of them use test scores in their analyses, sometimes they even use the same tests. The same context allows that each study can draw on the results of the other studies, without having to make further assumptions. Such interconnections are pointed out in Section 1.3 and made explicit throughout the thesis. The result is a collection of insights regarding imperfections in data, and measurement by test scores. This thesis provides an example of how various data sources, as well as methodologies from different disciplines, can be combined to reach a deeper understanding of empirical challenges in education.

\subsection{Outline}

In this section, the chapters are shortly summarized. For each chapter an empirical motivation, the main aim, the chosen approach, as well as the major findings, and contributions are provided. Finally, commonalities, and interconnections between the separate chapters are pointed out.

Chapter 2 has two functions. First of all, it introduces the data used in all studies. All four studies rely on test scores, and additional data collected within a regional educational monitor in the south of the Netherlands, the OnderwijsMonitor Limburg (OML). It comprises data from a variety of sources, including administrative school records, and surveys, filled in by teachers, parents, and students. The OML covers the school career from kindergarten to secondary education. More than 95 percent of all primary schools in the region of interest collaborate to some degree. Since the starting year of 2009, seven cohorts and in total almost 40.000 primary school students have been covered. Some of the cohorts can be followed through their school career already.

The OML can be seen as exemplary for other rich datasets or panels drawing on several data sources. The problem is that the more data sources are compiled, the more conditions have to be met to observe all required information for all targeted individuals. The more people are 


\section{Chapter 1: Introduction}

missing, the larger the potential non-random selection (Hauser, 2005). Probability weights can be used to account for this. However, as Chapter 3 shows, the relationship of interest among the covered population could still differ from that among the ones left out. Such a bias cannot be prevented by using probability weights. Many empirical studies start their empirical work, before having answered the questions, who is in their data, and in which way this group might be special. Chapter 2 is an exemplary analysis of the OML in this respect. In the overall structure of the thesis, Chapter 2 provides the basis for the other chapters. The analysis considers the underlying processes of data collection, such as different degrees of collaboration, software used by the school administration and testing policies across schools. Vulnerable points are identified and discussed.

The main analysis is threefold: First of all, it describes the setup, and the coverage of the education monitor. The second part analyzes which combinations of available data sources exist and identifies typical profiles of schools and individuals. The third part more specifically investigates how consistent, and how extensive schools use standardized mathematics tests and whether some students are tested more often than others.

Overall, more than 97 percent of the schools in south Limburg are covered by the OML. For more than 87 percent of the individual students, administrative data, and at least one performance measure are available. Most critical is the availability of parental survey data. There is little persistent non-collaboration on the school level, 94 percent of schools provide data from all, or all but one source. Yet, there are many changes on a yearly basis, pointing towards the cohort or class level as the critical one. Thus, most analyses are conducted on a school-year basis, as well as on an individual level. Data availability goes hand in hand with other favorable characteristics. The group for which most data are available, also shows the highest average performance. With respect to consistency, 15 to 38 percent of school-year combinations test more than 80 percent of their students, yet, not all. This is no proof of strategic testing behavior, however, the observation would be consistent with not testing specific students. The extent of testing in the student population also varies. More consistent testing refers to a case in which a school applies most or all tests, or a student takes most or all tests. On an individual level, this is associated with higher performance levels, while only taking some tests is associated with comparatively worse performance. Additionally, observed patterns of schools' participation, and testing behavior with respect to the region and the denomination of the school are presented, and discussed.

Many of the questions arising from the descriptive analyses are addressed in the following chapters. Chapter 3 analyses the reasons, and consequences of parental non-response. How the 
different degree of availability of test score might influence the results, is considered in Chapter 4. Chapter 5 complements the analysis, by zooming in to the item level of one specific test. Other questions raised are, whether schools, indeed, show strategic testing behavior, and whether there is a causal relationship between extensive testing and performance. Both questions would require detailed analysis and go beyond the scope of this thesis.

Both, Chapter 3 and Chapter 4, investigate questions related to intergenerational mobility or conversely intergenerational dependency. Black and Devereux (2011) define intergenerational dependency as the "persistence between parents and children's outcomes". Thus, intergenerational mobility is the degree to which children's outcomes are independent of their parents' characteristics and outcomes. There are many big questions in this context, such as, how much it depends on genetic differences or on differential human capital investment (nature versus nurture), and what the optimal level of intergenerational mobility would be. However, this thesis focusses on measuring the underlying correlations between outcomes.

In the above mentioned definition, the words "characteristics" and "outcome" are placeholders. They already point to the fact that this concept is very broad and encompasses a lot of specific cases. This thesis restricts itself to children's schooling outcomes in primary school and the first years of secondary school. On the parental side, Chapter 3 uses the measure of household income and Chapter 4 parental education. Both measures are widely used in empirical analyses of intergenerational mobility (e. g. Blau, 1999; Chevalier, Harmon, O’Sullivan, \& Walker, 2013). Compared to other measures, they are easy to operationalize and widely available, as in our case, sometimes even from administrative sources. The same holds for the outcomes of the second generation. Earlier test scores, as considered here, have the advantage that they provide insights in how intergenerational mobility develops and can inform policy makers who want to foster intergenerational mobility. As Black and Devereux (2011) state, test scores are an intermediate variables, which ultimately affect children's income.

Chapter 3 addresses potential biases in estimates of intergenerational mobility, based on nonresponse. In this case, intergenerational mobility is defined in terms of parental income and students' test scores at the end of primary school. The extent to which school success depends on parental income is often estimated based on information assessed in parental surveys (see e. g. Blau, 1999; Chevalier et al., 2013; Plug \& Vijverberg, 2005). However, participation in the latter is potentially not random. The analysis assesses whether, and how much survey-based estimates of the relationship between household income, and the child's school performance are biased due to selective non-response. 


\section{Chapter 1: Introduction}

Parental survey data from the OML are merged to administrative data from schools and national income registry data. Using this information, we can assess what the estimates would be, if based on all students in the dataset. This estimate can be compared to the estimates based on samples, artificially restricted by school non-collaboration in sending out the surveys, or by parental non-response on the survey, or item level. Similar approaches of combining survey data with full population register data to investigate the impact of survey non-response have been taken in health science (Reijneveld \& Stronks, 1999; Søgaard, Selmer, Bjertness, \& Thelle, 2004) and by Micklewright and Schnepf (2006) to assess the response bias in the PISA study in the UK.

In the context of the OML, the positive relationship between parental income and child schooling is found to be attenuated, because specific schools choose to participate in the data collection. Parental survey non-response on the other hand does not significantly affect the estimates in most of the cases. If at all, there is suggestive evidence for an underestimation of intergenerational dependency. Parental item non-response on the income question, on the other hand, leads to an overestimation of the relationship. Specifically, this study shows that schoollevel non-response as well as item non-response are most relevant in the context of intergenerational mobility. More generally, the proposed methodology can also be applied in other context to assess the influence of survey non-response.

Chapter 4 focusses on intergenerational mobility as well, here, with respect to the highest parental education level. The independence of a child's school success from parental education levels is considered a target dimension of education with respect to social cohesion (Luyten, Cremers-Van Wees, \& Bosker, 2003; Sammons, 1995). Often correlations are used as measures to assess this dimension. An alternative strand of literature analyzes test score gaps, and how they develop over time (Fryer Jr \& Levitt, 2004; Polidano, Hanel, \& Buddelmeyer, 2013). There are certain weaknesses to these approaches: Firstly, correlations capture solely one or few points in time. Secondly, the analysis of test score gaps has been criticized low robustness with respect to transformations of test scores (Bond \& Lang, 2013; Lang, 2010). Thirdly, both approaches are vulnerable to measurement error in test scores. This chapter aims to investigate the development of intergenerational dependence, measured as the correlation between highest parental schooling level and children's school performance over time. A particular focus is placed on how measurement error influences the observed correlations.

A series of comparable test scores in mathematics, covering six years of primary school, are analyzed stepwise: The first approach, of plotting correlations between consecutive test scores, leads to the development of a structural equation model. In a second step, the model is 
estimated. In a third step, the assumption of constant mathematic ability is relaxed. While simple correlations show an almost monotonic increase of intergenerational dependence with respect to parental education from grade 1 onwards, the proposed structural equation model shows a different result. Overall, a u-shape with a sharp decrease in the first year, a slow rise in the middle years, and a rise towards the end of primary school are found. The rise is first driven by decreasing measurement error. Towards the tracking decision, the connection to parental education becomes stronger. Additionally, an observed repeated pattern within the school years is consistent with an equalizing effect of school - at least in the middle years of primary school. Overall, the analysis shows that simple correlations might paint a misleading picture, and it provides an alternative way of analysis. Specifically, the results imply that the younger the children are, the less trustworthy the test results are - be it for a lack of stability of the skills, the fact that they are not used to testing yet, or the quality of the tests. Parents' influence particularly increases toward the high stakes final assessment test in primary school. Thus, this chapter contributes to the literature on the interpretation and comparison of test scores at different ages as well as to longitudinal analyses of intergenerational mobility.

Chapter 5 dives deeper into the development of mathematic skills. Mathematics has been shown to be an important general skill. The precursors of mathematic skills have so far only been investigated based on small or medium sized datasets (Aunio, Ee, Lim, Hautamäki, \& Van Luit, 2004; Aunio \& Niemivirta, 2010; Cirino, 2011; Kolkman, Kroesbergen, \& Leseman, 2013), as well as over restricted longitudinal time-spans (Aunio \& Niemivirta, 2010; Jordan, Kaplan, Nabors Oláh, \& Locuniak, 2006). This chapter aims to investigate the factor structure of number sense and its predictive value for later math achievement, based on a large dataset $(\mathrm{N}>3,000)$, covering a time span of six years. Instead of conducting an own experiment, a test widely applied in Dutch kindergarten, with the data covered by the OML, is used.

The analysis, in contrast is based on a large sample $(\mathrm{N}>3,000)$ and covers a time-span of six years. It is conducted in two steps: In a confirmatory factor analysis, earlier proposed factor structures are compared to a newly developed one. A regression analysis is used to investigate predictive power of early numeracy tests for mathematical achievement six years later. The results support a five factor model over a simple one-factor model, and over an earlier proposed three-factor model. Using the five factor model, the separate factors do not contribute to the total explained variance for later mathematical achievement compared to the sum score. However, some factors seem to be more important than others. The chapter provides a start into large scale assessment of the number sense structure as well as its long-term predictive value. Furthermore, the results of the regression analysis show that the established practice of only 


\section{Chapter 1: Introduction}

using sum scores for predicting later outcomes does not cause a loss in explained variance, compared to the more demanding analysis using item-based data.

\subsection{Perspectives}

As stated above, this thesis comprises four interrelated, yet independent studies, presented in Chapters 2 to 5 . All of them use the same dataset, the OML. However, the similarities go beyond that. Connections between the studies can be found on several different levels. In the following, some perspectives on how the chapters relate to each other are explicated. Choices that had to be made are explained.

As the title already suggests, all studies relate to test scores. Thus, the chapters can be structured by which fields, and age groups they cover. Except for Chapter 3, all analyses are restricted to tests in mathematics. Firstly, mathematics tests are easier, and less ambiguous to grade. Secondly, mathematics tests differentiate more (see Table 11). Thirdly, data availability is much better for mathematics tests than for language tests in our context (see Section 2.4.2). Due to this choice, Chapter 2 introduces the dataset with a specific focus on schools' testing behavior in mathematics. Chapter 4 uses the full series, plus the mathematics section of a final assessment test. Chapter 5 analyzes test scores of an early numeracy test, conducted in the last year of kindergarten. Further, test scores from the last low stakes mathematics test in primary school are used as an independent variable, to test the predictive power of factors of early numeracy. Chapter 3 constitutes the exception. Here, data from the final assessment test, for mathematics as well as for language, are used. The analysis is extended based on a longitudinal sub-sample, drawing on mathematics and language tests conducted in the third year of secondary school.

Regarding the content, there is an emphasis on intergenerational mobility or intergenerational dependency, with respect to different measures of parental socio-economic background. Chapter 3 looks at how to assess the relationship between parental income and schooling outcomes without a bias. Chapter 4 assesses how the relationship between highest parental schooling level, and own achievement in school develops. In this developmental perspective, Chapter 4 also relates to Chapter 5, which analyzes the factor structure of early numeracy and the predictive value for later achievement.

From a broader perspective with respect to the data structure, the four studies can be distinguished two by two. Two chapters focus on the processes underlying the data collection from several data sources (Chapter 2), as well as the administration of a survey (Chapter 3). The two other studies provide insight into how to use, and interpret test results; once for 
inferences regarding intergenerational dependency (Chapter 4), once regarding the prediction of later achievement or difficulties (Chapter 5).

Finally, the involved co-authors stem from a number of different academic disciplines. Chapters 2 and 3 are based on collaborations with other economists. Chapter 4 is influenced by a sociological perspective and methodology. The last study, in Chapter 5, is the result of a collaboration with psychologists. 



\title{
Representativeness and selective testing
}

\section{- An exemplary analysis of the Education Monitor Limburg ${ }^{1}$}

\begin{abstract}
Research in education often relies on different data sources. One increasingly important data source, used to assess student and school performance, are test scores. The completeness of survey and test score data depends on the collaboration of a number of different actors. However, with a specific research question in mind, quality and representativeness of the data often fade into the background. In this chapter, we investigate the dataset used in the rest of this dissertation. In particular, we examine how representative the participating schools and the covered student population are, as well as how selective schools test and provide test
\end{abstract} scores.

\footnotetext{
${ }^{1}$ This chapter is based on joint work with Trudie Schils. The data collection within the education monitor has been funded by the province of Limburg, regional school boards, the Dutch Ministry of Education, as well as by institutes for higher education in Limburg. We thank Jaqueline Haze for extensive information on the process of data collection as well as the collaboration with the schools. Further, we thank Lex Borghans, Karien Coppens, and Roxanne Korthals for valuable comments, as well as Tyas Prevoo, Raoul Haenbeukers, Leo Kockelkorn, and Paul Jungbluth for providing us with further background information.
} 
Chapter 2: Representativeness and selective testing

\subsection{Introduction}

Empirical research analyzes samples to make inferences about the full population. Whether those findings really generalize to a larger group is a question of validity and crucially depends on the representativeness of the sample. Non-response, hurdles in the data collection, as well as earlier stage decisions, such as non-testing in the context of education, do not only reduce the sample size, but are likely to induce non-random selection. As Hauser (2005) points out, "it may affect univariate distributions of key variables, or worse yet, it may distort observed relationships among variables". Although Hauser's statement refers specifically to nonresponse, it can be generalized to other systematic sources of data availability. The more data sources are required, the more potential is there for non-random selection. Thus, there might be a trade-off between the richness of a dataset and its validity.

This chapter relates to all the other chapters in this thesis, by introducing the underlying dataset. Further, it relates to the literature discussing representativeness of specific datasets (e. g. Bee, Gathright, \& Meyer, 2016; EUROSTAT, 2009; Hauser, 2005; National Longitudinal Surveys, 2016). However, scientific articles in the economics of education, not directly associated with a survey or panel, rarely target specific problems that may lead to non-representativeness or distorting strategic behavior (Sims, 2008, to name one of the exceptions). If addressing potential threads to representativeness, they mostly target individual non-response (Porter \& Whitcomb, 2005) and not the school level.

The aim of this chapter is to conduct an exemplary analysis of the representativeness and the underlying selection into the availability of test score and questionnaire data in the context of education research. Furthermore, this chapter also provides an introduction to the empirical context of this dissertation and the data used in the other three studies.

The analysis is based on a large-scale education monitor for a region in the south of the Netherlands, the OnderwijsMonitor Limburg. The monitor comprises data from various sources. Many different actors, such as school boards, schools, teachers, parents, and students, are involved in the data collection. Yearly data collections and following students throughout their school career are the basis for a panel-like structure. This complex setup provides many opportunities to investigate selectivity of data availability. We develop a series of different formats (schemes and tables) to provide insight into representativeness and data availability on the school as well as on the individual level. Since test scores are increasingly used to assess students and school performance, in a second step, we analyze how selectively schools test. 
We find that the OML covers a large share of the primary school population in south Limburg. At least 97 percent of the schools participate. And, on the individual level, administrative information, as well as at least one performance measure are available for more than 87 percent of the students. Only if data from all sources are required, the coverage reduces to about 40 percent. Most critical, among all data sources, is the parental survey participation. The large majority of the participating schools provides data from all or all but one data source at least once. However, there are large differences between the years, so that we choose school-year combinations as the main unit of analysis. On this level, we find evidence for potential strategic testing, because a sizable number of schools do not test all of their students. Regarding data availability on the individual level, we find that broad data availability goes along with a higher average performance of students. The same holds for more extensive testing throughout primary school. All in all, this study only provides a starting point for more detailed analysis of the different aspects.

The contribution of this chapter is two-fold. In the context of this dissertation, it provides an introduction into the data, insight into selectivity, and how representative the data are, conditional on which data sources are required for the analysis. More generally, this chapter raises awareness for how influential data selectivity can be, and that it can have severe consequences for conclusions drawn from data. Rather than an inconvenient obligation, analyzing selectivity of data can be a chance to specify for which group the research results hold.

The remainder of the chapter is structured as follows: Section 2.2 provides a description of the regional context. Section 2.3 introduces the education monitor and the individual data sources it comprises. Section 2.4 includes three sub-sections with the results. Section 2.5 concludes.

\subsection{Context}

This analysis focusses on data collected within the OnderwijsMonitor Limburg (OML), a regional collaboration between Maastricht University, educational institutes and government bodies. As the name suggests, it focusses on the Province of Limburg, particularly the southern part, where the city of Maastricht is situated. The aim of the OML is to gain insight into the educational development of pupils: first, to foster improvements of education and transitions from education to the labor market in the region of Limburg, and second, to acquire knowledge about the general dynamics of educational processes. A detailed description of the OML follows 
Chapter 2: Representativeness and selective testing

in section 2.3. As a background, this section provides a brief description of the specific socioeconomic situation in the region of Limburg as well as of the Dutch schooling system.

\subsubsection{South Limburg within the Netherlands}

Limburg is the southernmost of the 12 provinces of the Netherlands. The collaboration with primary schools concentrates on the southern half, while the collaboration with secondary schools covers the whole province. Thus the most complete dataset is available for the southern part of Limburg, which shares long borders with Belgium in the west and with Germany in the east.

Figure 1 Limburg in the Netherlands and sub-regions in south Limburg

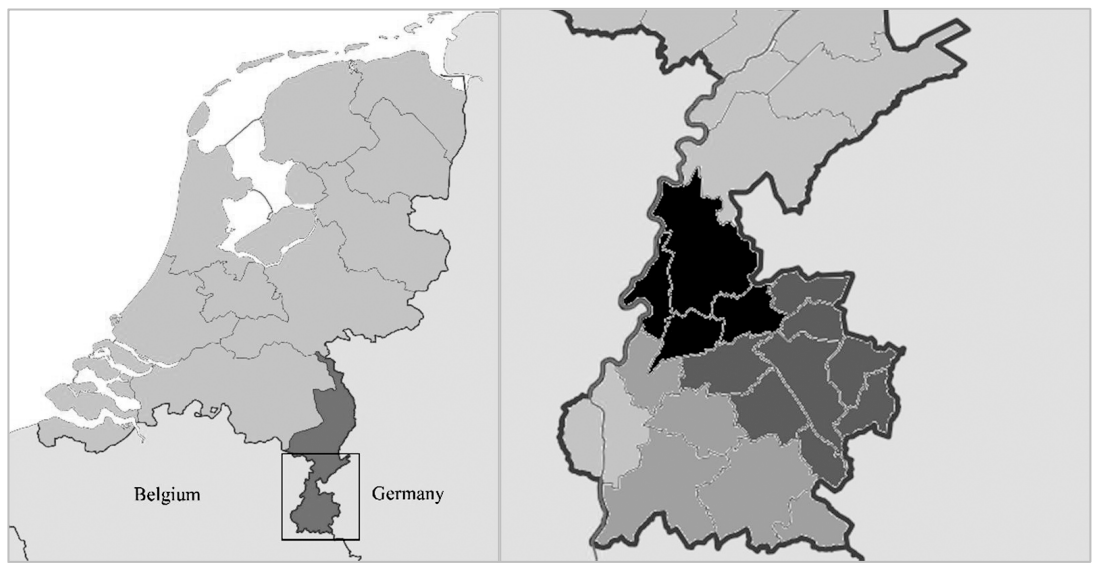

Notes: Map of Limburg in the Netherlands based on work by TUBS (2011), CC BY-SA 3.0, and map of Limburg based on Frohne (2009), CC BY-SA 3.0. Both maps were attained via Wikimedia Commons. The left map of the Netherlands highlights the province of Limburg. The right map of the south of Limburg distinguishes the four subregions: Westelijke Mijnstreek (north), Parkstad (east), Heuvelland (south) and the metropolitan area of Maastricht (east)

South Limburg itself can be distinguished again in four sub-regions, called: Westelijke Mijnstreek (north), Parkstad (east), Heuvelland (south) and the metropolitan area of Maastricht (east). Westelijke Mijnstreek as well as Parkstad both also comprise medium sized cities, Sittard-Geleen and Heerlen, respectively. ${ }^{2}$ For a map of south Limburg and how it is situated within the Netherlands see Figure 1. In the small map of the Netherlands the dark grey part is

\footnotetext{
${ }^{2}$ Different divisions of the region can be made. Especially the regions Westelijke Mijnstreek and Parkstad can be further distinguished in rural and urban areas. In this study, we chose to only separate Maastricht, which is the largest of the cities.
} 
Limburg. The large map zooms in and highlights the four sub-regions of Limburg mentioned above.

Table 1 provides some background characteristics, comparing Limburg to the Netherlands. In general, it is one of the economically weaker provinces with a GDP about 17 per cent lower than the national average. In comparison to other economically weak provinces, Limburg is quite densely populated, but with regional differences in the population density and structure. Overall, all sub-regions in south Limburg are shrinking, only at different rates. Parkstad is often considered a problematic region. It shrinks at the highest rate. Furthermore, it also has the second largest rate of first or second generation immigrants after Maastricht.

Table 1 Comparison Netherlands and (south) Limburg

\begin{tabular}{lrrrrr}
\hline & $\begin{array}{c}\text { Population } \\
\text { (in 1,000) }\end{array}$ & $\begin{array}{c}\text { Migration } \\
\text { background } \\
\text { (in percent) }\end{array}$ & $\begin{array}{c}\text { Population } \\
\text { density } \\
\text { (per km²) }\end{array}$ & $\begin{array}{c}\text { Population } \\
\text { growth } \\
\text { (per 1,000) }\end{array}$ & $\begin{array}{c}\text { GDP } \\
\text { (per capita) }\end{array}$ \\
\hline NL & 16,829 & 21.4 & 500 & 4.2 & 39,440 \\
Limburg & 1,120 & 20.7 & 521 & -1.8 & 32,734 \\
Westelijke Mijnstreek & 148 & 18.7 & $1,021.3$ & -1.2 & \\
Parkstad & 248 & 24.9 & $1,179.9$ & -6.4 & \\
Heuvelland & 85 & 16.8 & 357.3 & -2.8 & \\
Maastricht & 122 & 28.4 & $2,163.0$ & -.7 & \\
\hline
\end{tabular}

Notes: All figures refer to information from Statistics Netherlands (Statistics Netherlands, 2015, 2016), regarding the year 2014.

\subsubsection{The Dutch schooling system}

The Dutch schooling system is depicted schematically in Figure 2. As can be seen from the figure, most Dutch children start kindergarten $(\mathrm{kg})$ when they are 4 years old. From the age of 5 attendance is obligatory. ${ }^{3}$ Subsequently, when children are about 6 years old, they move on to primary school. Kindergarten and primary school are one institution; they differ only in the degree of formality of education. After six years of collective schooling, children make a transition to one of six major secondary schooling tracks (excluding the lowest level of practical education, "praktijkonderwijs", and special education). The tracks cannot be chosen freely.

\footnotetext{
${ }^{3}$ Even though those two years are considered to be part of Dutch primary school, education is less formal in these years. In the international comparison, based on ISCED, those first two years are not considered as being part of primary education (Central Bureau voor de Statistiek, 2011).
} 
Chapter 2: Representativeness and selective testing

Instead, they strongly depend on a recommendation by the primary school teacher. The application for secondary school includes this recommendation as well as an additional objective performance measure. However, many secondary schools treat the teacher's advice as binding.

Figure 2 Schematic depiction of the Dutch education system

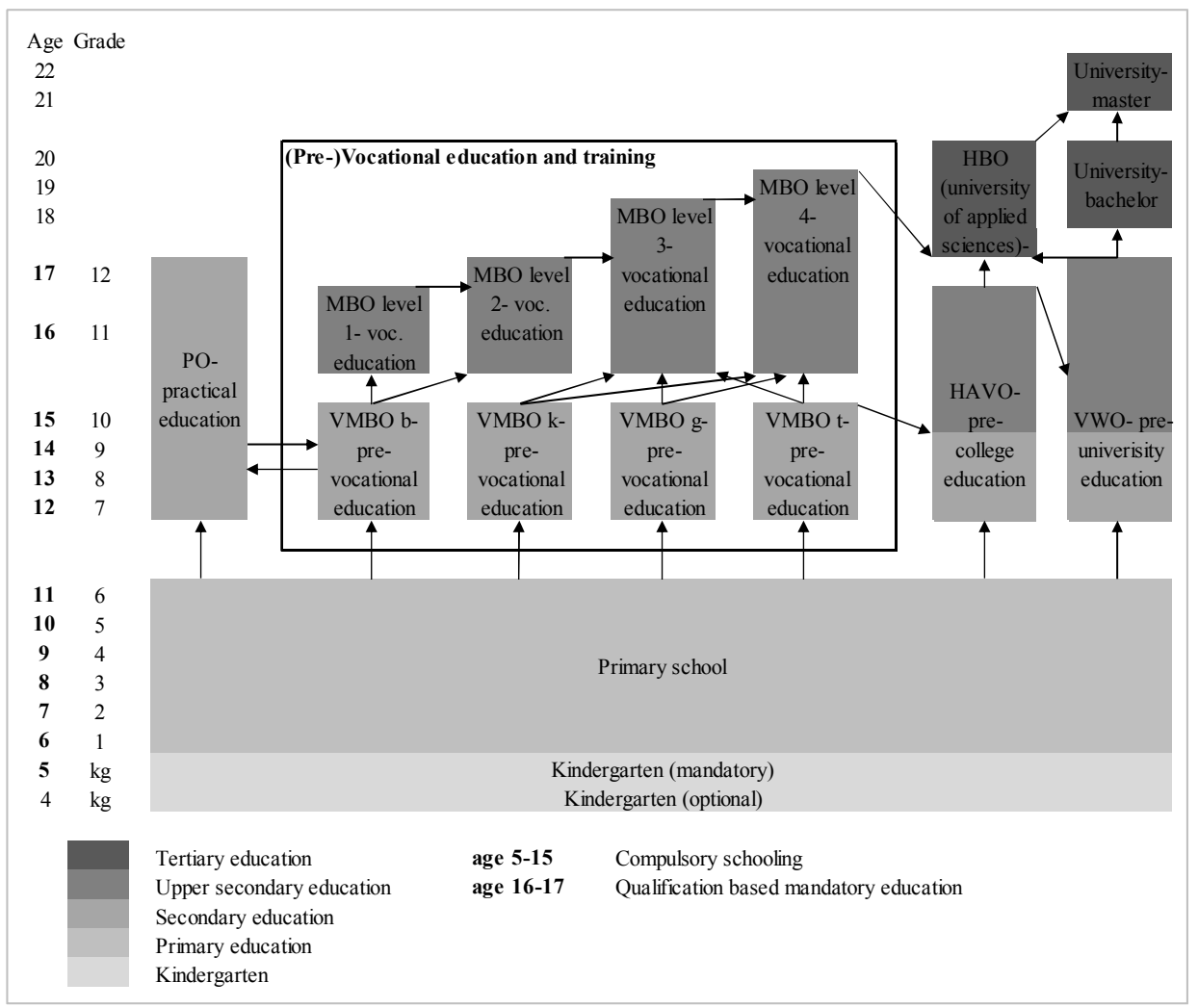

Notes: Scheme based on Dronkers and Korthals (2016, forthcoming) and modified. The scheme is simplified. The most common transitions are indicated by arrows, additional ones are possible. Special education is not depicted.

Most schools, more than four out of five, administer a nation-wide test, developed by Cito, "Centraal Instituut voor Toetsontwikkeling", meaning central institute for test development (Cito). ${ }^{4}$ Officially, this test is called the Cito Eindtoets, which translates to Cito Endtest.

\footnotetext{
${ }^{4}$ The institute was founded by the government in 1968 to develop and maintain standardized tests. Since 1999 Cito is a fully privatized testing and assessment company, active also internationally (Cito B.V., 2014). Through
} 
Commonly and in the following, it is referred to simply as the Cito test. ${ }^{5}$ It comprises questions on the primary school curriculum in Dutch, mathematics, study skills as well as an optional part, mixing questions from social and natural sciences. The test is administered in the schools, but graded externally and the questions change every year.

The Cito test used to be taken in February, but since 2014/15 it is taken in April and the results are only announced after the teachers' track recommendations. The test result is now only used to correct the recommendation in cases where the test strongly suggests a higher or lower track then the assigned recommendation. Thus, the stakes for doing well in the Cito test decreased between the school years 2013/14 and 2014/15.

The track recommendation is highly relevant. Firstly, the different tracks (see Figure 2) lead to specific qualifications for the labor market, e. g. only the two highest tracks (HAVO and VWO) provide access to tertiary education). Secondly, the many transition possibilities between the tracks are only used with restrictions. During the first three years after the transition, a quarter of the children changes the track at least once. Among them only 40 percent change to a higher schooling level Inspectie van het Onderwijs (2014). Thus, the initial track assignment is of great importance

Besides the most well-known high stakes test at the end of primary school, Cito also develops and offers tests for the whole curriculum in primary as well as in secondary school. Each school has to buy all the tests it wants to use. Only the final assessment test is free of costs. Other than for the final assessment in grade 6 , schools are not obliged to use standardized tests throughout the curriculum, there are alternatives. ${ }^{6}$ Yet, many use the low-stakes tests, which are part of the so called Cito Leerling Volgsysteem (LVS), which translates to Cito tracking system. It provides the advantage of national reference tables and growth curves across time for each series of tests. Cito also offers a software, called LOVS (Leerling Onderwijs Volgsysteem), for analyzing students' test scores and their development.

the mother foundation it still indirectly receives public subsidies for the development of new tests or for pilot studies (Buitelaar, Ros, Vink, and van der Kroft (2013).

${ }^{5}$ The schools are required to use some test at the end of primary school. In 2013 about $86 \%$ of the schools used the "CITO Eindtoets" for this purpose (Inspectie van het Onderwijs, 2014). From 2015/16 onwards schools are obliged to use an officially admitted test at the end of primary school. There are also other providers, but Cito is most likely to remain the dominant one.

${ }^{6}$ Schools still have to be able to account for the development of their pupils upon request of the Inspectorate of Education. They can do so with the low stakes tests provided by Cito or by the means of other instruments. 
Chapter 2: Representativeness and selective testing

\subsection{Data}

\subsubsection{The OnderwijsMonitor Limburg}

As stated above in Section 2.2.2, the aim of the OML is to gain insight into the educational development of pupils. It is a collaborative project between researchers, schools and policy institutions, such as the Inspectorate of Education.

The OML covers the school career from kindergarten, over primary school to secondary school. In the long run, it should further extend to the complete education chain, till tertiary education as well as labor market entry. The different datasets are linked and students are followed, allowing longitudinal analyses. ${ }^{7}$ Figure 3 depicts schematically which type of data is collected at what time in the school career.

This study focusses particularly on one sub-project, formerly called 'Balaans', which collects data when students are in their final year of primary school at the age of about 12 . As can be seen from Figure 3, this is the point in time with the most extensive data collection. ${ }^{8}$

As a starting point, schools provide basic administrative data of the pupils (e. g. name, address, gender, date of birth, and an indicator of low socio-economic status). This information is collected in fall, just after the start of a new school year. This way, full populations for the schools are known. In a next step, schools provide information on the standardized low stakes tests $^{9}$ from the Cito Leerling Volgsysteem. Depending on the computer program used, some schools provide the complete test history, while others only provide the most recent test results. This is done at the end of the school year, near the summer holiday. Thereby ensuring that almost all test results of the respective year are in the system. Additionally, the results of the high stakes Cito test, taken in the final year of primary school, are obtained centrally from Cito. Additional testing, including a test of general cognitive ability and non-cognitive skills, as well as surveying of students, parents and teachers was conducted in close collaboration with the schools. The surveys included information on the social-emotional and socio-economic background of the children.

\footnotetext{
${ }^{7}$ So far, the longitudinal nature of the data collection allows some cohorts to be followed from kindergarten to primary school (see Chapter 5) or from primary school to secondary school (see Chapter 3).

${ }^{8}$ A description of the complete OML and how it evolved can be found on the website of the OML (Educatieve Agenda Limburg, 2016).

${ }^{9}$ The term "low stakes" tests, as it is used in this thesis, refers to tests with low relevance. Bad results might lead to grade retention, but the consequences do not extend beyond primary school.
} 
Figure 3 Data collected by domain, grade and project

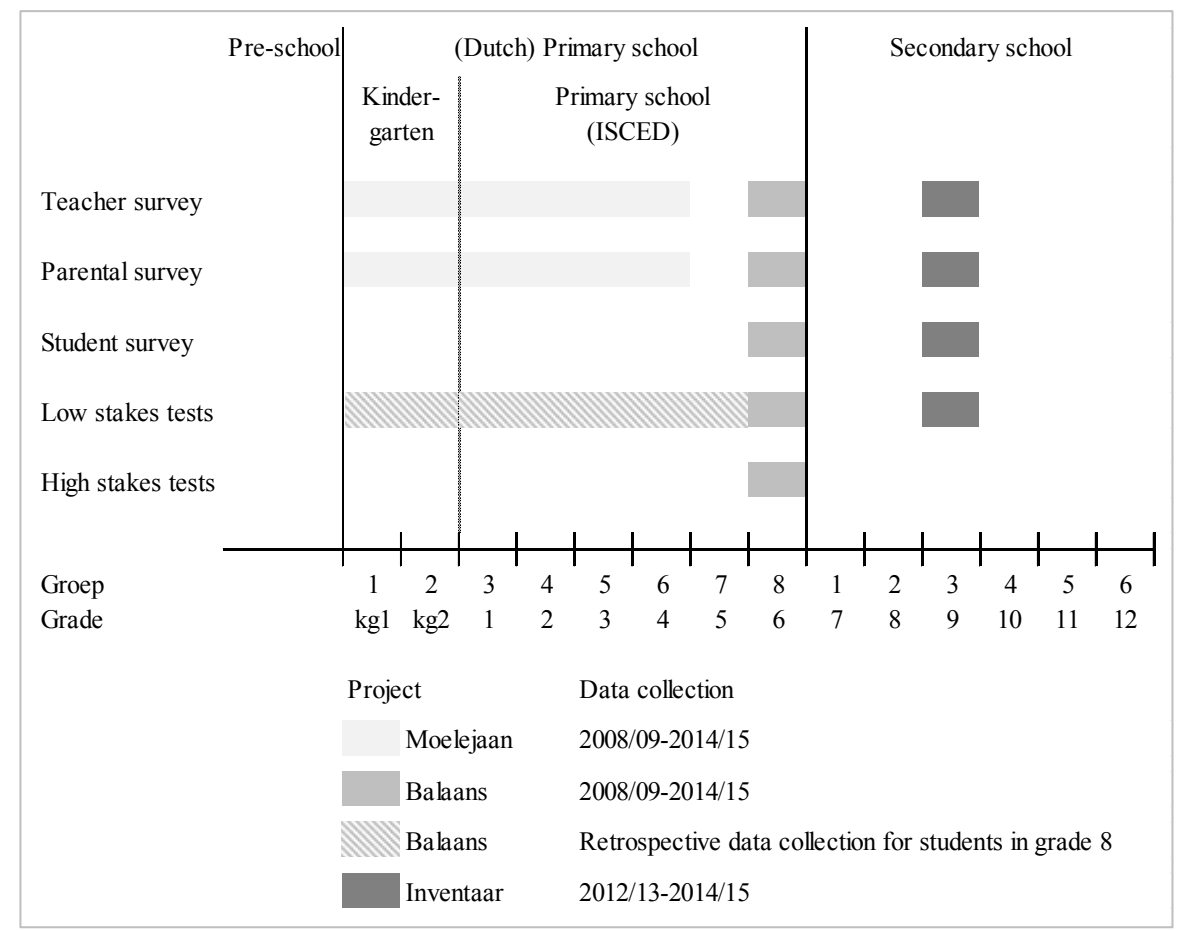

Notes: Schematic depiction of the data collection. The grades covered by the sub-project Moelejaan changed over the years. In 2008/09 data were collected in kg1 and grade 1; in 2009/10 no data were collected; in 2010/11 data were collected in both kindergarten years and grade 1 to 3 ; in 2011/2011 in both kindergarten years and grade 1 to 4; in 2012/13 as well as 2013/14 in kg2, grade 2 and grade 4; in 2014/15 data were only collected in $\mathrm{kg} 2$.

The first time that some of these data were collected was in the school year 2008/09. The data were collected yearly. Thus, at the moment these data are available for seven cohorts of students, finishing their primary school in the years 2008/09 to 2014/15. From 2015/16 onwards, the additional tests and surveys will be administered only every two years at the end of kindergarten and in grade 6 . Administrative information and test scores will still be collected every year for both years of kindergarten and all grades.

\subsubsection{Data sources}

In the following, the different data sources and potential reasons for missing data on the individual or the school level are described. 
Chapter 2: Representativeness and selective testing

Administrative data (e. g. name, address, gender, date of birth and an indicator of low socioeconomic background) are mostly provided by school boards. However, not always all schools of a school board end up participating. This is mostly the case for schools which are not situated in the south of Limburg. The provision of administrative data was a condition for participation in the OML. Thus, low-stakes test scores and questionnaire data are only available for a subgroup of schools for whom administrative data are available.

Cito test scores were downloaded directly from Cito, after schools provided us with the access codes. Alternatively, they downloaded the scores themselves and provided them. There might be selection into using the Cito test or strategic testing on the class room level leaving out certain students. However, there are fewer concerns about additional selection being introduced via the process of data collection than with the other test scores. The Cito test results are likely available for all schools that administered the Cito test and for all students that took it.

LVS data, the series of low-stakes test scores, were provided by the school, likely the headmasters, or a technician from the board. There is a huge variety of tests in terms of the tested skills. And most tests have been renewed several times already, which leads to an even larger number of different test versions. As a result no school uses all tests available. None of them are mandatory. Thus, if no test scores are available, there are several potential explanations for that: (1) The school might not test at all (e. g. because they follow a pedagogical concept, not in favor of standardized tests), (2) the school might use other tests or (3) the school uses the LVS tests, but does not provide the test scores for research. Furthermore, even in schools that provide LVS data not necessarily all tests are administered (schools can choose to administer only a subset) and not necessarily all students are tested (e. g. due to being sick at the day of testing or differential participation across class rooms). An additional challenge in the data collection are the different computer programs used by the schools to store and organize the test scores. Only a fraction of schools uses the original LOVS program from Cito. Some programs, e. g. ESIS, make it very complicated and time-consuming to export scores from earlier years. Consequently, schools using this software are less likely to provide full test score histories.

Parental survey data, including questions regarding the situation at home and the socioeconomic background, were collected via the schools. Likely a teacher sends out the surveys to the parents and also received them back. Consequently there are several potential sources of non-response: (1a) schools could not have sent out the surveys or (1b) they could not have returned them to the researchers. Conditional on the school's collaboration, (2a) the parents 
could have returned it, leaving out certain questions, or (2b) parents cannot return the survey at all. $^{10}$

Student survey data, including a diverse set of questions regarding the situation at home, at school, as well as measures for non-cognitive skills, were also collected via schools. The data collection was conducted in class, likely by the individual teacher. Consequently, there can be non-response on the school, the class room as well as on the individual level. After a child filled in the survey, the parents could still refuse their consent. In that case, the data were not used. This concerns about one percent of the students.

Additionally, tests of students' general cognitive ability were conducted in class and teachers were surveyed regarding their behavior and engagement. In order not to make it too complicated, these parts of the data collection are disregarded in the detailed analysis below.

\subsection{Results}

The dataset comprises information on 39,868 pupils from seven cohorts, attending 230 different primary schools, for which data from at least one of the above mentioned data sources is available in at least one year. In the following, we analyze how representative the data are; with respect to overall participation in the OML as well as with respect to sub-samples. After all, how representative the data are might change, depending on which information is required and which data sources provides it. Since there might be different underlying selection mechanisms on the school and on the individual level, we address them separately. In a second step, we analyze testing behavior of schools with respect to using standardized tests: which schools provide test scores, which tests are used most often and which students are tested.

\subsubsection{Representativeness and data availability}

What fraction of the population of interest is covered by the OML?

All school boards and primary schools in and south of Sittard were approached to participate in the OML, and all large school boards in that region participate. In the absence of information on how many students were attending grade 6 in the region of interest in each year, we make a rough estimation of the fraction of students covered by birth cohort for the data collected in 2011/12. According to (Statistics Netherlands, 2014) 6,166 students were born in or south of

${ }^{10}$ In Chapter 3 we analyze those three different sources of non-response and how they affect estimates of intergenerational dependency. 
Chapter 2: Representativeness and selective testing

Sittard in $2000 .{ }^{11}$ Relating this to the 5,683 students in our dataset in 2011/12 provides a coverage rate of about 92 percent. For two reasons this can be considered a lower bound for the covered fraction of the cohort. First, the shrinking of the population is partly due to movements towards other parts of the Netherlands (Statistics Netherlands, 2016). Second, students in special education or attending Belgium schools will naturally not show up in the OML dataset.

The strength of the OML is that it combines information from different sources (school administration, test score records, questionnaire data) for a large part of the regional population. At the same time, when using the data, one has to be aware of the fact that several decision makers are involved in the process of data collection. Figure 4 shows an exemplary calculation for one birth cohort on how the fraction of the cohort that is covered shrinks, depending on which data sources are required.

Figure 4 Number of observations depending on data sources required

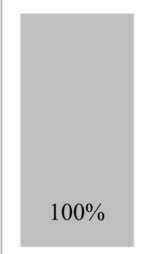

Cohort

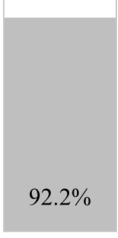

OML

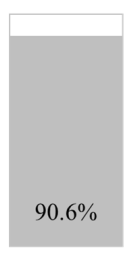

Administrative data

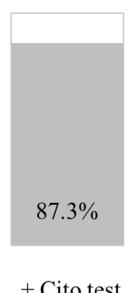

Cito test

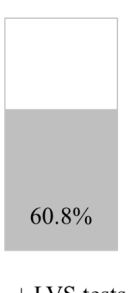

+ LVS tests

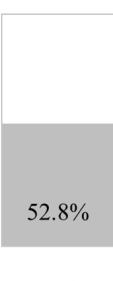

+ Student survey

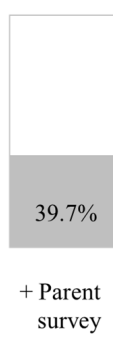

Parent
survey

Notes: The calculation refers to the data collected in the school year 2011/12. The 92.2 percent coverage of the cohort by the OML is calculated based on the cohort born in 2000, using publicly available data from (Statistics Netherlands, 2014).

When administrative information, including demographic variables, and Cito scores are required, still 87.3 percent of the complete cohort are covered. In case an analysis requires information from all data sources, the coverage rate reduces to about 40 percent. To put this rate into perspective, the Cito scores are available for all schools that apply the test. The remaining students without a result very likely did not take the test. Regarding the LVS tests, the case is similar. They are reported via the schools, but from the personal contact with the schools we know that the vast majority of schools not reporting LVS results, also do not use these tests. On the other hand, when constructing a longitudinal dataset, making the link to either kindergarten or secondary school, the sample consequently shrinks further. The same

${ }^{11}$ This makes up for about 3 percent of all children born in the Netherlands in 2000 . 
holds for analyses based on items with a substantial non-response rate. However, for the remaining group the data are very rich.

In the following, we first investigate the underlying participation behavior on the school level. Then, we turn to differences in individual characteristics of students grouped with respect to data availability.

\section{What fraction of the schools is covered by the OML?}

Overall 230 primary schools ${ }^{12}$ participated in the OML. This means that they provided data from at least one of the above mentioned data sources, in one or more of the seven school years. The comparison to administrative registry data from Dienst Uitvoering Onderwijs (2016), DUO, shows that there are only four primary schools in the region, which never appear in the data. Table 2 presents the number of participating schools per school year. Overall it decreased. However, this is partly driven by schools closing or merging. When directly compared to administrative data on schools in south Limburg for the most recent three years, the fraction of coverage is almost stable and never below 97 percent. As mentioned above, the discrepancy to the estimated individual coverage rate can be explained by students in special education and attending Belgium schools. Thus, this 97 percent can be interpreted as the specific primary school coverage rate. In the following, reasons of incomplete participation are provided, as far as they are known.

Table 2 Participating schools per school year

\begin{tabular}{lrrr}
\hline School year & $\begin{array}{r}\text { Participating } \\
\text { schools }\end{array}$ & $\begin{array}{r}\text { \% of schools } \\
\text { (ever participating) }\end{array}$ & $\begin{array}{r}\text { \% schools covered } \\
\text { (in south Limburg) }\end{array}$ \\
\hline $2008 / 09$ & 218 & $94.78 \%$ &. \\
$2009 / 10$ & 216 & $93.91 \%$ &. \\
$2010 / 11$ & 207 & $90.00 \%$ &. \\
$2011 / 12$ & 204 & $88.70 \%$ &. \\
$2012 / 13$ & 206 & $89.57 \%$ & $97.94 \%$ \\
$2013 / 14$ & 197 & $85.65 \%$ & $97.88 \%$ \\
$2014 / 15$ & 191 & $83.04 \%$ & $97.27 \%$ \\
\hline
\end{tabular}

Notes: The reference for the schools covered in south Limburg stems from a comparison of school registration numbers between the dataset, and DUO registry data (Dienst Uitvoering Onderwijs, 2016). Those latter data were only available for the most recent three school years.

\footnotetext{
${ }^{12}$ In case a school has several locations and they have separate identifiers, each location is considered as a separate school here and in the following.
} 


\section{Chapter 2: Representativeness and selective testing}

Among all schools that ever participated, 48 schools, or 20 percent, missed to provide data in one or several years. Within this group the majority of schools ( 80 percent) have uninterrupted participation spells, meaning that they do not leave out years of participation to start again. The reasons for incomplete participation are: that schools closed (11), merged with other schools (7), stopped participating (2), started participating (6) or only a sub-location participated inconsistently, while the main location participated throughout all years (13). For the remaining 9 schools the reasons could not yet be identified.

\section{How extensively do the schools participate in the data collection?}

Among the schools which participated in the OML there are still differences with respect to the extent of their collaboration and the data they provided. Table A.1 in the Appendix shows all 32 possible combinations that arise from providing or not providing administrative data, Cito scores, LVS test scores, parental questionnaires or student questionnaires for at least one student in at least one year. It becomes apparent that there is a clear pattern. There are only five combinations with each more than one percent of all schools. Four more options are observed each once or twice only. In the following the typology of the most prevalent patterns is shortly described.

Figure 5 Participation of schools in different domains

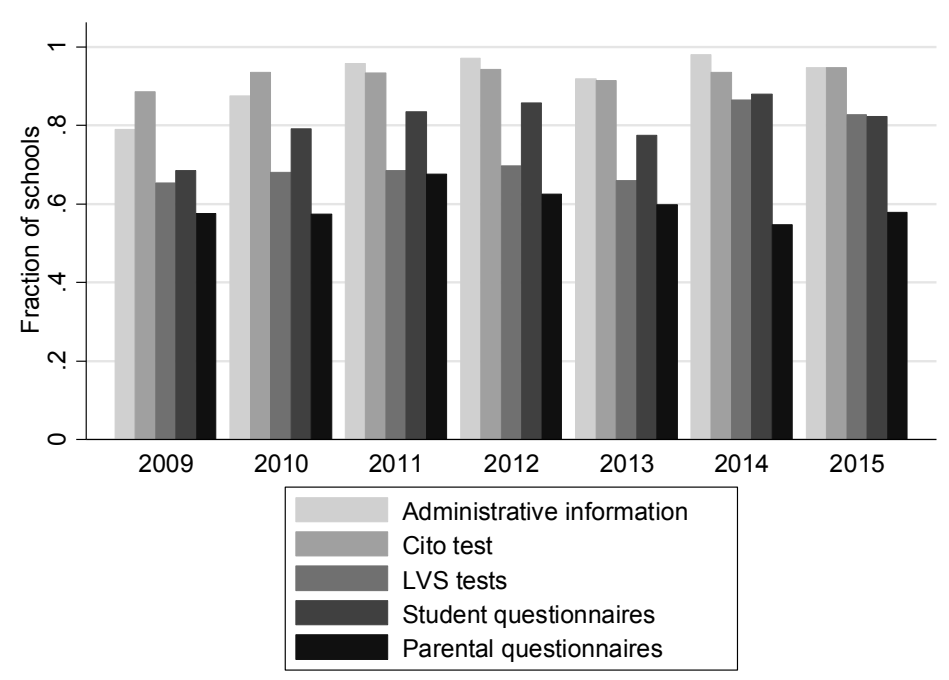

Notes: The bars indicate the fraction of all schools in the dataset, which participated in each of the domains, by providing the respective data. 
With almost 85 percent, the majority provided data from all sources at least once in the seven years. The second most common pattern with 6.5 percent are schools that do not provide LVS test scores, in most cases because they do not use them. The other three categories each apply to between 1 and 3 percent: all data except for Cito scores, only administrative data or in turn only Cito scores are provided.

One important conclusion from this table is that among the schools which provided at least administrative information only six never conducted parental surveys and five never conducted student surveys. Among the ones which provided at least some test scores (either for the Cito test or LVS tests) only one never conducted the parental survey and only one never the student survey. Overall participation among schools is good with 93.9 percent providing data from either all or all but one data source at least once. Thus, persistent non-collaboration on the school level can be ruled out as an important source for missing data.

Figure 5 provides a visualization of how the overall participation rate in the different domains developed over time. Most notably, there is a tendency of increased participation in all domains. Especially the provision of LVS test data and data from student questionnaires improved and remained above 80 percent the last two years. The most critical point in terms of completeness and likely also representativeness is the availability of parental questionnaire data. Chapter 3 focusses specifically on non-response in this area. ${ }^{13}$

Analogue to the analysis on the school level, Table A.2 shows the combinations of provided data on the school-year level. The pattern looks a lot different than on the school level, suggesting that participation is not consistent over the years. Reasons for that could be changes in personnel, such as the headmaster, or responsibilities. Different people might set different priorities. Further, more pressing tasks might have had to be completed during the time of data collection. Still the majority (66.4 percent) provided data from all sources and an additional 18.5 percent provided all data but LVS test scores. Using information on classrooms ${ }^{14}$ we can zoom in even further. However, the participation patterns on the school-year level and classroom-year level are not very different.

\footnotetext{
${ }^{13}$ Underlying reasons and patterns of non-response are investigated. The main target of the study is the impact of non-response on estimates of intergenerational dependency.

${ }^{14}$ The analysis of the classroom-year level is further restricted to where administrative data is available, and of course relative fractions of participation change slightly due to schools having different number of classes participating.
} 
Chapter 2: Representativeness and selective testing

\section{Does data availability for students relate to students characteristics?}

School participation in the different domains is a necessary, however, no sufficient condition for data availability on the individual level. For the availability of test scores the particular student has to take the test first. Furthermore, parents and students decide individually whether to fill in the survey or not. Furthermore, parents can object to the use of their children's questionnaire data. Consequently, data availability on the individual level is more spread across the 32 possible combinations, as can be seen in Table A.3. Also here we can distinguish five major groups accounting for 84.1 percent of students in the OML. For an additional 7.9 percent no administrative information and no questionnaire data are available. ${ }^{15}$ The rest is scattered among various combinations with at least administrative information. Descriptive statistics for basic characteristics of the five major groups and all others with administrative information are provided in Table 3 . Table 4 adds the location and denomination of the attended schools.

The groups in column 1 to 3 are the largest, referring to students with data from all sources, no LVS test scores and no parental questionnaire data. The other three groups together account for only 21.2 percent. For most of them data from more than two sources are missing.

Most notably, the students in column 1 and 2 show the highest scores for general cognitive ability as well as the highest Cito test scores. There seems to be a positive selection into the sub-groups for which either all data are available or only LVS test scores are missing. In contrast, the worst results are observed for students whose average in the Cito test is about a third of a standard deviation below that of the students in column 1 and 2 . The only difference between them, with respect to the data availability, is the lack of parental questionnaire data. While one may intuitively attribute that to parental non-response, Chapter 3 shows that there is also a substantial number of schools not forwarding the questionnaires to the parents.

\footnotetext{
15 These students are most likely attending schools outside of the region of interest, but belong to a school board that participated in the OML and provided test scores centrally.
} 


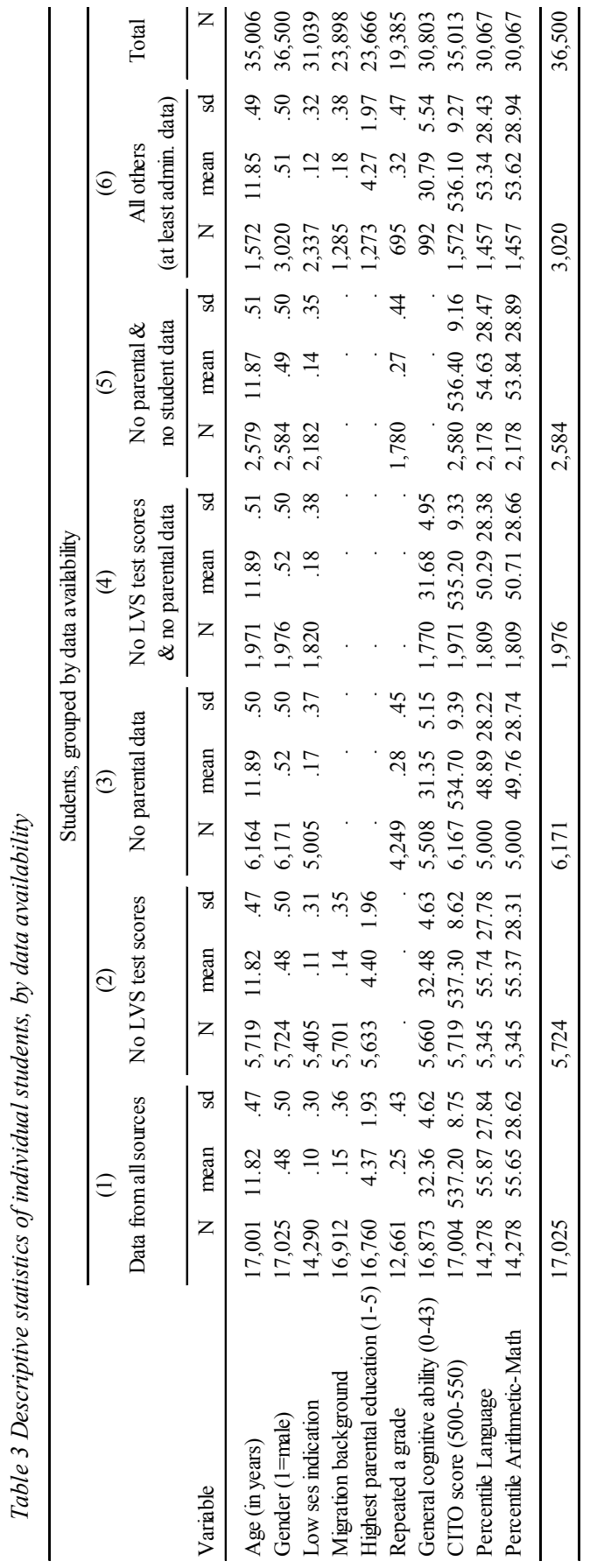

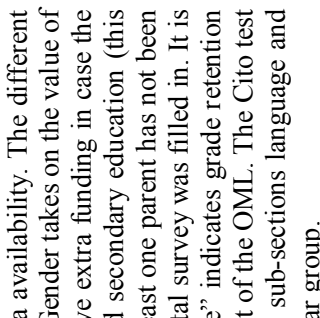

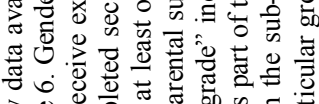

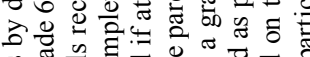

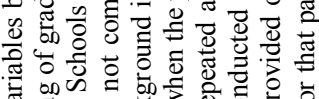

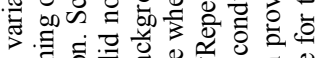

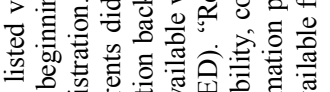

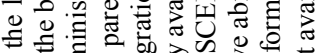

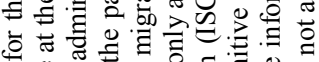

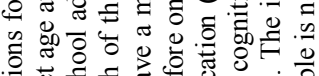

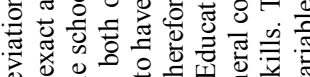

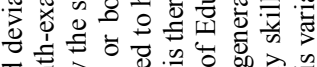

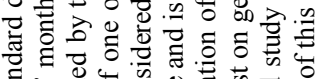

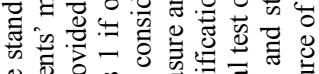
के

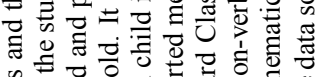
仓

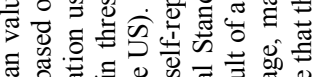

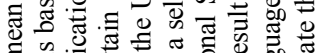

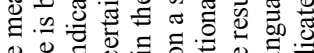

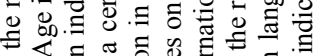

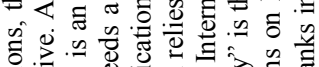
.0.0.

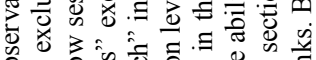
ôn

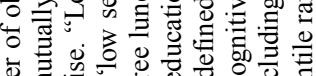

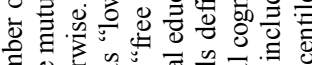

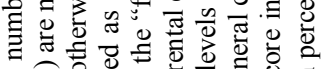

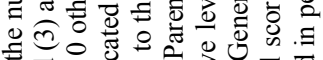

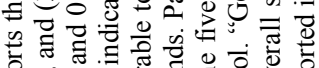

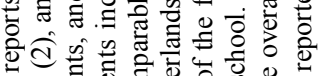

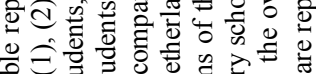

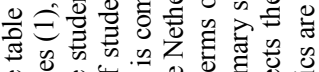

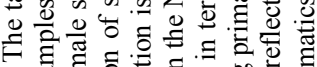
记 范

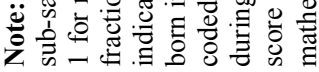


Chapter 2: Representativeness and selective testing

For both, the students in column 3 and 4, no parental data are available. For students in column 4, also no LVS test scores are available, which makes it likely that those tests were not used in the schools they attended. While the two groups are most comparable with respect to the student characteristics, they differ by the region of the school attended. Parkstad and Heuvelland are overrepresented among students without parental data. Students that additionally lack test scores more often come from Westelijke Mijnstreek or Maastricht. A similar pattern can be observed for columns 1 and 2 respectively. Thus, schools in Parkstad and Heuvelland seem to be more likely to test their students than those in Westelijke Mijnstreek and Maastricht. However, there could be an alternative technical explanation. School boards from both these regions use the software ESIS to manage test score data. This particular software causes problems with exporting data. Before a final conclusion on this question, it needs to be worked out what causes the regional differences, a lack of testing or reporting.

Table 4 Location and denomination of school attended, grouped by data availability

\begin{tabular}{|c|c|c|c|c|c|c|c|c|c|c|c|c|c|c|}
\hline \multirow[b]{4}{*}{ Location of school } & \multicolumn{12}{|c|}{ Students, grouped by data availability } & & \\
\hline & \multirow{2}{*}{\multicolumn{2}{|c|}{$\begin{array}{c}\text { (1) } \\
\text { Data from all } \\
\text { sources }\end{array}$}} & \multirow{2}{*}{\multicolumn{2}{|c|}{$\begin{array}{c}\text { (2) } \\
\text { No LVS test } \\
\text { scores }\end{array}$}} & \multirow{2}{*}{\multicolumn{2}{|c|}{$\begin{array}{c}\text { (3) } \\
\text { No parental } \\
\text { data }\end{array}$}} & \multirow{2}{*}{\multicolumn{2}{|c|}{$\begin{array}{c}\text { (4) } \\
\text { No LVS test } \\
\text { scores \& no } \\
\text { parental data }\end{array}$}} & \multirow{2}{*}{\multicolumn{2}{|c|}{$\begin{array}{c}\text { (5) } \\
\text { No parental \& } \\
\text { no student } \\
\text { data }\end{array}$}} & \multirow{2}{*}{\multicolumn{2}{|c|}{$\begin{array}{c}\text { (6) } \\
\text { All others } \\
\text { (at least } \\
\text { admin. data) }\end{array}$}} & \multirow{2}{*}{\multicolumn{2}{|c|}{ Total }} \\
\hline & & & & & & & & & & & & & & \\
\hline & $\mathrm{N}$ & $\%$ & $\mathrm{~N}$ & $\%$ & $\mathrm{~N}$ & $\%$ & $\mathrm{~N}$ & $\%$ & $\mathrm{~N}$ & $\%$ & $\mathrm{~N}$ & $\%$ & $\mathrm{~N}$ & $\%$ \\
\hline Westelijke Mijnstreek & 2,956 & 17.4 & 3,097 & 55.5 & 1,121 & 18.2 & 960 & 49.7 & 590 & 22.9 & 1,099 & 35.1 & 9,823 & 27.0 \\
\hline Parkstad & 7,662 & 45.1 & 985 & 17.7 & 3,171 & 51.5 & 477 & 24.7 & 1,056 & 41.0 & 988 & 31.5 & 14,339 & 39.4 \\
\hline Heuvelland & 3,649 & 21.5 & 164 & 2.9 & 975 & 15.8 & 101 & 5.2 & 403 & 15.7 & 302 & 9.6 & 5,594 & 15.4 \\
\hline Maastricht & 2,505 & 14.7 & 1,283 & 23.0 & 812 & 13.2 & 391 & 20.2 & 326 & 12.7 & 585 & 18.7 & 5,902 & 16.2 \\
\hline \multirow[t]{2}{*}{ North Limburg } & 232 & 1.4 & 48 & .9 & 81 & 1.3 & 2 & .1 & 198 & 7.7 & 159 & 5.1 & 720 & 2.0 \\
\hline & 17,004 & 100 & 5,577 & 100 & 6,160 & 100 & 1,931 & 100 & 2,573 & 100 & 3,133 & 100 & 36,378 & 100 \\
\hline Denomination of school & $\mathrm{N}$ & $\%$ & $\mathrm{~N}$ & $\%$ & $\mathrm{~N}$ & $\%$ & $\mathrm{~N}$ & $\%$ & $\mathrm{~N}$ & $\%$ & $\mathrm{~N}$ & $\%$ & $\mathrm{~N}$ & $\%$ \\
\hline Roman Catholic & 14,072 & 82.8 & 4,138 & 74.2 & 4,725 & 76.7 & 1,320 & 68.4 & 1,824 & 70.9 & 1,701 & 54.3 & 27,780 & 76.4 \\
\hline Public & 1,754 & 10.3 & 1,255 & 22.5 & 805 & 13.1 & 499 & 25.8 & 571 & 22.2 & 1,081 & 34.5 & 5,965 & 16.4 \\
\hline Antroposophic & 0 & .0 & 0 & .0 & 0 & .0 & 0 & .0 & 0 & .0 & 112 & 3.6 & 112 & .3 \\
\hline \multirow[t]{2}{*}{ Other } & 1,178 & 6.9 & 184 & 3.3 & 630 & 10.2 & 112 & 5.8 & 178 & 6.9 & 239 & 7.6 & 2,521 & 6.9 \\
\hline & 17,004 & 100 & 5,577 & 100 & 6,160 & 100 & 1,931 & 100 & 2,573 & 100 & 3,133 & 100 & 36,378 & 100 \\
\hline
\end{tabular}

Notes: The table reports the location, and denomination of the school attended by the individuals, grouped by data availability. Westelijke Mijnstreek, Parkstad, Heuvelland, and Maastricht are the main regions which can be distinguished in south Limburg (see also Figure 1). Schools in the north of Limburg were not specifically targeted. In some cases they share a school board with a targeted school. The category "Others" in denomination includes schools with a specific pedagogical concept, protestant Christian schools, ecumenical Christian schools, and Islamic schools.

There are less specific patterns observed with respect to the denomination of the schools. Overall, about three quarter of all students in the OML attend a Roman Catholic school. A little 
more than 17 percent attend a public school, which has no specific denomination. These two types of schools account for the vast majority. Public schools have the tendency to provide less data. Roman Catholic schools, on the other hand, are over represented among the groups with broad data availability. The small but specific group of seven anthroposophical schools participate very selectively. Almost all of them provide test scores for their students, but only one provides data from student questionnaires and one from parental questionnaires.

The student group in column 5, for whom neither parental nor student questionnaire data are available, does not stick out in any way. Students attending schools from the north of Limburg are overrepresented in this group. This also explains the non-participation with respect to the questionnaire data. Those schools were not particularly targeted by the OML and did not even receive questionnaires. Most likely, the administrative information and test scores are provided by the school board.

With respect to the gender composition, it can be observed that parents of girls return the questionnaire more often (comparing column 1 to 3 , and 2 to 4 ). This could relate to girls being more conscientious in giving it to their parents, maybe reminding them about it, and returning it to school (Schmitt, Realo, Voracek, \& Allik, 2008). Alternatively, this difference could have to do with parents of girls behaving differently themselves (examples of child-to-parent behavioral influence have been provided, for example by Diekmann and Schmidheiny (2004); Washington (2008)). Finally, differences between the fractions of students indicated to come from a low socio-economic background go along with the performance levels.

\subsubsection{Selective testing}

Cito provides many different standardized tests (see Section 2.2.2). For primary schools there are a number of test series on language tests (e. g. spelling, decoding, vocabulary, reading comprehension, etc.), and one test series on mathematics. The language test series are not comparable with each other and each of them consists of fewer tests than the series in mathematics. Furthermore, mathematics is likely to differentiate better different skill levels (see standard deviation in Table 3). Thus, in the following we concentrate on mathematics tests only to analyze schools' testing behavior.

There are in total 20 mathematics tests for kindergarten and primary school available from Cito. They are defined by the specific test content as well as the point of testing. In the two years of kindergarten only two tests on early numeracy are used, but they can be conducted at 5 different points in time. Thus, in the dataset these tests show up as five tests, three in year one and two 


\section{Chapter 2: Representativeness and selective testing}

in year two. Children can take the same test repeatedly. Throughout the six years of primary school there are 11 tests and 12 points of testing in the mathematics series. From year one to five two distinct tests are available to be used in the middle of the year and in the end of the school year. For the final year, there is only one test, but it can be either administered in the beginning of the school year or in the middle. Additionally to those 11 tests there are so called "Entreetoetsen", entrance tests, for the beginning of grades 3, 4, and 5.

The mathematics tests for kindergarteners are measuring early numeracy skills. The mathematics tests in the middle and the end of each school year in primary school focus on curriculum based mathematic skills. The starting tests are meant to assess the skill level of the children at that point based on all the curricular skills they have been taught before.

The main questions of interest in this section are: which tests are most often used, how consistent schools use standardized tests, and whether schools that test more consistently differ also in other respects. Finally, the students are grouped by the number of tests they took throughout their school career and those groups are compared.

One preliminary note before turning to those questions: We only observe whether the school provides test scores within the OML or not. Those that do not provide test scores might still test their students, but not allow access to the data for research purposes. However, the majority of schools not providing LVS test score informed the OML administration that they do not administer those tests. Even though there might be some exceptions from this, in the following we consider not providing test scores as a strong predictor of not testing.

\section{Which tests are administered most often?}

Most popular among primary schools are the regular mathematics tests from grade 1 through 6 , with an emphasis on the tests administered in the middle of the school year (see Table 5). The last test, Mathematics 11, is most often administered in the middle of the school year. Among the other tests Mathematics 10 is used less often; potentially, because when also administering Mathematics 11 early in the school year, the schools do not want to overload the students with test taking.

The tests in kindergarten are only used about half as often as most of the later mathematics tests. Overall, test taking is increasing from kindergarten year one to two. The early numeracy test in the middle of kindergarten year two is administered most often. The content of this particular test is analyzed in detail in Chapter 5. 
Table 5 Number of participants per test

\begin{tabular}{lrrr}
\hline Test & Year & Time & $\mathrm{N}$ \\
\hline Early numeracy 1 & $\mathrm{kg}$, year 1 & beginning & 500 \\
Early numeracy 1 & $\mathrm{kg}$, year 1 & middle & 8,211 \\
Early numeracy 1 & $\mathrm{kg}$, year 1 & end & 9,419 \\
Early numeracy 2 & $\mathrm{kg}$, year 2 & middle & 14,413 \\
Early numeracy 2 & $\mathrm{kg}$, year 2 & end & 11,842 \\
& & & \\
Mathematics 1 & grade 1 & middle & 18,513 \\
Mathematics 2 & grade 1 & end & 18,615 \\
Mathematics 3 & grade 2 & middle & 20,399 \\
Mathematics 4 & grade 2 & end & 20,451 \\
Mathematics 5 & grade 3 & middle & 21,684 \\
Mathematics 6 & grade 3 & end & 20,830 \\
Mathematics 7 & grade 4 & middle & 22,413 \\
Mathematics 8 & grade 4 & end & 21,204 \\
Mathematics 9 & grade 5 & middle & 22,983 \\
Mathematics 10 & grade 5 & end & 16,295 \\
Mathematics 11 & grade 6 & beginning & 6,044 \\
Mathematics 11 & grade 6 & middle & 19,520 \\
Entrance test 1 & grade 3 & beginning & 453 \\
Entrance test 2 & grade 4 & beginning & 812 \\
Entrance test 3 & grade 5 & beginning & 5,348 \\
\hline & & &
\end{tabular}

Notes: The table indicates how many students in the OML took each of the listed tests. The year indicates the year in kindergarten $(\mathrm{kg})$ or the grade in primary school. Time refers to the time within the school year, when the test is supposed to be taken.

The entrance tests are less frequently used than the other mathematics tests. Among those three tests, the entrance test to grade 5 is most important. However, the number of students tested is still lower than for all other regular mathematics tests.

How consistently do the schools test?

Table 6 shows for each school year how many schools did not provide any test scores, how many provided at least one test score for less than 80 percent of their students, for 80 to 99 percent, or for all students. Inconsistent testing of the student population could be the result of strategic behavior by the schools. However, these broad descriptive statistics can neither 
Chapter 2: Representativeness and selective testing

confirm nor falsify that. An alternative explanation could also be some kind of skill-adaptive testing, where students at the top and bottom end of performance take a test constructed for a higher or lower grade.

Table 6 Fraction of students tested per school, by school year

\begin{tabular}{lrrrrrrrr}
\hline $\begin{array}{c}\text { Fraction of } \\
\text { students } \\
\text { tested }\end{array}$ & $2008 / 09$ & $2009 / 10$ & $2010 / 11$ & $2011 / 12$ & $2012 / 13$ & $2013 / 14$ & $2014 / 15$ & Total \\
\cline { 2 - 7 } $0 \%$ & 74 & 66 & 59 & 56 & 65 & 18 & 28 & 366 \\
& 33.94 & 30.56 & 28.50 & 27.45 & 31.55 & 9.14 & 14.66 & 25.43 \\
$<80 \%$ & 15 & 6 & 5 & 1 & 3 & 8 & 4 & 42 \\
& 6.88 & 2.78 & 2.42 & .49 & 1.46 & 4.06 & 2.09 & 2.92 \\
$80 \%-99 \%$ & 61 & 42 & 49 & 33 & 68 & 75 & 30 & 358 \\
& 27.98 & 19.44 & 23.67 & 16.18 & 33.01 & 38.07 & 15.71 & 24.88 \\
$100 \%$ & 68 & 102 & 94 & 114 & 70 & 96 & 129 & 673 \\
& 31.19 & 47.22 & 45.41 & 55.88 & 33.98 & 48.73 & 67.54 & 46.77 \\
\hline Total & 218 & 216 & 207 & 204 & 206 & 197 & 191 & 1,439 \\
& 100 & 100 & 100 & 100 & 100 & 100 & 100 & 100 \\
\hline
\end{tabular}

Notes: The table reports the fraction of students tested for all schools, and by year.

Only very few schools test less than 80 percent of their student population. However, a substantial fraction of schools, between 15 and 38 percent, leave out up to 20 percent of their student population from their testing. Overall, there is a trend towards more schools testing and more consistent testing. In 2008/09, about 60 percent of the schools provided data on 80 percent or more of their student population. In 2013/14 and 2014/15, this number had increased to above 80 percent.

For the purpose of analyzing the location and denomination of the schools, the two middle groups are combined. The remaining three groups, listed in Table 7, refer to non-testing schools, inconsistently testing schools, and consistently testing schools. Since some schools changed their testing behavior, the table is based on school-year level.

In many parts, Table 7 confirms the findings from Table 3: Schools in Westelijke Mijnstreek test less often, schools in Parkstad or Heuvelland test more often. With respect to the 
denomination, there is more testing in Roman Catholic schools and less in public schools. New is the distinction of how consistent schools test. In Parkstad, a larger fraction of schools tests only a fraction of their students, while in Heuvelland, more schools test all their students.

Table 7 School characteristics, by fraction of all students tested per school and year

\begin{tabular}{|c|c|c|c|c|c|c|c|c|}
\hline \multirow[b]{4}{*}{ Location of school } & \multicolumn{8}{|c|}{ School-year combinations by fraction of students tested } \\
\hline & \multirow{2}{*}{\multicolumn{2}{|c|}{$\begin{array}{l}\text { (1) } \\
0 \%\end{array}$}} & \multirow{2}{*}{\multicolumn{2}{|c|}{$\begin{array}{c}(2) \\
1-99 \%\end{array}$}} & \multirow{2}{*}{\multicolumn{2}{|c|}{$\begin{array}{c}(3) \\
100 \%\end{array}$}} & \multirow{2}{*}{\multicolumn{2}{|c|}{ Total }} \\
\hline & & & & & & & & \\
\hline & $\mathrm{N}$ & $\%$ & $\mathrm{~N}$ & $\%$ & $\mathrm{~N}$ & $\%$ & $\mathrm{~N}$ & $\%$ \\
\hline Westelijke Mijnstreek & 178 & 48.63 & 66 & 16.50 & 123 & 18.28 & 367 & 25.50 \\
\hline Parkstad & 70 & 19.13 & 192 & 48.00 & 253 & 37.59 & 515 & 35.79 \\
\hline Heuvelland & 16 & 4.37 & 69 & 17.25 & 177 & 26.30 & 262 & 18.21 \\
\hline Maastricht & 55 & 15.03 & 59 & 14.75 & 104 & 15.45 & 218 & 15.15 \\
\hline North Limburg & 19 & 5.19 & 10 & 2.50 & 11 & 1.63 & 40 & 2.78 \\
\hline \multirow[t]{2}{*}{ Unknown } & 28 & 7.65 & 4 & 1.00 & 5 & .74 & 37 & 2.57 \\
\hline & 366 & 100 & 400 & 100 & 673 & 100 & 1,439 & 100 \\
\hline Denomination of school & $\mathrm{N}$ & $\%$ & $\mathrm{~N}$ & $\%$ & $\mathrm{~N}$ & $\%$ & $\mathrm{~N}$ & $\%$ \\
\hline Roman Catholic & 211 & 57.65 & 284 & 71.00 & 535 & 79.49 & 1,030 & 71.58 \\
\hline Public & 100 & 27.32 & 59 & 14.75 & 82 & 12.18 & 241 & 16.75 \\
\hline Antroposophic & 1 & .27 & 0 & .00 & 6 & .89 & 7 & .49 \\
\hline \multirow[t]{2}{*}{ Other } & 54 & 14.75 & 57 & 14.25 & 50 & 7.43 & 161 & 11.19 \\
\hline & 366 & 100 & 400 & 100 & 673 & 100 & 1,439 & 100 \\
\hline
\end{tabular}

Notes: The table reports the location and denomination for each school-year combination, grouped by the fraction of students tested. Westelijke Mijnstreek, Parkstad, Heuvelland, and Maastricht are the main regions which can be distinguished in south Limburg (see also Figure 1). Schools in the north of Limburg were not specifically targeted. In some cases they share a school board with a targeted school. The category "Others" in denomination includes schools with a specific pedagogical concept, protestant Christian schools, ecumenical Christian schools, and Islamic schools.

\section{How extensively do schools test?}

After discussing how consistently schools test, here, we focus on how extensively students are tested. For that purpose, we consider how many of the potential 12 test scores of the Mathematics series (see Table 8) are observed for each student. As discussed above, there are in fact 11 tests in that series of tests, but one of them can be conducted at two different points in time. This explains the small fraction of students taking 12 tests. 
Chapter 2: Representativeness and selective testing

Table 8 Number of tests taken by individual students

\begin{tabular}{|c|c|c|c|}
\hline No. of tests & $\mathrm{N}$ & Percent & Cummulative \\
\hline 0 & 12,355 & 30.99 & 30.99 \\
\hline 1 & 1,971 & 4.94 & 35.93 \\
\hline 2 & 1,928 & 4.84 & 40.77 \\
\hline 3 & 621 & 1.56 & 42.33 \\
\hline 4 & 589 & 1.48 & 43.80 \\
\hline 5 & 766 & 1.92 & 45.73 \\
\hline 6 & 864 & 2.17 & 47.89 \\
\hline 7 & 1114 & 2.79 & 50.69 \\
\hline 8 & 1376 & 3.45 & 54.14 \\
\hline 9 & 2,081 & 5.22 & 59.36 \\
\hline 10 & 6,184 & 15.51 & 74.87 \\
\hline 11 & 9,690 & 24.31 & 99.17 \\
\hline 12 & 329 & .83 & 100.00 \\
\hline Total & 39,868 & 100 & \\
\hline
\end{tabular}

Notes: Number of tests, from the LVS Mathematics series for primary school, taken by individual students.

There are two major groups, forming at the extremes: A little more than 40 percent of all students took at least 10 tests. For about 31 percent of students no test scores are observed. An additional 9.8 percent took only either one or two tests. This latter group mostly took tests at the end of primary school, at the end of grade 5 or in grade $6 .{ }^{16}$ In case only a few tests were left out, it was usually one in grade 1 or at the end of grade 7 . This pattern of increased testing throughout primary school is consistent with testing as a preparation for the Cito test, conducted in the middle of the last year in primary school.

For comparing student characteristics with respect to how extensively they were tested, we form five groups: No tests, 1 to 2 tests, 3 to 7 tests, 8 to 10 tests, and 11 to 12 tests. The latter group can be considered to have taken all tests, because there are only 11 tests that differ in content.

\footnotetext{
${ }^{16}$ This might have to do with the fact that schools not administering the Cito test could use test scores from grade 4 to 6 to support the secondary school advice.
} 


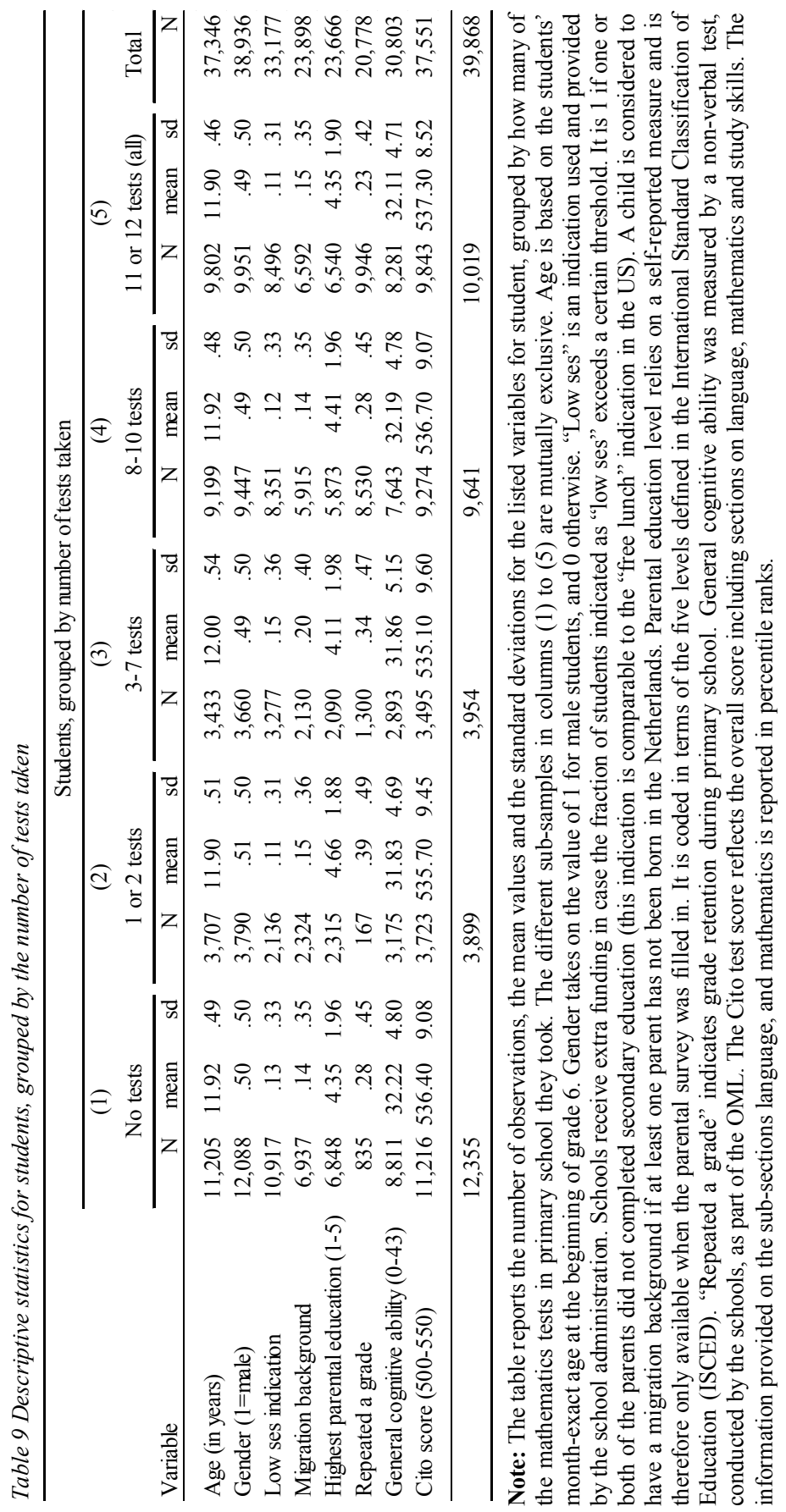


Chapter 2: Representativeness and selective testing

Do the students taking many tests differ from those that took fewer or no tests?

Table 9 provides descriptive statistics for students by the number of mathematics tests they took, throughout primary school. The highest average in the Cito test is observed for students taking all tests. However, the average on the test of general cognitive ability is insignificantly higher among students who took no tests and those who took 8 to 10 tests. Also the parental education level of those best performing students is not particularly high in comparison. These latter information have to be interpreted with caution, because they are available only for a part of the students. These slight inconsistencies provide reason to investigate further whether consistent testing and / or school quality can account for the advantage better performance of consistently tested students.

Figure 6 Students' Cito score distributions, by the number of tests taken in primary school

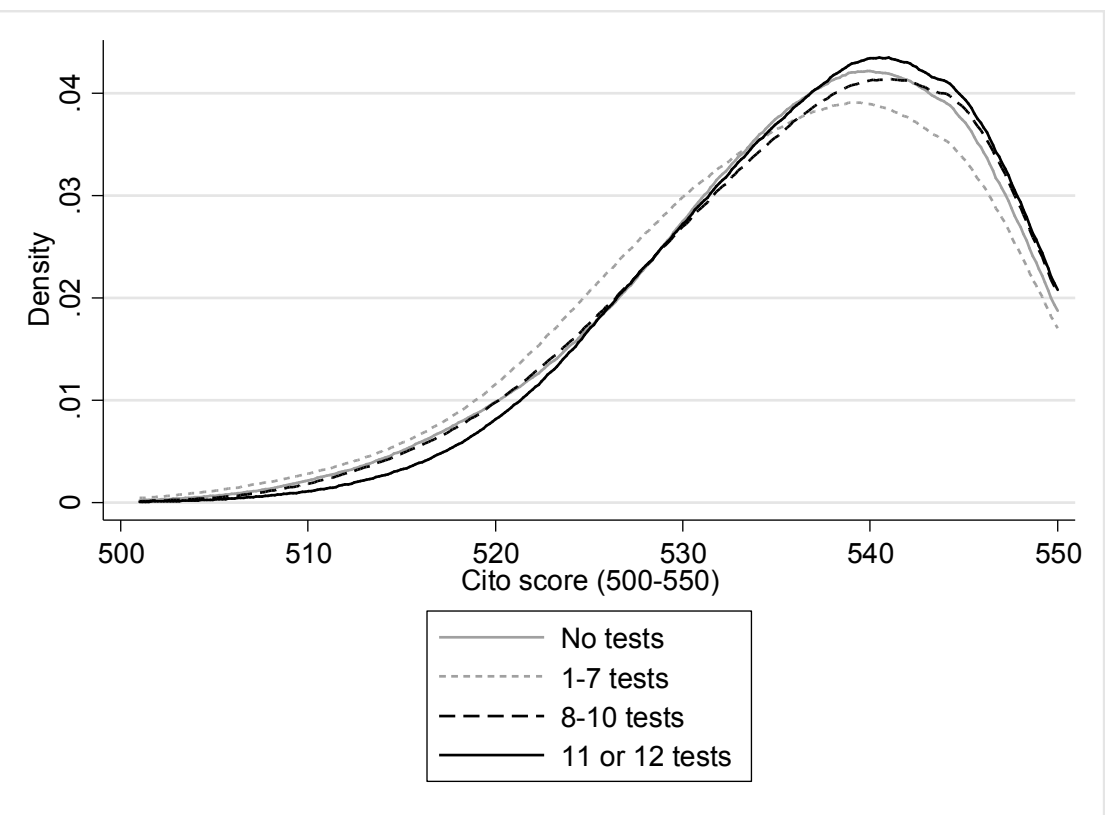

Notes: The figure shows distributions of Cito scores for individuals, grouped by how many of the mathematics tests they took.

Overall, those students being tested consequently (column 5) significantly outperform the other groups in the Cito test. They are followed by those either not being tested at all (column 1) or almost taking all tests (column 4). Students that only took some tests (column 2 and 3) perform 
on average worse. Figure 6 shows the distributions of the Cito test results. In Figure 6, the groups from column 2 and 3 are merged, because with respect to their performance the differences between them are negligible. ${ }^{17}$

\section{How extensively do schools in different location and of different denomination test?}

As shown above, schools in Westelijke Mijnstreek tend to test less than schools in other locations. Additionally, if they test, they administer mostly only one or two tests (see Table 10). In Parkstad and in Heuveland schools tend to use more tests. Students attending schools in those regions are overrepresented among the extensively tested (column 4 and 5), but also among the occasionally tested (column 3). Maastricht shows a slight overrepresentation of students that are occasionally (column 3), rarely (column 2) or not tested at all (column 1).

Table 10 Extensity of testing, by location and denomination of school

\begin{tabular}{|c|c|c|c|c|c|c|c|c|c|c|c|c|}
\hline \multirow[b]{4}{*}{ Location of school } & \multicolumn{12}{|c|}{ Students, grouped by number of tests taken } \\
\hline & \multirow{2}{*}{\multicolumn{2}{|c|}{$\begin{array}{c}\text { (1) } \\
\text { No tests }\end{array}$}} & \multirow{2}{*}{\multicolumn{2}{|c|}{$\begin{array}{c}(2) \\
1 \text { or } 2 \text { tests } \\
\end{array}$}} & \multirow{2}{*}{\multicolumn{2}{|c|}{$\begin{array}{c}(3) \\
3-7 \text { tests }\end{array}$}} & \multirow{2}{*}{\multicolumn{2}{|c|}{$\begin{array}{c}(4) \\
8-10 \text { tests } \\
\end{array}$}} & \multirow{2}{*}{\multicolumn{2}{|c|}{$\begin{array}{c}(5) \\
11 \text { or } 12 \text { tests } \\
\end{array}$}} & \multirow{2}{*}{\multicolumn{2}{|c|}{ Total }} \\
\hline & & & & & & & & & & & & \\
\hline & $\mathrm{N}$ & $\%$ & $\mathrm{~N}$ & $\%$ & $\mathrm{~N}$ & $\%$ & $\mathrm{~N}$ & $\%$ & $\mathrm{~N}$ & $\%$ & $\mathrm{~N}$ & $\%$ \\
\hline Westelijke Mijnstreek & 5,386 & 43.59 & 1,812 & 46.47 & 321 & 8.12 & 1,309 & 13.58 & 1,761 & 17.58 & 10,589 & 26.56 \\
\hline Parkstad & 2,784 & 22.53 & 1,023 & 26.24 & 2,047 & 51.77 & 4,706 & 48.81 & 4,775 & 47.66 & 15,335 & 38.46 \\
\hline Heuvelland & 980 & 7.93 & 156 & 4.00 & 751 & 18.99 & 1,993 & 20.67 & 2,088 & 20.84 & 5,968 & 14.97 \\
\hline Maastricht & 2,376 & 19.23 & 845 & 21.67 & 721 & 18.23 & 1,271 & 13.18 & 1,187 & 11.85 & 6,400 & 16.05 \\
\hline North Limburg & 531 & 4.30 & 60 & 1.54 & 99 & 2.50 & 339 & 3.52 & 163 & 1.63 & 1,192 & 2.99 \\
\hline \multirow[t]{2}{*}{ Unknown } & 298 & 2.41 & 3 & .08 & 15 & .38 & 23 & .24 & 45 & .45 & 384 & .96 \\
\hline & 12,355 & 100 & 3,899 & 100 & 3,954 & 100 & 9,641 & 100 & 10,019 & 100 & 39,868 & 100 \\
\hline Denomination of school & $\mathrm{N}$ & $\%$ & $\mathrm{~N}$ & $\%$ & $\mathrm{~N}$ & $\%$ & $\mathrm{~N}$ & $\%$ & $\mathrm{~N}$ & $\%$ & $\mathrm{~N}$ & $\%$ \\
\hline Roman Catholic & 8,315 & 67.30 & 2,920 & 74.89 & 2,712 & 68.59 & 7,726 & 80.14 & 7,961 & 79.46 & 29634 & 74.33 \\
\hline Public & 3115 & 25.21 & 728 & 18.67 & 641 & 16.21 & 1119 & 11.61 & 1227 & 12.25 & 6830 & 17.13 \\
\hline Antroposophic & 22 & .18 & 8 & .21 & 91 & 2.30 & 37 & .38 & 17 & .17 & 175 & .44 \\
\hline \multirow[t]{2}{*}{ Other } & 903 & 7.31 & 243 & 6.23 & 510 & 12.90 & 759 & 7.87 & 814 & 8.12 & 3229 & 8.10 \\
\hline & 12,355 & 100 & 3,899 & 100 & 3,954 & 100 & 9,641 & 100 & 10,019 & 100 & 39,868 & 100 \\
\hline
\end{tabular}

Notes: The table reports the location, and denomination of the school attended by individual students, grouped by how many mathematics tests they took in primary school. Westelijke Mijnstreek, Parkstad, Heuvelland, and Maastricht are the main regions which can be distinguished in south Limburg (see also Figure 1). Schools in the north of Limburg were not specifically targeted to participate in the OML. In some cases they share a school board with a targeted school. The category "Others" in denomination includes schools with a specific pedagogical concept, protestant Christian schools, ecumenical Christian schools, and Islamic schools.

\footnotetext{
${ }^{17}$ With respect to other characteristics, such as the fraction of students with a migration background or the mean of the highest parental education level they are less comparable. However, the parental non-response rate in both groups is substantial. Thus, those comparisons can only be made with reservations.
} 
Chapter 2: Representativeness and selective testing

Students attending Roman Catholic schools are often tested extensively. Students at public schools are strongly overrepresented among the not tested group. Finally anthroposophical schools and schools of other denominations use tests most occasionally (column 3).

\subsection{Conclusion}

In this chapter, we introduce the education monitor Limburg, OnderwijsMonitor Limburg (OML), and with it the Dutch education system, specifically focusing on primary education. Thereby, this chapter puts the other studies of this dissertation into perspective. In itself, it is an exploration of the OML, providing insight into the representativeness of the data and questions of selective testing. Furthermore, the compilation of descriptive evidence on these topics raises several additional research questions that go beyond the scope of this dissertation. Lastly, we use several different ways to structure and analyze the descriptive statistics. Thereby, we provide an example of how to zoom in to complicated datasets.

The strength of the OML is the combination of many data sources (administrative information from the schools, test score records and questionnaire data), for a large part of the regional population. At the same time, when using the data, one has to be aware of the fact that several decision makers were involved in the process of data collection. The following paragraphs summarizes our findings, and observed patterns. We will end by mentioning some open questions and potential underlying processes, which are still to be investigated.

The representativeness of the OML is investigated on the individual, as well as on the school level. A lower bound estimate for the individual coverage rate is 92 percent. On the schoollevel, the coverage rate can be assessed more precisely. Every year it slightly changes, always remaining above 97 percent. At least some performance measures are available for 87.3 percent of the individuals. Only if information from all data sources are required, the data availability reduces to about 40 percent of the cohort.

Regarding school level participation, we identify the most common participation patterns and are able to explain most of the changes in participation of individual schools. The overall participation is good. About 94 percent of schools provide data from all, or all but one data sources. So there is no persistent non-collaboration on the school level. Most schools who provide administrative information also participate in conducting the parental, and student surveys at least once. Only a hand full do not. However, the extent of participation changes on a yearly basis. Therefore, we use school-year combinations as the unit of observation in later analysis. 
Seen individually, the provision of LVS test score data and student questionnaires remains above $80 \%$. The most critical point is the availability of the parental questionnaire data. The highest rates of parental non-response are observed in the regions Parkstad and Heuvelland. The reasons, and consequences of parental survey non-response are analyzed in more detail in Chapter 3.

When grouping students by the availability of their data, patterns can be observed: The best performance in terms of general cognitive ability and Cito scores ${ }^{18}$ is observed for students with information from either all data sources or only missing LVS test scores. In most of the cases, for the latter group also all data are available. Most schools that do not provide LVS test scores do not use those tests. On a regional level, availability of test scores is worse for schools in Westelijke Mijnstreek, and Maastricht than for schools in Parkstad and Heuvelland. It remains to be investigated whether this discrepancy is based on differential testing behavior or systematic differences in the process of data transmission, from schools to the research project. With respect to denomination, Roman Catholic schools make up the largest group. They tend to provide data on a broad basis. Public schools generally provide less data and anthroposophical schools participate very selectively.

The analysis of selective testing concentrates on the series of 11 mathematics tests from Cito, for grades 1 through 6 . The aim was to investigate how consistently, and extensively schools test their students. The first finding is that only very few schools test less than 80 percent of their student population. However, depending on the year, between 15 and 38 percent test more than 80 percent, but still not all students. This leaves potential for strategic testing. Regionally, less consistent testing of the student population concentrates in Parkstad, schools in Heuvelland test more complete.

On the individual level, about 40 percent of the students take almost all tests, 31 percent take no test, and the rest is in between. Students taking all tests outperform all others on the Cito test, even though their other characteristics are not more favorable, compared to those of students with slightly fewer or no tests. Students only taking some tests performed worst. Testing schools in Westelijke Mijnstreek often only use some tests, while in Parkstad, and Heuvelland schools tend to use more tests. Anthroposophical schools, and those of other

\footnotetext{
${ }^{18}$ In this analysis the only performance measure used is the Cito test. We refrained from analyzing LVS test scores, because this requires more detailed distinctions, due to several versions of each test (digital and analogue, with and without calculator and so on) in order to ensure comparability.
} 
Chapter 2: Representativeness and selective testing

denominations not distinguished use tests most occasionally. Here as well, technical difficulties in the data export and transmission could distort the picture.

The many descriptive statistics and sub-group comparisons raise a lot of further questions that lie beyond the scope of this study. Here, we only mention the two main ones. Firstly, we identified potential strategic behavior by schools. Whether this observation is really based on schools excluding low-performing parts of the student population from testing, remains to be investigated. Alternatively, there could be other reasons for the non-availability of test scores for a part of the student population, such as a recent school-change or special education students. Secondly, we observe correlations between consistent testing and performance. Whether there is a causal link behind this correlation cannot be concluded, yet. It remains to be analyzed what the causal effect of being tested consequently is.

This chapter focusses at the meta-level. The following three chapters dive deeper into the data, with more specific questions. All of them connect to this chapter at different points. Overall, this chapter shows, that the OML provides a close to full population coverage of south Limburg. Most critical is data availability with respect to parental surveys. As already mentioned, Chapter 3 analyzes the reasons and consequences of non-response on the parental questionnaire in the OML. As implied by this chapter, selection can be induced on different level, by schools as well as by individual parents. These different types of non-response are considered and analyzed separately. Later, in Chapter 4, mathematics test scores are used to investigate how the correlation between parental education and child performance develops over the course of primary education. However, as shown above, students for whom the complete test score records are available constitute a special group. Thus, Chapter 4 considers next to a balanced sample of students taking all math tests, also an unbalanced sample. Based on a sub-group of schools, Chapter 5 zooms in to the item level of one of the early numeracy tests. By comparing the use of sum scores and item-based categories, it contributes to answering how detailed information on test results need to be to make valid predictions. Altogether, Chapters 3 to 5 fill in details and complement the frame, provided by this chapter. 


\title{
Are Estimates of Intergenerational Mobility Biased by Non-Response? ${ }^{19}$
}

\begin{abstract}
Research on intergenerational mobility is predominantly based on survey data. Important potential concerns with this approach are that parents' or schools' participation in surveys may be non-random, and that only a specific subset of the responding parents responds to questions related to income. Linking Dutch survey data to administrative income data, we investigate whether selective response behavior biases the estimated relationship between parental income and children's schooling. We find that the relationship is attenuated because specific schools refuse to participate in the data collection endeavors. Parental survey nonresponse shifts coefficients in the same direction, but not significantly. Parental item nonresponse on income questions on the contrary, biases the estimates upward.
\end{abstract}

\footnotetext{
${ }^{19}$ This chapter is based on joint work with Bart H. H. Golsteyn. It has been sponsored by grants of the Network of Social Innovation (Maastricht University) and the Dutch Ministry of Education, Culture and Science. The data collection has been funded by the Dutch Ministry of Education as well as by the school boards in the province of Limburg. We thank Paul Jungbluth, Tyas Prevoo, Trudie Schils, Lex Borghans, and Roxanne Korthals for useful feedback. Furthermore, we thank conference participants at the Dutch Economists' Day 2015, the $21^{\text {st }}$ Annual Meeting of the Society of Labor Economists (2016) and the $30^{\text {th }}$ Annual Conference of the European Society for Population Economics (2016), as well as seminar participants at Maastricht University and University Tuebingen for helpful comments.
} 
Chapter 3: Are Estimates of Intergenerational Mobility Biased by Non-Response?

\subsection{Introduction}

The relationship between parental income and children's schooling outcomes is predominantly estimated with survey data (see, e. g. Blau, 1999; Chevalier et al., 2013; Plug \& Vijverberg, 2005). ${ }^{20}$ A potentially important issue in this literature is that survey response may be nonrandom. Most notably, the probability to respond to a survey has been shown to be positively related to income and other indicators of socio-economic status (see, e. g. Martikainen, Laaksonen, Piha, \& Lallukka, 2007; Porter \& Whitcomb, 2005; Turrell, Patterson, Oldenburg, Gould, \& Roy, 2003). ${ }^{21}$ An unresolved question is whether selective non-response biases the estimated intergenerational relationship between parental income and child schooling.

In this study we investigate whether survey based estimates of the relationship between household income and the child's performance in school are biased because of selected nonresponse. We analyze three sources of non-response: (1) specific schools may be more willing to collaborate more extensively in the data collection; (2) specific parents may be more likely to participate in surveys; and (3) there may be selective item non-response by parents on questions regarding their income.

We combine parental survey data with administrative data from schools and income registry data. The base of our analysis is an ongoing regional education monitor conducted in the south of the Netherlands. This monitor covers more than 95 percent of the primary schools in the target region. Parental survey information is available for approximately 69 percent of children. We link the data of the children to administrative income data of their parents from Statistics Netherlands. From this source, we have information on parental income for responding and non-responding parents, in both responding and non-responding schools. Non-responding schools are those that participated in the education monitor, yet did not send out parental surveys. Our variable of interest - children's school performance - is based on the administrative records of the schools: we use standardized mathematics and language test scores for all students in the sample that participated in the test.

All our estimates are based on administrative data only, from schools as well as the income registry. ${ }^{22}$ We distinguish different types of non-response biases by using observed survey

\footnotetext{
${ }^{20}$ Other studies use administrative data (see e. g. Black, Devereux, \& Salvanes, 2005). Black and Devereux (2011) provide an extensive review of this recent literature and the different empirical methods used.

${ }^{21}$ Some studies have imputed missing responses based on geographically-aggregated data (e. g. Sabelhaus et al., 2015). Recent evidence from the U. S. Census Bureau (Bee et al., 2016) raises questions regarding the validity of this approach.

${ }^{22}$ Therefore, our results are not affected by misreported declarations by parents.
} 
response behavior to artificially restricting the full sample to the data that would be available if the survey had suffered from a certain type of non-response. Observing non-responding individuals or individuals at non-responding institutions with administrative information enables us to directly assess whether response rates are selective and whether this biases the relationship between parental income and child performance.

Our main findings are, firstly, that the positive relationship between parental income and child schooling is attenuated, since specific schools choose not to participate in sending out parental surveys. Secondly, although parents from low income groups participate less frequently in the parental survey, this non-response does not significantly affect the estimated relationship between parental income and children's schooling. ${ }^{23}$ Thirdly, we find evidence that nonresponse by parents on the income question leads to an overestimation of the relationship. The results for school non-response and item non-response bias are stronger for test scores in language than in mathematics.

This chapter contributes to methodological aspects of the literature on intergenerational mobility, specifically the empirical literature that analyzes how children's schooling outcomes relate to parental income. ${ }^{24}$ In cross-sectional surveys a consistent significant positive relationship between parental income and schooling outcomes is found (Blau, 1999; Chevalier et al., 2013). Also when adoption is used as a natural experiment to exclude genetically transferred ability as a factor of influence, a significant relationship with income remains (Plug \& Vijverberg, 2005). This result is robust to controlling for characteristics of the biological parents and extending the focus to economic outcomes of the children (Björklund, Lindahl, \& Plug, 2006). Hence, parental income appears to constitute an important determinant of success in school and the labor market.

While findings on the direction of the relationship are unambiguous, their magnitude is often contested. Besides the difficulty of comparing results across time and empirical contexts, there are four issues that potentially lead to empirical problems in studies based on survey data: (1) non-representative samples, (2) truncated samples, (3) survey non-response (often referred to as unit non-response) and (4) item-based non-response. ${ }^{25}$ Many samples are non-representative

\footnotetext{
${ }^{23}$ The result is insignificant but the sign reveals some evidence for attenuation.

24 This chapter also relates more generally to the literature on biases from unit and item non-response in samples (see, e. g. Bee et al., 2016). Here, we analyze the specific consequences for estimates of intergenerational mobility. ${ }^{25}$ Additionally, erroneous answers might be considered as a potential source of bias. However, it is almost impossible to determine which income measure is true for several reasons. For example, while survey answers might suffer from social desirability, administrative income data could omit undeclared income.
} 


\section{Chapter 3: Are Estimates of Intergenerational Mobility Biased by Non-Response?}

by construction, but truncations could also be the result of a choice, such as excluding observations with low or no income. The latter likely leads to overestimations of intergenerational correlations (Couch \& Lillard, 1998). Survey non-response is inevitable and ubiquitous in survey studies. Furthermore, virtually all self-reported measures of income are subject to item-based non-response. ${ }^{26}$ The question, both with respect to survey and item nonresponse, is whether the non-response is selective and whether this may lead to bias in the intergenerational relationship. One might think that drawing on administrative data, as done by Björklund et al. (2006), could help avoiding biases based on survey or item non-response. However firstly, as mentioned by the authors, non-response at earlier stages can still be a problem in administrative data. Secondly, the availability of such datasets is mostly limited to the Scandinavian countries.

This chapter also relates to the more general methodological literature on missing data. Schafer and Graham (2002), for example, provide a structure to classify missing data and describe criteria by which missing data procedures can be evaluated. The main distinction is whether data are missing completely at random, missing at random or missing not at random. In the first case, the probability of missing a value neither depends on the observed, nor the unobserved characteristics, while missing at random allows that the probability of data being missing is related to observed characteristics. However, we do not go into the details of this question. Instead, the focus lies on the consequences when missing data are not considered and dealt with thoroughly.

The contribution of our study is to identify and assess the magnitude of survey and item nonresponse bias in the context of the intergenerational relationship between parental income and schooling. We investigate different sources of bias by non-response, and thereby, provide an appraisal of the validity of survey studies in this field. Similar approaches of comparing survey data with full population register data have been taken in health science (Reijneveld \& Stronks, 1999; Søgaard et al., 2004) and by Micklewright and Schnepf (2006) to assess the response bias in the PISA study in the UK. We are not aware of existing applications in the context of intergenerational mobility.

\footnotetext{
${ }^{26}$ Riphahn and Serfling (2005) investigate this phenomenon and relate it to several demographic and interviewer characteristics. As (Bielby, Hauser, \& Featherman, 1977) show, response errors might lead to overestimations of the racial gap and accordingly to other severe misinterpretations.
} 
The remainder of the chapter is structured as follows: Section 3.2 provides a description of the data. Section 3.3 discusses the results. Section 3.4 discusses potential mechanisms and Section 3.5 concludes.

\subsection{Data}

We combine different sources of administrative records and survey data. The base of our dataset is an ongoing regional education monitor for the south of the Netherlands: the OnderwijsMonitor Limburg (OML). Since 2009, the monitor is conducted as a cooperative project between schools and Maastricht University. Almost all regular primary schools in the southern part of the Dutch province Limburg participate in the project and provide records from their students on a yearly basis. ${ }^{27}$

The data we use were gathered for one cohort of students at two points in time. The students are observed in 2009 in grade 6 (their last year of primary school, on average at age 12). Three years later about 88.1 percent of them could be found back in their third year of secondary school in grade 9 (at about age 15). We give more information about the data below.

At both points in time, a parental survey has been conducted and the results are linked to the school records. In grade 6, the parental survey was distributed via the school. In grade 9, the survey was distributed directly to the parents. For the grade 6 data, the overall response rate among the parents amounts to 69 percent. ${ }^{28}$ Approximately one third of all non-responding parents can be traced back to schools, in which none of the parents participated in the survey. This makes it highly likely that those schools either did not send out the survey to the parents or they did not forward the completed questionnaires back to the university. In the following, these schools will be referred to as "non-responding schools", not to be mistaken with schools not participating in the OML. ${ }^{29}$ Therefore, in our analysis we distinguish non-response at the parental level (22 percent) and non-response at the school level (9 percent). In grade 9, the

\footnotetext{
${ }^{27}$ A more detailed introduction into the OML is provided in Chapter 2.

${ }^{28}$ This compares very well to the response or survival rates in the articles by Chevalier et al. (2013) and by Plug and Vijverberg (2005), as can be seen from technical reports on the underlying surveys (EUROSTAT, 2009; Hauser, 2005). The response rate of 58 percent reported by Björklund et al. (2006) is even lower. The only higher response (or remain) rate in any of the articles cited above amounts to 87 percent ( 83 percent) in the National Longitudinal Surveys (2016), NLSY, used by Blau (1999).

${ }^{29}$ The issue of selective participation in the OML is addressed in detail in Chapter 2.
} 


\section{Chapter 3: Are Estimates of Intergenerational Mobility Biased by Non-Response?}

overall response rate of 43 percent is substantially lower than in the survey conducted in grade 6 , even though the parental survey was distributed directly to the parents. ${ }^{30}$

Consequently, there is only one source of survey non-response in grade 9. However, the surveys also differed in content. In grade 9, a question regarding household income was included in the parental survey, allowing us to analyze additionally the effect of item non-response on the income questions. This item non-response is the third aspect we consider in our analyses besides school and parental survey non-response. Approximately 63 percent of the responding parents do not fill out the income question.

The process of data collection, as well as the approximate response and non-response rates for both samples, are depicted in Figure 7. Parental survey non-response can be observed in both samples. School non-response can only be assessed in the baseline sample and item nonresponse only in the sub-sample in grade 9.

Figure 7 Data collection and approximate response rates in both samples

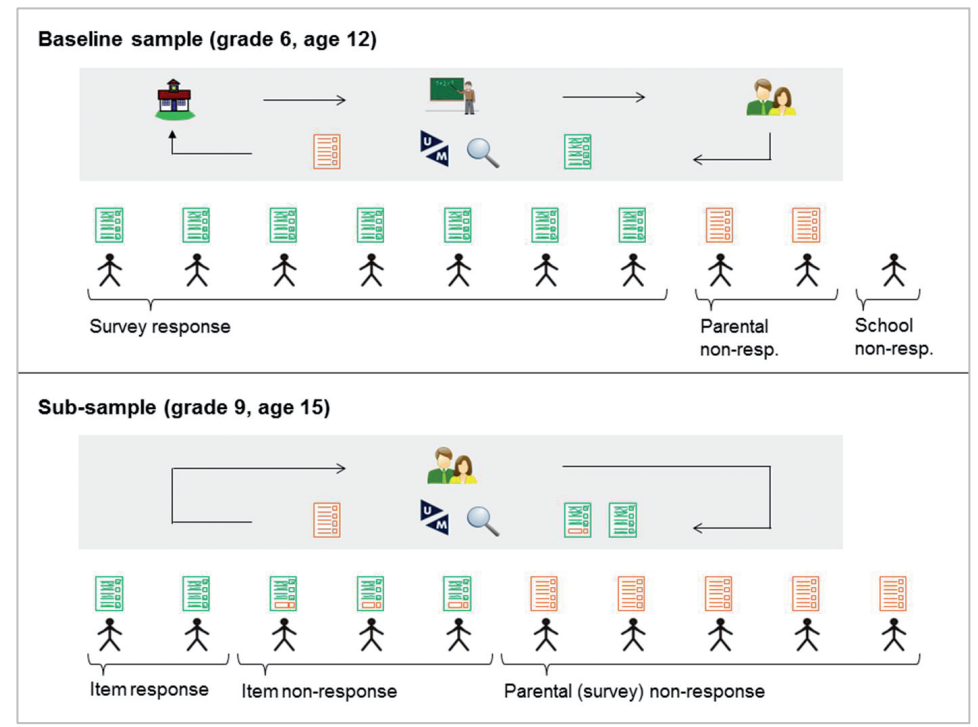

Notes: Generic depiction of the data collection process and the proportionate response behavior.

\footnotetext{
${ }^{30}$ In this wave of the data we observe that at least one parent from each school completed the survey. This supports our claim of non-response at the school level based on observing a zero response rate. The overall low response rate can be explained by the fact that the initial invitation letter only included a link to an online survey. Only the reminder letter included a paper version. Among the participants 52.8 percent completed the paper survey.
} 
We merge the data on this cohort from the OML to the administrative information from the household register of the municipalities and the income register from Statistics Netherlands. The match is made based on surnames and addresses. It can be completed for 81.5 percent of the students in the baseline sample, assessed in grade $6 .^{31}$

\subsubsection{Schooling and income measures}

Our measure of school performance in grade 6 is the result of a nation-wide skill assessment test, ${ }^{32}$ in the following referred to as the Cito test. The mean age of the students when they take the test is 12.2. The result is a main determinant of the teacher's recommendation for secondary schooling track, which is often treated as binding by secondary schools. ${ }^{33}$ Therefore, the students face strong incentives to score well on this test.

Among the grade 9 students, the OML administered its own tests on language and mathematics achievement, based on questions from larger standardized studies. ${ }^{34}$ The results are solely used for research purposes. Hence, in contrast to the Cito test, these tests are low stakes tests. There were three difficulty levels, administered at different tracks: one test for the two upper tracks (HAVO and VWO), one for the two medium tracks (VMBO g/t), and one for the two lowest tracks (VMBO b/k). ${ }^{35}$ Overlapping questions make it possible to use item response theory (IRT) to transform the raw scores into test scores on a common scale. We use a two-parameter logistic model for binary items, allowing items to vary in their difficulty and discrimination. The resulting latent trait scores are used in the analysis below.

The administrative data from Statistics Netherlands on the financial situation of the households comprise measures for total and corrected income. The corrected income is based on the total income, adjusted for the number of household members. In our analysis, we rely on this corrected measure of household income. This comes closer to the income available per child,

\footnotetext{
${ }^{31}$ As a comparison, Bee et al. (2016) manage to link between 76 and 79 percent of households to tax administration data. As a major source of non-linking they identify non-filing of taxes.

${ }^{32}$ Officially the test is called "Cito Eindtoets." It comprises three parts, focusing on: language, mathematics, and study skills. It is constructed and also graded externally by the central institute for test development (Centraal Instituut voor Toetsontwikkeling, Cito).

${ }^{33}$ The different tracks lead to specific qualifications for the labor market. Even if the teacher deviates from the final assessment test result, some secondary schools only accept students with a score above a certain threshold (Borghans, Korthals, \& Schils, 2015). During the first three years after the transition, a quarter of the children changes the track at least once. And among them only 40 percent change to a higher schooling level (Inspectie van het Onderwijs, 2014).

${ }^{34}$ The tests comprise questions used in the tests of the Programme for International Student Assessment (PISA) as well as the Dutch cohort study on educational careers for students from 5 to 18 years (Cohort Onderzoek OnderwijsLoopbanen, $\mathrm{COOL}^{5-18}$ ).

${ }^{35}$ For a description of the Dutch education system see Section 2.2.2.
} 


\section{Chapter 3: Are Estimates of Intergenerational Mobility Biased by Non-Response?}

which for instance can be invested in tutoring. ${ }^{36}$ For each of the income measures, we know to which quintile of the income distribution in the overall population of the Netherlands a household belongs.

Having data on schooling outcomes, as well as an objective measure of household income for an unusually large share of the population, and having a measure for survey participation are unique features of our dataset. This setting enables us to observe and analyze the non-response bias in the intergenerational relationship of parental income and children's schooling outcomes.

\subsubsection{Baseline sample, grade 6 (age 12)}

The OML covers 95 percent of schools in the region. The baseline sample consists of all students attending those schools, and taking the final assessment test in grade 6 in 2009. ${ }^{37}$ This group consists of 4,512 observed students. As mentioned, among their parents, 69 percent answered the parental questionnaire. Administrative data on income could be merged for 83.6 percent of the children with participating parents, and for 79.9 percent of the children with nonparticipating ones. The other 18 percent of the students could not be linked to the administrative income data, due to missing or erroneous address data from the school records.

Table 11 provides descriptive statistics for all students in our baseline sample merged to administrative data. The table shows that for 2,722 students parental information is available, while for the other 1,209 students no parental information is available. This latter group is split up into a group of parents whose child is in a school where no answers of any parents are available (429), and a group of parents who do not respond, but whose child attends a school in which other parents do respond (780). The former group we consider to be missing due to school non-response, and the latter to be missing due to parental survey non-response.

Regarding basic demographic characteristics, such as age and gender, the three groups are similar. Students of non-participating parents and at non-participating schools are only slightly older, and among them a higher fraction are first or second generation immigrants. Both differences are significant at the five percent level. The descriptive statistics already suggest that distinct selection mechanisms might be at work at the institutional and the individual level. With respect to the socio-economic status, household income, and student outcomes, there is

\footnotetext{
${ }^{36}$ In a robustness check, we compare the results based on the raw income data. These are qualitatively similar.

${ }^{37}$ The schools are required to use some test at the end of primary school. With about 86 percent coverage in 2013, the Cito test, that we use in the analysis, is the most common one (Inspectie van het Onderwijs, 2014). Therefore, this is the best comparative measure available in this context.
} 
significant negative selection into parental non-response, as well as non-significant suggestive evidence for positive selection into school non-response.

Table 11 Descriptive statistics by survey response status, baseline sample grade 6 (age 12)

\begin{tabular}{|c|c|c|c|c|c|c|c|c|c|}
\hline \multirow[b]{3}{*}{ Variable } & \multicolumn{9}{|c|}{ Survey participation status } \\
\hline & \multicolumn{3}{|c|}{$\begin{array}{c}\text { (1) } \\
\text { Survey participation }\end{array}$} & \multicolumn{3}{|c|}{$\begin{array}{c}\text { (2) } \\
\text { School non-response }\end{array}$} & \multicolumn{3}{|c|}{$\begin{array}{c}\text { (3) } \\
\text { Parental non-response }\end{array}$} \\
\hline & $\mathrm{N}$ & mean & $\mathrm{sd}$ & $\mathrm{N}$ & mean & $\mathrm{sd}$ & $\mathrm{N}$ & mean & sd \\
\hline Age (in years in grade six) & 2,611 & 12.21 & .54 & 373 & 12.27 & .55 & 737 & 12.27 & .54 \\
\hline Gender (fraction male) & 2,722 & .49 & .50 & 429 & .48 & .50 & 780 & .49 & .50 \\
\hline Low ses (fraction) & 2,611 & .12 & .33 & 373 & .10 & .31 & 737 & .19 & .39 \\
\hline Migration background (fraction) & 2,722 & .14 & .35 & 428 & .20 & .40 & 777 & .22 & .42 \\
\hline Highest parental education (1-5) & 2,681 & 3.25 & 1.09 & 0 & · & . & 0 & $\cdot$ & \\
\hline Corrected Income (1-5) & 2,709 & 3.05 & 1.32 & 426 & 3.13 & 1.36 & 767 & 2.81 & 1.35 \\
\hline Cito test score (500-550) & 2,611 & 536.90 & 8.86 & 373 & 537.32 & 9.14 & 737 & 534.93 & 9.06 \\
\hline Cito test: language section (\%) & 2,611 & 77.19 & 11.16 & 373 & 77.88 & 11.64 & 737 & 74.85 & 11.70 \\
\hline Cito test: mathematics section (\%) & 2,611 & 73.50 & 16.95 & 373 & 73.74 & 16.98 & 737 & 70.64 & 17.00 \\
\hline General cognitive ability (0-43) & 2,655 & 32.69 & 4.68 & 22 & 28.91 & 6.08 & 556 & 31.82 & 5.07 \\
\hline & 2,722 & & & 429 & & & 780 & & \\
\hline
\end{tabular}

Notes: The table reports the number of observations, the mean values and the standard deviations for the listed variables by response status on the parental survey in grade 6 at age 12, conditional on having school administrative information on the students $(81,5 \%)$ and the students having taken the Cito test $(92,4 \%$ of the students with administrative data). The different sub-samples (1), (2), and (3) are mutually exclusive. Age is based on the students' month-exact age at the beginning of grade 6 . Gender takes on the value of 1 for male students and 0 otherwise. "Low ses" is an indication used and provided by the school administration. Schools receive extra funding in case the fraction of students indicated as "low ses" exceeds a certain threshold. It is 1 if one or both of the parents did not complete secondary education (this indication is comparable to the "free lunch" indication in the US). A child is considered to have a migration background if at least one parent has not been born in the Netherlands. Parental education level relies on a self-reported measure and is therefore only available when the parental survey was filled in. It is coded in terms of the five levels defined in the International Standard Classification of Education (ISCED). Corrected income is reported on the household level in terms of quintiles relative to the complete Dutch population. It is based on the income register at 31 December 2008. The Cito test score reflects the overall score including sections on language, mathematics and study skills. The information provided on the sub-sections language and mathematics are reported in the percentage of questions answered correctly. Blanks indicate that the data source of this variable is not available for that particular group.

Table A.4 provides statistics of the group for which we do not have administrative data analogue to Table 11. We observe a similar pattern of descriptive statistics with respect to the survey participation status in the non-merged compared to the merged sample. Therefore, we are confident that our results are not severely influenced by missing parental income data for this group of students. 
Chapter 3: Are Estimates of Intergenerational Mobility Biased by Non-Response?

Figure 8 Cito score distributions, by survey response, baseline sample grade 6

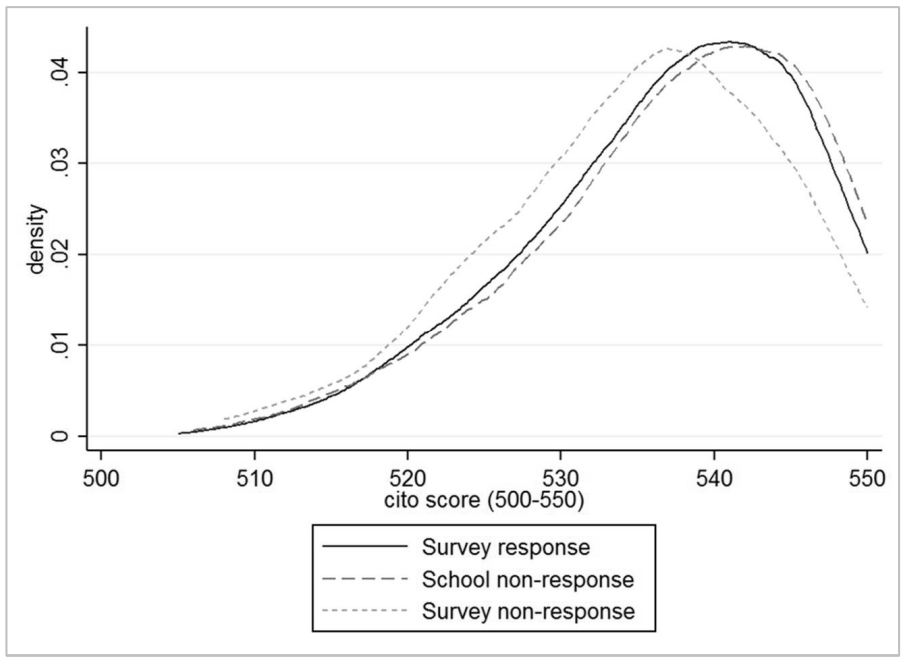

Notes: This graph is restricted to all students for whom Cito test scores were available and data could be merged with administrative household information. The group with responding parents relates to column (1) from Table 11 , the groups with non-responding schools and from non-responding parents correspond to column (2) and (3) respectively.

Distribution plots of Cito scores confirm the differential performance of student groups based on the response to the parental survey. Figure 8 reveals that students whose parents decide to participate in the survey, indeed outperform students whose parents decide not to participate (significant at 1 percent). However, the graph also shows that students attending schools, which did not send out the parental surveys, perform even slightly better in the Cito test than students, whose parents respond (significant at 10 percent). Because the Cito test is a main determinant of track placement, these differences potentially also matter for long run outcomes (College voor Toetsen en Examens, 2015).

Table 12 shows parental survey participation rates by quintile of corrected income. The quintiles are based on the incomes of the full Dutch population. Two thirds of survey nonresponse are due to parental non-response, and one third to school non-response. While parental non-response is highest in the lower income quintiles, school non-response is most prevalent among families in the higher income quintiles. No income records were available for 29 of the 3,931 households. 
Table 12 Parental survey participation by income quintile, baseline sample grade 6 (age 12)

\begin{tabular}{crrrr}
\hline \multirow{2}{*}{$\begin{array}{c}\text { Standardized } \\
\text { income }\end{array}$} & \multicolumn{2}{c}{ Survey participation status } & \\
\cline { 2 - 4 } & \multicolumn{1}{c}{$\begin{array}{c}\text { Survey } \\
\text { participation }\end{array}$} & $\begin{array}{c}\text { School } \\
\text { non-resp. }\end{array}$ & $\begin{array}{c}\text { Parental } \\
\text { non-resp. }\end{array}$ & Total \\
\cline { 2 - 4 } $0-20 \%$ & 423 & 73 & 170 & 666 \\
& 63.51 & 10.96 & 25.53 & 100.00 \\
$20-40 \%$ & 582 & 65 & 170 & 817 \\
& 71.24 & 7.96 & 20.81 & 20.94 \\
$40-60 \%$ & 609 & 105 & 166 & 880 \\
& 69.20 & 11.93 & 18.86 & 100.00 \\
$60-80 \%$ & 632 & 98 & 154 & 884 \\
& 71.49 & 11.09 & 17.42 & 100.00 \\
$80-100 \%$ & 463 & 85 & 107 & 655 \\
& 70.69 & 12.98 & 16.34 & 100.00 \\
\hline Total & 2,709 & 426 & 767 & 3,902 \\
& 69.43 & 10.92 & 19.66 & 100.00 \\
\hline
\end{tabular}

Notes: The table shows survey participation rates by quintile of corrected income for the three groups distinguished in Table 11. It includes all observations for which data from school administration and Cito test scores is available and the data can be linked to administrative records of the parents.

\subsubsection{Sub-sample, grade 9 (age 15)}

The OML follows students through their school career. The cohort observed in grade 6 in 2009 was the first to also be observed in grade 9, the third year of secondary school. Again, a parental survey was conducted and achievement tests in language and mathematics, this time with low stakes for students, were performed. We use this sample to repeat our analysis of parental nonresponse, and explore the influence of item non-response on income questions.

Matching on names and addresses, we could track down 88.1 percent of the baseline sample. When we restrict ourselves to those participating in the achievement tests, the remaining sample consists of 2,963 observed students or 75.4 percent of the baseline sample. Since the parental surveys are sent out directly, the response rate (43.2 percent) in this sample reflects parental participation. The survey allows investigating item non-response on questions regarding the household income. Among the survey respondents, 37 percent answer the income question. 


\section{Chapter 3: Are Estimates of Intergenerational Mobility Biased by Non-Response?}

Table 13 provides descriptive statistics for the students in this sub-sample, analogue to Table 11. Columns (1) and (3) include children of parents that return the survey, distinguished by whether they provide information on the household income $(\mathrm{N}=474)$ or not $(\mathrm{N}=807)$. Column (2) shows the descriptive statistics for all children who can be found back and participate in the achievement test, but whose parents do not return the survey $(\mathrm{N}=1,682)$.

Table 13 Descriptive statistics by survey response status, sub-sample grade 9 (age 15)

\begin{tabular}{|c|c|c|c|c|c|c|c|c|c|}
\hline \multirow[b]{3}{*}{ Variable } & \multicolumn{9}{|c|}{ Survey participation status } \\
\hline & \multicolumn{3}{|c|}{$\begin{array}{c}(1) \\
\text { Survey \& item response }\end{array}$} & \multicolumn{3}{|c|}{$\begin{array}{c}\text { (2) } \\
\text { Survey non-response }\end{array}$} & \multicolumn{3}{|c|}{$\begin{array}{c}(3) \\
\text { Item non-response } \\
\end{array}$} \\
\hline & $\mathrm{N}$ & mean & $\mathrm{sd}$ & $\mathrm{N}$ & mean & $\mathrm{sd}$ & $\mathrm{N}$ & mean & $\mathrm{sd}$ \\
\hline Age (in years in grade six) & 474 & 15.10 & .41 & 1,682 & 15.20 & .47 & 807 & 15.12 & .46 \\
\hline Gender (fraction male) & 474 & .46 & .50 & 1,682 & .49 & .50 & 807 & .48 & .50 \\
\hline Low ses (fraction) & 455 & .04 & .50 & 1,595 & .17 & .38 & 777 & .07 & .26 \\
\hline Migration background (fraction) & 474 & .10 & .30 & 1,680 & .20 & .40 & 806 & .09 & .29 \\
\hline Highest parental education (1-5) & 352 & 3.61 & 1.03 & 1,093 & 3.15 & 1.12 & 619 & 3.39 & 1.00 \\
\hline Corrected Income (1-5) & 472 & 3.51 & 1.24 & 1,669 & 2.88 & 1.33 & 804 & 3.18 & 1.27 \\
\hline Cito test score $(500-550)$ & 455 & 539.70 & 7.82 & 1,595 & 535.98 & 8.95 & 777 & 537.76 & 8.63 \\
\hline Language test, grade 9 (stand.) & 363 & .21 & .99 & 1,268 & -.08 & .96 & 620 & .14 & .95 \\
\hline Mathematics test, grade 9 (stand.) & 360 & .30 & .93 & 1,269 & -.13 & .97 & 617 & .16 & .99 \\
\hline \multirow[t]{2}{*}{ General cognitive ability $(0-43)$} & 399 & 33.45 & 4.53 & 1,385 & 32.33 & 4.80 & 690 & 33.06 & 4.41 \\
\hline & 474 & & & 1,682 & & & 807 & & \\
\hline
\end{tabular}

Notes: The table reports the number of observations, the mean values and the standard deviations for the listed variables by response status on the parental survey at age 15 , conditional on being in the baseline sample, being found back in secondary school ( 88.1 percent of baseline sample), and that they take either a mathematics or language test (85.6 percent of the students found back or 75.4 percent of the baseline sample). The different subsamples (1), (2), and (3) are mutually exclusive. Age refers to the students' month-exact age at the beginning of grade 9 . The variables gender, low ses, migration background, parental education, income and Cito test were assessed in grade 6 and are the same as in Table 11. Gender takes on the value of 1 for male students and 0 otherwise. "Low ses" is an indication used and provided by the school administration. Schools receive extra funding in case the fraction of students indicated as "low ses" exceeds a certain threshold. It is 1 if one or both of the parents did not complete secondary education (this indication is comparable to the "free lunch" indication in the US). A child is considered to have a migration background if at least one parent has not been born in the Netherlands. Parental education level relies on a self-reported measure and is therefore only available when the parental survey was filled in. It is coded in terms of the five levels defined in the International Standard Classification of Education (ISCED). Corrected income is reported on the household level in terms of quintiles relative to the complete Dutch population. It is based on the income register at 31 December 2008. The Cito test score reflects the overall score including sections on language, mathematics and study skills. The variables language test and mathematics test refer to scores on tests conducted specifically for the OML. The reported scores are standardized to a mean of zero and a standard deviation of one.

Children of parents who did not respond to the survey are slightly older, and substantially more likely to be first or second generation immigrants. With respect to parental socio-economic 
status and income, as well as all measures of students' school performance, the group of parents who do not respond have unfavorable characteristics. Within the group of respondents, parents who also provided an answer to the income question have on average more favorable characteristics and their children also perform better in all tests considered. ${ }^{38}$

Distribution plots for language and mathematics tests (see Appendix: Chapter 3, Figure A. 1 and Figure A. 2) show that children of survey responders clearly outperform children of nonresponding parents (significant at 1 percent). The distributions are similar for children with responding parents who did or did not answer the income question.

From Table 14 it can be seen that the survey non-response rate is higher in lower income quintiles. In turn, the item non-response rate is lowest among parents in the lowest income group. No income measure was available in the income registry for 18 of the 2,963 households.

Table 14 Parental survey participation by income quintile, sub-sample in grade 9 (age 15)

\begin{tabular}{lrrrr}
\hline \multirow{2}{*}{$\begin{array}{c}\text { Standardized } \\
\text { income } \\
\text { (quintile) }\end{array}$} & \multicolumn{2}{c}{ Survey participation status } & \\
\cline { 2 - 3 } & $\begin{array}{c}\text { Survey } \\
\text { participation }\end{array}$ & $\begin{array}{c}\text { Survey } \\
\text { non-resp. }\end{array}$ & $\begin{array}{r}\text { Item } \\
\text { non-resp. }\end{array}$ & Total \\
\cline { 2 - 4 } $0-20 \%$ & 33 & 324 & 92 & 449 \\
& 7.35 & 72.16 & 20.49 & 100.00 \\
$20-40 \%$ & 75 & 371 & 174 & 620 \\
& 12.10 & 59.84 & 28.06 & 15.89 \\
$40-60 \%$ & 107 & 394 & 175 & 676 \\
& 15.83 & 58.28 & 25.89 & 100.00 \\
$60-80 \%$ & 130 & 337 & 222 & 689 \\
& 18.87 & 48.91 & 32.22 & 100.00 \\
$80-100 \%$ & 127 & 243 & 141 & 511 \\
& 24.85 & 47.55 & 27.59 & 100.00 \\
\hline Total & 472 & 1,669 & 804 & 2,945 \\
& 16.03 & 56.67 & 27.30 & 100.00 \\
\hline
\end{tabular}

Notes: The table shows survey and item response rates by quintile of corrected income for the three groups distinguished in Table 13. It includes observations for which data from school administration and test scores is available and the data can be linked to administrative records of the parents.

\footnotetext{
${ }^{38}$ All those differences in means are significant.
} 
Chapter 3: Are Estimates of Intergenerational Mobility Biased by Non-Response?

\subsection{Results}

In this section, we analyze the non-response bias separately for parents, and schools; and we investigate income item non-response. Further, we report robustness checks. Potential underlying mechanisms of school, parental, and item non-response are discussed in the following section.

\subsubsection{School non-response and parental non-response}

In the baseline sample, assessed in grade 6 (age 12), we distinguish school survey non-response, and parental survey non-response. The box plots in Figure 9 provide a first insight into the test score distributions by income group. They allow a comparison of the median, the 25 th and 75 th percentile, as well as the span of Cito scores, between the different subgroups. For all income quintiles, differences between the groups can be observed. The median student whose parents did not respond, performs worse than the median student whose parents responded, in all income quintiles. The same holds at the $25^{\text {th }}$ and $75^{\text {th }}$ percentiles of the distributions. A Kolmogorov-Smirnov test on the underlying distributions shows that this difference is significant for the third and fourth income quintile. Students attending non-responding schools mostly outperform students with responding parents at the lower end of the test score distribution. However, in the lowest income quintile, students in non-responding schools show a larger variance. In the highest income quintile, students at non-responding schools outperform both other groups across the full distribution.

Figure 9 confirms the finding of Table 11 that children of non-responding parents perform significantly worse than those of responding parents. However, these differences could be explained by differences with respect to background characteristics or income levels. In the following, we therefore explore whether the gap in schooling outcomes between children of responding parents, and non-responding parents, as well as those attending non-responding schools remains, after controlling for demographics, and income level. As a basic set of controls we use the students' gender, age, and an indication for low socio-economic status. ${ }^{39}$

\footnotetext{
${ }^{39}$ As indicated earlier, this latter variable is mainly based on whether the parents have a particularly low educational background. It is our best available proxy for parental education background available for the full sample, including non-responding parents.
} 
Figure 9 Box plots of Cito scores, by survey response and income, baseline sample grade 6

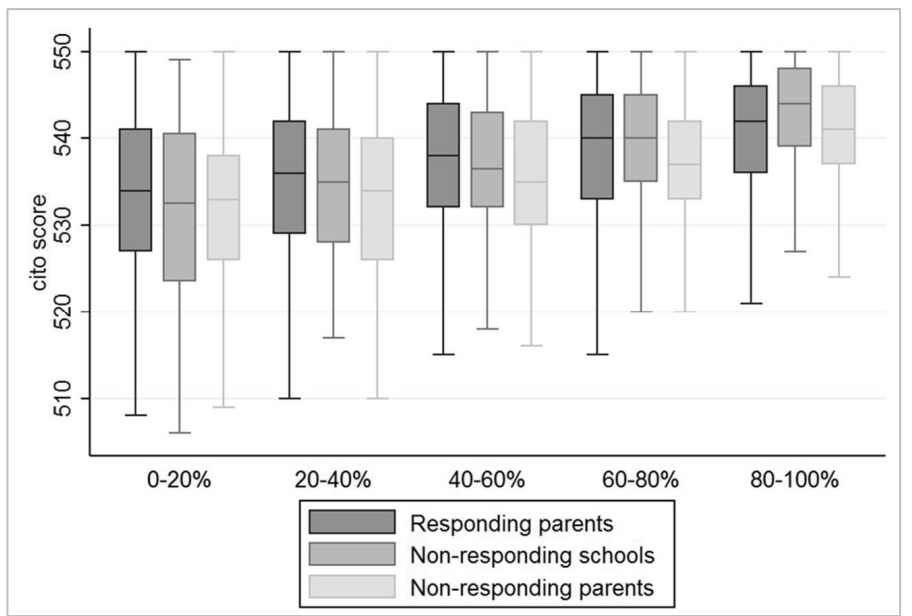

Notes: Box plots for Cito test results, displayed by survey response status and income quintile. The boxes are drawn around the median, indicated by the line in the box, and show the interquartile range, from the 25 th percentile to the 75 th percentile. The whiskers show the span of the data points. Their maximum length is 1.5 times the interquartile range. Data points outside this span are usually displayed separately. In accordance with the policy on non-disclosure of individual data by Statistics Netherlands the Figure does not include those outside values. In this case those were 24 observations. The graph is based on 2,602 students whose parents participated in the survey, 726 students whose parents did not respond and 371 students whose schools did not respond.

Based on administrative data only (for test scores, household income, and control variables), we investigate the relationship between parental income, and students' school performance. We use parental surveys solely to construct hypothetical sub-samples, suffering from different types of non-response. We run the same regression, based on responding, and non-responding subgroups. Comparing the coefficients for parental income between these regressions, provides insight into whether a certain type of non-response biases the estimated relationship between income, and schooling outcomes.

Table 15 shows the results of the main regression specifications, displaying only the income coefficients. We run the same regression of students' performance on parental income quintile, and controls; for the full sample, and for a number of artificially restricted samples. In a first step, the full sample is split up into students attending a non-responding school (NRS), and a responding school (RS). In a second step, the sub-sample attending responding schools is distinguished by parental response status. This allows to compare children of non-responding parents (NRP) to children of responding parents (RP). 
Chapter 3: Are Estimates of Intergenerational Mobility Biased by Non-Response?

Table 15 Parental income coefficients explaining test scores, by survey response (grade 6)

\begin{tabular}{|c|c|c|c|c|}
\hline & & \multicolumn{3}{|c|}{ Coefficients for income quintile } \\
\hline & & $(1)$ & \multirow{2}{*}{$\begin{array}{c}\text { (2) } \\
\text { Language } \\
\text { (sub-section) }\end{array}$} & \multirow{2}{*}{$\begin{array}{c}\text { (3) } \\
\text { Mathematics } \\
\text { (sub-section) }\end{array}$} \\
\hline & $\mathrm{N}$ & Cito test & & \\
\hline Full sample & 3,699 & $\begin{array}{l}.160 * * * \\
(.012)\end{array}$ & $\begin{array}{l}.156 * * * \\
(.013)\end{array}$ & $\begin{array}{l}.132 * * * \\
(.013)\end{array}$ \\
\hline Non-responding schools (NRS) & 371 & $\begin{array}{l}.219 * * * \\
(.029)\end{array}$ & $\begin{array}{l}.221 * * * \\
(.029)\end{array}$ & $\begin{array}{l}.189 * * * \\
(.033)\end{array}$ \\
\hline Responding schools (RS) & 3,328 & $\begin{array}{l}.152 * * * \\
(.013)\end{array}$ & $\begin{array}{l}.147^{* * *} \\
(.013)\end{array}$ & $\begin{array}{l}.125^{* * *} \\
(.013)^{2}\end{array}$ \\
\hline Non-responding parents (NRP) & 726 & $\begin{array}{l}.167^{* * *} \\
(.029)\end{array}$ & $\begin{array}{l}.169^{* * *} \\
(.028)^{*}\end{array}$ & $\begin{array}{l}.123 * * * \\
(.028)\end{array}$ \\
\hline Responding parents (RP) & 2,602 & $\begin{array}{l}.146^{* * *} \\
(.014)\end{array}$ & $\begin{array}{l}.140 * * * \\
(.015)\end{array}$ & $\begin{array}{l}.124^{* * *} \\
(.014)\end{array}$ \\
\hline Wald test on income coefficients & Hypothesis & & $\mathrm{p}$-values & \\
\hline School non-response & $\mathrm{NRS}=\mathrm{RS}$ & $.037 * *$ & $.018 * *$ & $.069 *$ \\
\hline Parental non-response & $\mathrm{NRP}=\mathrm{RP}$ & .533 & .376 & .981 \\
\hline
\end{tabular}

Notes: The table reports OLS regressions of children's Cito test scores on parental income. Each cell represents a separate regression. The dependent variables are total Cito scores as well as percentile scores on the sub-sections language and mathematics, standardized to a mean of zero and a standard deviation of one. The coefficients shown in each cell are those of the independent variable income, which is measured in quintiles, based on the Dutch population. Income refers to the corrected income, adjusted for the number of household members. Each regression controls for a number of variables: age, gender, and indicators of low socio-economic status as well as of being a first or second generation immigrant. Standard errors are reported in parenthesis. They are clustered at the school level, distinguishing 174 schools. Significance levels are reported as follows: .1*,.05**, and $.01 * * *$.

In this setup, comparing the coefficients of the NRS and RS samples provides a measure of whether and how school non-response biases the estimate. The comparison between the NRP and RP samples shows the bias induced by parental non-response. This analysis has been repeated for three different schooling outcomes: (1) the total Cito score, (2) the fraction of correct tasks in subsections for language, and (3) the fraction of correct tasks in subsections for mathematics. All of these measures are standardized to a mean of zero and a standard deviation of one. Thus, the resulting coefficients can be interpreted as a change in standard deviations, associated with an increase of one quintile in income. In the second panel of Table 15, p-values for Wald tests on the differences in the estimated income coefficients, between samples of nonresponding and responding schools, as well as non-responding and responding parents, are provided. 
All coefficients of the relationship between parental income quintile, and student's schooling outcomes are significant at the one percent level. ${ }^{40}$ Focusing on the regressions using the overall Cito scores, the smallest coefficients (.146) are found for the most selective sample of responding parents (RP), suffering from school as well as parental non-response. The largest coefficients, on the other hand, can be observed for the sample of non-responding schools (.219). A quantitative comparison of the coefficients across the samples shows that only the difference induced by school non-response is significant. Widening the focus to the separate regressions for performance in language and mathematics, it becomes apparent that the bias is more strongly driven by differences in the language sub-section of the Cito test.

A similar empirical approach, based on the full sample and the use of interaction terms between different types of non-response, and the income quintile, confirms these results (see Table A.5). The interaction term between income quintile, and school non-response for total Cito scores or the language sub-section is significant at the 5, and in some cases at the 1 percent level. Again, this is different for mathematics scores. The magnitude of this interaction effect amounts to more than half of the coefficient on income quintile. When applying this to the difference between the lowest and the highest income quintile, the gap in the estimates for children of responding parents, and non-responding schools amounts to about a third of the standard deviation in Cito test scores. Using probability weights to account for differential participation based on the parental income group cannot correct this bias. ${ }^{41}$

\subsubsection{Survey non-response and item non-response}

As an extension to the analysis above, we apply the same empirical strategy to a sub-group of the baseline sample assessed in grade 9 (average age 15). In this wave, the parental survey was sent out directly, providing a direct measure of parental survey response. This parental survey included a question regarding household income, allowing to further assess a potential bias due to specific item non-response. In the following, we distinguish three groups: (1) children of parents who responded to the survey, and provided a measure of household income, (2) children of survey responders who did not provide an income measure, and (3) children of survey nonresponders.

\footnotetext{
${ }^{40}$ All control variables, gender, age and "low ses" are significant. The coefficient for coming from a low socioeconomic background has a negative sign. Being older is associated with a lower Cito score, most likely because we are not able to control for grade retention. In addition male students perform slightly better.

${ }^{41}$ The regressions are not shown here. They are available upon request. Included control variables are the same as in Table 15 .
} 


\section{Chapter 3: Are Estimates of Intergenerational Mobility Biased by Non-Response?}

The box plots presented in Figure 10 show how achievement in the language test is distributed within the different income quintiles, separately by parental response status. In general, the graph reveals that the differences by participation status based on this test seem to be smaller than the differences based on the Cito test in grade 6 (compare to Figure 9). A tendency towards positive selection into survey response is observed. However, among children of survey responders, particularly children of low income parents, who did not respond to the income question, outperform the children of those who did respond to the income question, at most points in the distribution. The analogue box plots for achievement in the mathematics test in grade 9 are provided in the Appendix, in Figure A.3

Figure 10 Box plots of language scores, by survey response and income, sample grade 9

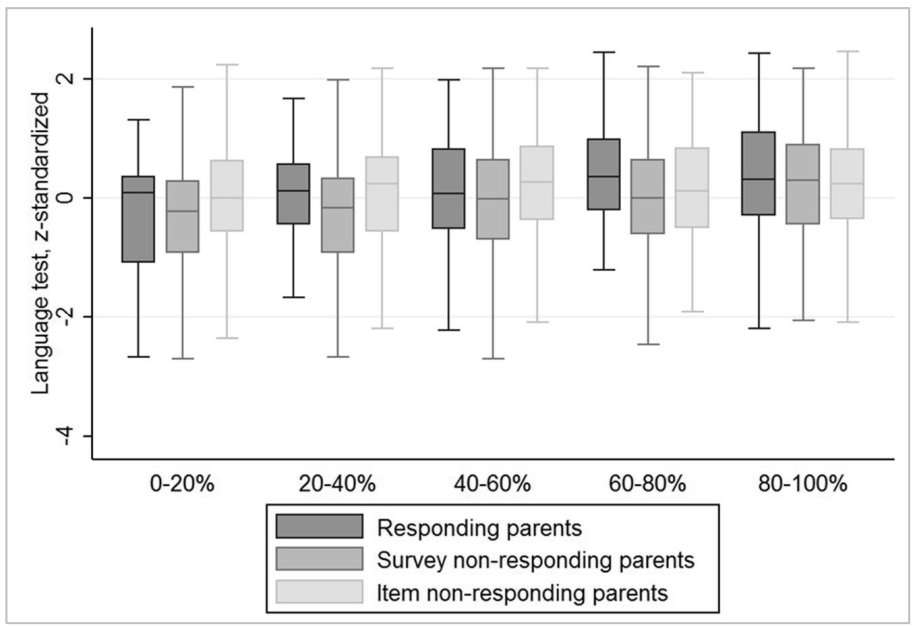

Notes: Box plots for language test results in grade 9 , displayed by survey response status and income quintile. The boxes are drawn around the median, indicated by the line in the box, and show the interquartile range, from the 25 th percentile to the 75 th percentile. The whiskers show the span of the data points. Their maximum length is 1.5 times the interquartile range. Data points outside this span are usually displayed separately. In accordance with the policy on non-disclosure of individual data by Statistics Netherlands the Figure does not include those outside values. In this case those were 34 observations. The graph is based on 356 students whose parents participated in the survey, including the income question, 614 students whose parents responded to the survey without reporting the household income and 1,251 students whose parents did not return the survey.

Applying the same approach used in the baseline sample, we investigate whether parental survey non-response, and item non-response bias the estimated relationship between parental income, and children's schooling. The performance measures used, were assessed in grade 9, at the average age of 15 . Table 16 displays the income coefficients of the main regression specification, for the full sample, as well as artificially restricted sub-samples. 
Table 16 Parental income coefficients explaining test scores, by survey response (grade 9)

\begin{tabular}{|c|c|c|c|c|c|}
\hline & & \multicolumn{4}{|c|}{ Coefficients for income quintile } \\
\hline & & \multicolumn{2}{|l|}{$(1)$} & \multicolumn{2}{|l|}{$(2)$} \\
\hline & & Language & $\mathrm{N}$ & Mathematics & $\mathrm{N}$ \\
\hline Full sample & & $\begin{array}{l}.078 * * * \\
(.000)\end{array}$ & 2,120 & $\begin{array}{l}.110 * * * \\
(.000)\end{array}$ & 2,094 \\
\hline Survey non-responding pare & $\mathrm{s}(\mathrm{SNR})$ & $\begin{array}{l}.083^{* * *} \\
(.000)\end{array}$ & 1,189 & $\begin{array}{l}.131 * * * \\
(.000)\end{array}$ & 1,177 \\
\hline Survey responding parents (S & & $\begin{array}{l}.057 * * \\
(.035)\end{array}$ & 931 & $\begin{array}{l}.069 * * * \\
(.004)\end{array}$ & 917 \\
\hline Item non-responding pare & ts (INR) & $\begin{array}{r}.011 \\
(.729)\end{array}$ & 590 & $\begin{array}{l}.064 * * \\
(.043)\end{array}$ & 580 \\
\hline Survey, and item respond & g parents (IR) & $\begin{array}{l}.138 * * * \\
(.002)\end{array}$ & 341 & $\begin{array}{l}.075 * * \\
(.038)\end{array}$ & 337 \\
\hline Wald test on income coefficients & Hypothesis & & $\mathrm{p}$-values & & \\
\hline $\begin{array}{l}\text { Parental survey non-response } \\
\text { Parental item non-response }\end{array}$ & $\begin{array}{l}\mathrm{SNR}=\mathrm{SR} \\
\mathrm{INR}=\mathrm{IR}\end{array}$ & $\begin{array}{l}.460 \\
.016 * *\end{array}$ & & $\begin{array}{l}.059 * \\
.817\end{array}$ & \\
\hline
\end{tabular}

Notes: The table reports OLS regressions of children's language and mathematics scores on parental income. Each cell represents a separate regression. The dependent variables are the fraction of correctly answered questions on the tests, standardized to a mean of zero and a standard deviation of one. The coefficients shown in each cell are those of the independent variable income, which is measured in quintiles, based on the Dutch population. Income refers to the corrected income. Each regression controls for a number of variables: age, gender, and indicators of low socio-economic status as well as of being a first or second generation immigrant. Standard errors are reported in parenthesis. They are clustered at the school and track level, distinguishing 579 school-track combinations. Significance levels are reported as follows: $.1 *, .05 * *$, and $.01 * * *$.

First, children are split up according to whether their parents did (SR) or did not respond to the survey (SNR). Then, children of survey respondents are distinguished by whether the parents did (IR) or did not fill in the included income question (INR). Comparing the coefficients of the SNR and SR samples provides a measure for parental survey non-response bias. A comparison between the INR and IR samples provides insight into whether item non-response induces a bias as well. This analysis has been conducted for the language (1) as well as the 
Chapter 3: Are Estimates of Intergenerational Mobility Biased by Non-Response?

mathematics achievement test (2) administered in grade 9 as part of the OML. ${ }^{42}$ Both measures are standardized to a mean of zero and a standard deviation of one.

As can be seen from Table 16, the analysis based on the language test confirms the results from the baseline sample: no evidence is found that parental survey non-response is a source of bias in the estimated relationship between parental income and students' language outcomes. However, item non-response leads to an overestimation of the income coefficient, the opposite direction than the bias found for school non-response. Surprisingly, the estimated coefficient for parental income in the sample of item non-responding parents is very small and far from significant. This observation is further discussed in Section 3.4.3. An alternative approach, using interaction terms in a regression (see Table A.6), confirms the underestimation driven by item non-response. Applied to the difference between the lowest and the highest income quintile, the induced bias amounts to more than half a standard deviation in the language achievement test. It almost completely offsets the estimated positive association between parental income, and performance regarding the language test.

Regarding the mathematics tests, there is suggestive evidence that the estimate based on the sample suffering from parental survey non-response might underestimate the actual relationship. However, the regression analysis with interaction terms does not confirm this. The interaction effect between income and parental non-response in Table A.6 is neither significant for the language, nor for the mathematics test.

Overall, the magnitude of the income coefficients is smaller than in the analysis of the baseline sample. This observation may be explained by the contrast between the Cito test as a high stakes test and the low stakes tests in grade 9.

\subsubsection{Robustness checks}

All above shown regression results rely on a corrected measure of household income, based on the total income of the household adjusted for the number of household members. As a robustness check, we conduct all analyses also with the measure of total income. The results remain qualitatively similar, but are somewhat weaker in magnitude and significance. Since the correction by household member is highly relevant for the actual standard of living, this is not surprising. In support of this, for the sub-sample of parents with known education level, we also

\footnotetext{
42 The difficulty level of the tests differed across schooling tracks, but with an overlap in questions. To place students on one scale across schooling tracks we ran a two parameter item response theory model.
} 
find that the quintile of a household's corrected income correlates higher with the highest education level than the total income.

The error terms of the test scores are unlikely to be independent across students in the same environment. Attending the same school and having the same teacher could influence student achievement systematically. Therefore, we account for common factors of influence in the results shown above. To ensure that our results are not driven by clustering, we repeat all analyses with non-clustered standard errors. We do not find any major difference relative to the results discussed above. ${ }^{43}$

\subsection{Potential mechanisms}

We do not find much evidence for a bias due to selective survey response by parents. This means that, in our sample, the relationship between parental income and schooling outcomes of children with non-responding parents does not significantly differ from that of responding parents. However, the difference in estimated coefficients points to a potential underestimation due to parental non-response, which might become significant in larger samples. For school non-response and item non-response, on the other hand, we find evidence for a significant underestimation, respectively overestimation, of the relationship between parental income and children's language achievement. In the following, we discuss potential mechanism behind the observed biases.

\subsubsection{Selection into school survey non-response}

The fourteen schools, which did not send out the parental surveys, show a stronger relationship of parental income and children's schooling outcomes than responding schools. These differences could either be explained by different characteristics, by anticipation of the parental response behavior, or because non-response could be a strategy of schools to avoid unfavorable results.

All of the non-responding schools except for one are roman-catholic, as is the majority of primary schools in the sample. Table 11 shows that significantly fewer students from a low socio-economic background are attending non-responding schools, but more first- or secondgeneration immigrants are. This combination of characteristics would be consistent with a large

\footnotetext{
${ }^{43}$ Regression results with interaction terms are provided in the Appendix, in Table A.5 and Table A.6. Results analogue to Table 15 and Table 16 are available on request.
} 
Chapter 3: Are Estimates of Intergenerational Mobility Biased by Non-Response?

fraction of children from academically trained expats in the student population. ${ }^{44}$ Furthermore, while the students at non-responding schools score on average higher on the Cito test, they also have a higher standard deviation. The same holds for parental income. With the favorable selection of the student population, and the high average performance, non-responding schools are unlikely to attract the attention of the inspectorate of education. However, they seem to be of low quality in terms of addressing socio-economic dependency of students' performance. In case the schools are aware of this, a potential explanation for their non-response could be that they do not want to disclose this weakness. Similarly, participation in the research project could be positively related to how much schools care about equality of opportunity. This comparison of the responding and non-responding schools is purely descriptive and unconditional. A regression of school participation on aggregated characteristics (see Appendix, Table A.7) does not show any significant relationships with the above mentioned characteristics. However, schools situated in two regions are significantly more likely to participate.

School non-response could also be driven by anticipated parental non-response. Thus, schools may not respond, because they assume that the respective parents are not willing to participate in surveys. Since the survey in grade 9 is sent out directly to the same parent population, we can check whether there is a basis for this assumption. The differences in the parental response behavior that we find are very small. Parents whose children attended a non-responding primary school seem to be even more willing to participate in surveys, and to provide complete information. So if schools did not respond because they thought parents in the school did not want to respond, their assumption was incorrect.

\subsubsection{Selection into parental survey non-response}

In the above presented analysis, the relationship between parental income and children's school performance did not significantly differ between parents who returned the survey and who did not. However, this could change in larger samples. The magnitude of the coefficient in the group of responding parents is, across both age groups, and for all outcome measures, slightly lower than in the group of non-responding parents. Thus, same as school survey non-response, parental survey non-response could potentially lead to attenuated estimates of intergenerational dependency.

\footnotetext{
${ }^{44}$ This group of immigrants is overrepresented in the south of Limburg due to the presence of Maastricht University as well as some international companies in chemical industry.
} 
To get better insight into the sorting of parents in terms of survey participation, we regressed parental survey response on individual student characteristics. The results are presented in the Appendix, in Table A.8. In both surveys, grade 6 and 9, being a first or second generation immigrant is associated with a lower probability of parental survey participation. Also, children's school performance goes along with a higher probability of parental response. In primary school, Cito scores significantly predict parental response. In secondary school, the attended track as well as more recent performance measures are more important. Attending one of the two highest secondary school tracks is associated with a higher response rate among the parents. Additionally, the coefficient on having low educated parents ("low ses") is negative. Among the sample conducted in secondary school, parents in households not belonging to the lowest or the middle income quintile are more likely to respond to the survey. Coefficients regarding the regional school location become insignificant, once a variable on speaking dialect is added. Speaking the local dialect well is in both samples associated with a higher probability of parental survey response.

All in all, parents of well-performing students, without a migration background, who speak the local dialect well, are more likely to answer across both surveys. In the secondary school sample, socio-economic background, and track placement play an important role as well.

\subsubsection{Selection into parental item non-response}

Among parents who return the survey, but do not answer questions regarding their household income, the relationship of parental income and children's schooling outcomes is weaker than among parents who do respond to the question. The selection into item non-response might shed some light on the potential mechanisms behind this bias.

In general, there is a positive selection into survey response with respect to parental education, parental income and students' test scores. Among the responding parents, the lower income groups are overrepresented in the group of item non-responders. As can be concluded from the box plot in Figure 10 (as well as Figure A.3), particularly children of low income item nonresponders outperform the ones of item responders. An explanation, fitting this pattern, is that parents with low income, but otherwise favorable characteristics, ${ }^{45}$ are likely most ashamed and thus reluctant to report their income. This is consistent with non-responders having untypical characteristics for the area they live in, as has been shown for the US census (Bee et al., 2016).

\footnotetext{
${ }^{45}$ Examples for people with a low income but otherwise favorable characteristics would be a university graduate, holding a degree in philosophy, who ends up being a taxi driver or people still completing their education, like $\mathrm{PhD}$ candidates.
} 


\section{Chapter 3: Are Estimates of Intergenerational Mobility Biased by Non-Response?}

Further, item non-responders belonging to a group of untypical low income households provide an explanation for the insignificant income coefficient in this sub-sample. Such a systematic item non-response pattern is particularly harmful for estimates of intergenerational mobility. Since the non-responders are untypical for the area they live in, imputation of missing data based on the postal code area, as applied by Sabelhaus et al. (2015), is risky.

An additional difference can be observed in the mode of how respondents answer the survey. The majority of item responders ( 88.9 percent) filled in the online-survey, provided in the initial invitation letter. Most of the item non-responders (77.5 percent) instead filled in the paper survey, only provided in the reminder letter. This points towards a potential link between the mode of the survey, and the willingness to respond to certain items. In this case, it can unfortunately not be distinguished from the effect of the initial letter and the reminder.

A regression of parental item response on individual student and parent characteristics can be found in the Appendix, in Table A.9. Student performance measures are only positively significantly predicting parental item response, if track and school location are not included. Parental item response is dominantly associated with belonging to the highest income quintile ${ }^{46}$, and answering the survey upon the first request online.

\subsection{Conclusion}

By combining administrative and survey data, we are able to assess the potential bias in estimates of the relationship between parental income, and students' school performance, induced by various reasons for non-response. We find, firstly, that the positive relationship between parental income and children's schooling is attenuated because specific schools choose to participate in the data collection. Secondly, although parents from low income groups participate less frequently in the parental survey, this selective non-response does not significantly affect the estimated relationship between parental income and children's schooling. As the magnitude of the estimates suggests, in larger samples parental non-response could potentially also lead to an attenuation bias. Thirdly, we find evidence that non-response by parents on the income question leads to an overestimation of the relationship. All results are stronger for language than for mathematics test scores.

\footnotetext{
${ }^{46}$ The coefficient indicating households in the middle income quintile most likely only becomes significant due to the sample restriction between column (2) and column (3). Restricting the regressions in column (1) and (2) in the same way leads to significant coefficients as well.
} 
Our findings indicate that it is very important for the interpretation of results about intergenerational mobility to critically assess how the data were collected. Involving nonscientific organizations, such as schools, in the data collection can increase acceptance in the targeted population. However, this also introduces an additional source of potential nonresponse bias. In our study, this led to an underestimation of the true relationship between parental income and child schooling. Directly targeting parents avoids selective organizational non-response. In our case, it also did not lead to any significant bias in the estimated relationship. However, a selective group of parents was less willing to answer questions about their income. This item non-response biased the estimated intergenerational relationship upward. Therefore, it is important as well to consider how selectively parents are willing to answer the relevant questions.

Our analysis provides a first study of the bias due to selective survey non-response in the important relationship between parental income and children's school performance, as an early measure of intergenerational mobility. Obviously, the results could be driven by the specific setting of our study. Therefore, this study needs to be replicated in different contexts. This is feasible in countries where large administrative datasets are already available, for example in Scandinavia. Combining administrative data with survey data including self-reported income measures can further help to disentangle the different sources of response bias. 



\title{
Measurement error and intergenerational mobility
}

- Three methods to investigate the role of measurement error in the developing relationship between parental education and students' test scores ${ }^{47}$

\begin{abstract}
There is no doubt that our family shapes us. However, at the latest when children start school they are exposed to a formal structure that allows for comparison and enables competition. Using a series of mathematics tests from Dutch primary education we investigate how parental education relates to student achievement over time and within school years. We find an increasing correlation of parental education level and test scores. Our results suggest that in the first four years the main driver of the increased correlation is more precise measurement. While the influence of parental education is first constant or even decreases, it steeply increases towards the transition to secondary school. Furthermore, within-year patterns suggests an equalizing influence of school during the first three years.
\end{abstract}

\footnotetext{
${ }^{47}$ This chapter is based on joint work with Lex Borghans and Paul Jungbluth. We are grateful for most constructive and detailed comments by Kevin Lang, Trudie Schils, Tyas Prevoo, and Roxanne Korthals. We also want to thank seminar participants at the universities of Maastricht and Tuebingen as well as conference participants at the Fourth SOLE/EALE World Meeting (2015), the Third Lisbon Research Workshop on Economics, Statistics and Econometrics of Education (2015) and the 2015 LEER Workshop on Education Economics in Leuven for their thoughtful questions and useful suggestions.
} 
Chapter 4: Measurement error and intergenerational mobility

\subsection{Introduction}

School is not the first time that children learn. However, for many it is the first formal learning environment with the opportunity of comparison. Each child starts school with a unique endowment, shaped by their innate abilities, personality, and their experiences in the family. School serves all of them, puts them in a comparable setting, and provides them with the same information. Still, parental background most likely continues to affect the child's skill development and interacts with the effect school has. Parental pressure and teachers' expectations based on the parental background, whether conscious or unconscious, are only two of those channels.

In this chapter, we focus on the relation between parental education and children's schooling outcomes and use a longitudinal setting to analyze the role of measurement error. Our empirical context are twelve mathematics test scores for five cohorts of primary school students in the Dutch province of Limburg. We start our analysis with the observation that the correlation between our measure of parental education and the students' test scores increases throughout the six years that we observe. In a first approach to go beyond correlations, measured at one point in time, we look at how the correlation between scores in consecutive tests develop. We find that they increase as well. Predictions of a theoretical model show that this pattern could be either driven by increasing importance of parental education for predicting test scores or by decreasing variance in the error term of the test results. In a second step, we develop a latent variable model estimating the influence of mathematic ability as well as parental education on the observed test scores. This allows us to distinguish these two factors and assess the development of the error term. Finally, in a third step, the assumption of constant mathematical ability is relaxed. The analysis is repeated for ability sub-groups, and a variance decomposition is conducted.

This stepwise investigation sheds some light on the developments of the relation between parental education and children's mathematics test scores. During the first three years of school, a within-year pattern suggests an equalizing effect of school, and this effect is dominating the relationship with parental background. In contrast, the last two years leading up to the primary school exit test, the so-called Cito test, the influence of parental education increases strongly from test to test. The results in the mathematics section of this Cito test itself are less dependent on the parental background than those of the last low stakes test. This last result is mostly driven by students in the lower half of the test score distribution and consistent across different model specifications. 
A decomposition of the total variance of the mathematics test scores into a mathematic ability, a parental education, and an error component allows us to compare the relative importance of these different factors: All different model specifications show a clear decrease of the importance of measurement error until grade 4, in some models even until grade 5 . In the first year it accounts for more than eight times as much variance than the component referring to parental education. Even with the decrease, the error term still accounts for a sizable part of the variance, exceeding that explained by parental education level.

The basis for the analyses in this chapter are panel data on test scores and family background from more than 6,000 primary school students of five cohorts from the Dutch province Limburg. The data consist of administrative records as well as questionnaire-based data, collected for an ongoing regional education monitor, conducted as a cooperative project between schools and Maastricht University since 2009. An advantage of this dataset for this particular analysis is the large number of comparable tests over the course of six years. All but the last test have been validated to be comparable over different school years and to measure mathematic ability consistently. The last test differs from the others because it is constructed as an assessment test at the end of primary education. It is still validated to be comparable across cohorts. The test result, the Cito test, is a main determinant of the teacher's advice for the secondary schooling track placement.

This chapter is related to the literature dealing with the reproduction or even amplification of inequality through intergenerational dependency of educational attainment - in short: the rich get richer, the poor get poorer. The educational or sociological field calls this the Matthew Effect, referring to a verse in the biblical Gospel of Matthew (Luyten et al., 2003; Sammons, 1995). In this context, increasing correlations of measures for the socio-economic background with schooling outcomes over time within one cohort are considered an observation supporting an increasing influence of socio-economic factors. The economic field takes a different approach. They leave these terms aside and mostly examine test score gaps, and how they develop over time (Fryer Jr \& Levitt, 2004; Polidano et al., 2013). This method has been criticized for treating test scores as being measured on an interval scale. Theoretical considerations have shown the low robustness of common methods in this field to transformations of test scores (Bond \& Lang, 2013; Lang, 2010).

In addition to the methodological problems pointed out by Bond and Lang (2013), another difficulty lies in the fact that each test score is also influenced by an individual error term. In case the size of the error term systematically evolves over time, this might influence the 
Chapter 4: Measurement error and intergenerational mobility

observed correlations, as well as the comparison of test score gaps. We address this concern by estimating the predictive power of mathematic ability, parental education, as well as the error term for each test simultaneously. The unique dataset of Dutch primary student outcomes allows us to analyze the relation of parental education, measured as the highest parental education level, with twelve standardized tests over the course of six years of primary school.

The remainder of this chapter is structured as follows: In Section 4.2 we introduce the dataset. As a starting point for the analysis in Section 4.3 we take a glance at the data and provide the correlation of our parental education measure with the series of test scores. In Section 4.4 we present three ways to explore the role of measurement error in this relationship. Section 4.5 includes a discussion of the results and its implications and Section 4.6 concludes.

\subsection{Data and empirical context}

\subsubsection{Data}

The basis for the analysis is a panel of mathematics test scores for more than 6,000 primary school students of five cohorts, covering six years. The data consist of administrative records as well as questionnaire-based data, collected within an ongoing regional education monitor (OnderwijsMonitor Limburg, short OML). It is conducted as a cooperative project between schools and Maastricht University since 2009 and almost all primary schools in the southern part of the Dutch province Limburg participate in the project. ${ }^{48}$

An advantage of the dataset is the large number of comparable tests over the course of the six years of Dutch primary education. ${ }^{49}$ We use test scores for two mathematics tests, which are conducted each year, and provided by Cito, an institute for test development. The schools are not obliged to buy and use those tests, but many do. They do so, first, in order to monitor the

\footnotetext{
${ }^{48}$ For a detailed description of the education monitor, the Dutch education system, and the province of Limburg, see Chapter 2.

${ }^{49}$ In the Netherlands education starts at the age of four and primary school runs for eight years ("groep 1" to "groep 8"). The first two years consist mostly of preparatory activities and the types of tests taken during those years are not comparable to the tests considered here. In accordance with the international classification "groep 3" is hereafter referred to as grade 1 and primary school is considered to run from "groep 3" till "groep 8" (Central Bureau voor de Statistiek, 2011).
} 
skill development of their students and, second, as a preparation to the popular nation-wide skill assessment test at the end or primary school, also constructed by Cito. ${ }^{50}$

For grade 1 through the middle of grade 6, we use low-stakes tests conducted at the middle and the end of the school year. The tests are validated to be comparable over the years and to measure mathematic ability consistently. In the final year there is no low stakes end-year test. Instead, we use the score of the mathematic section of the nation-wide skill assessment test at the end of primary school, usually taken shortly after the mid-year test. In contrast to the earlier tests, here the incentives to score high are strong. The test is graded externally, and the result is a main determinant of the teacher's recommendation for secondary schooling track. Many schools treat this recommendation as binding, and the schooling track has long-term effects, also on the student's labor market prospects. ${ }^{51}$ If nothing else is stated explicitly, in this chapter, the term "Cito test" refers to the mathematics section of the Cito end test.

Our measure for socio-economic background is the highest parental education level, based on self-reports in a parental survey, conducted when the children are in grade 6 . The answers are coded according to the five levels of the International Standard Classification of Education. In the Dutch education system this corresponds to the following categories: ISCED 1 for at most primary education, ISCED 2 for lower secondary / pre-vocational education (VMBO), ISCED 3 for upper secondary or lower vocational education (HAVO/VWO/MBO), ISCED 4 for upper vocational education (HBO), and ISCED 5 for higher education on the university level.

\footnotetext{
${ }^{50}$ There are tests by other providers, but the one by Cito is by far the most popular one. In 2013 about 86 percent of the schools used the "CITO Eindtoets" for this purpose (Inspectie van het Onderwijs, 2014), enabling an easy comparison with other schools.

${ }^{51}$ The different tracks lead to specific qualifications for the labor market. Even if the teacher deviates from what the Cito test result suggests, some secondary schools only accept students with a score above a certain threshold. During the first three years after the transition about a quarter of children changes the track at least once. And among them only 40 per cent change to a higher schooling level (Inspectie van het Onderwijs, 2014).
} 
Chapter 4: Measurement error and intergenerational mobility

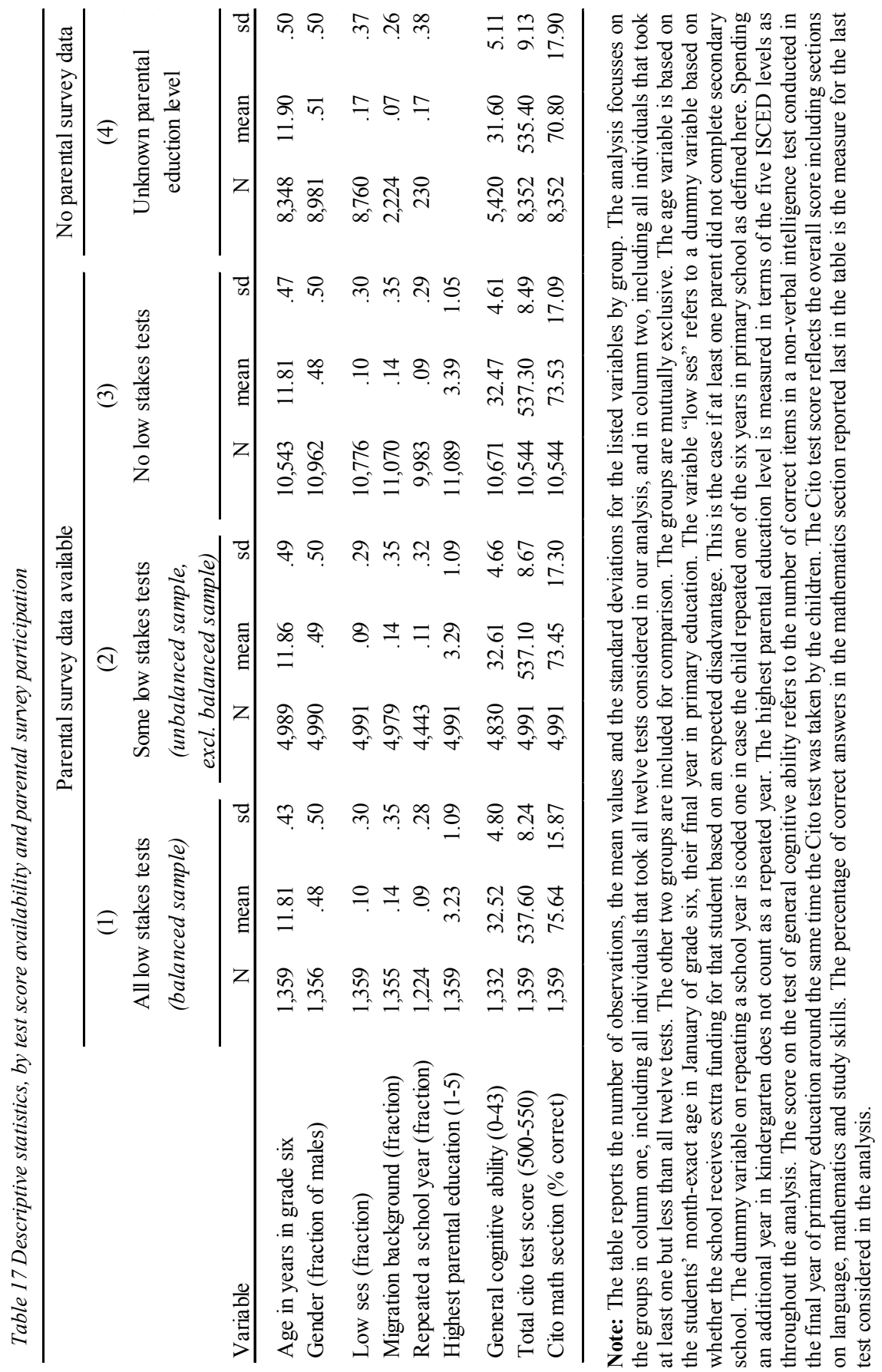




\subsubsection{Sample}

In order for a student to be in the sample that is used for the analysis the following criteria have to be fulfilled: (1) the school has to use the tests provided by Cito and had to agree to provide us with the test scores, (2) the parents did not object to the data use ${ }^{52}$ and (3) at least one parent had to participate in the survey and provide information on his or her highest attained education level. The overall parental response rate was between 66 and 71 per cent. Concerns regarding potential selection bias will be addressed as far as possible by providing descriptive statistics for the children based on the availability of parental information and test scores. The dataset and selection into the data are discussed in more detail in Chapter 2.

For the analysis, we use two different samples. The unbalanced sample includes all 6,350 students for which the parental education level, the result of the Cito test and at least one additional test result are available. The balanced sample in contrast is restricted to 1,359 students for which all twelve test scores are available. Table 17 provides some descriptive statistics for the two samples used (column 1 and 2) and compares them to students with known parental education only taking the Cito test or no test (column 3) as well as to students with unknown parental education level (column 4).

In many respects, the balanced (column 1) and the unbalanced sample (column 1 and 2 together), that are the basis for our analysis, are similar. The most notable difference is that the fraction of children who repeated a school year is two percentage points lower in the balanced sample than in the unbalanced sample. This also leads to a lower average age in grade 6 and might explain the slightly lower test scores in that group. Nonetheless, the unbalanced sample offers the advantage of a larger number of observations. So it is a good source of information for the overall developments in primary school. However, due to potential selective testing ${ }^{53}$, the within-year patterns will not be interpreted for this sample.

Comparing the mean values and the standard deviations of the balanced sample to those with insufficient test score information (column 3) shows almost no differences. Only the average parental education level is a little higher for the latter group. With about twice as many observations as the unbalanced sample, this group accounts for the majority of students for

\footnotetext{
${ }^{52}$ Each year between one and two per cent of all parents made use of this opportunity. Even though this is most likely a specific group of parents, the number of cases concerned is small enough to be disregarded. ${ }^{53} \mathrm{In}$

Table A.11 we provide information on the number of observations and the composition of participating students for each of the tests in the unbalanced sample.
} 
Chapter 4: Measurement error and intergenerational mobility

whom parental information on education are available. Since the balanced sample barely differs from this group with respect to the observed outcome variables, we however conclude that the selection with respect to being tested or not should not have much influence on our findings.

Selection with respect to the availability of parental information in contrast seems to be more important: The group with unknown parental education level (column 4) differs strongly from the others. Children whose parents did not participate in the survey are on average slightly older, are more often assigned a weight and score lower in the general cognitive ability as well as achievement tests. In Chapter 3, this selection is investigated with respect to the relationship between parental income and children's schooling outcomes. If at all, estimates of intergenerational dependency of schooling outcomes are slightly attenuated due to survey nonresponse.

\subsection{The raw correlation between parental education and achievement tests}

In the debate about intergenerational mobility and inequality, in the media as well as in the scientific literature (Torche, 2015), authors commonly refer to observed correlations between schooling outcomes and parental characteristics to support their claims or theories. With only one outcome measure at hand this is often the best that can be done.

We, however, have outcome measures at different points in time and can therefore improve upon earlier work. To allow for comparisons, we also take correlations as the starting point for our analysis of how the relationship between parental education and mathematics tests scores develops over time. Figure 11 shows this correlation separately for each test from grade 1 through grade 6 for the balanced sample as well as for the larger unbalanced sample. The graphs further include quadratic prediction plots and confidence areas.

Overall, in magnitude the correlation of parental education with the mathematics score in the Cito test are very similar to the correlations calculated based on the corresponding sub-scores that Dutch adults attain in the OECD's Programme for the International Assessment of Adult Competencies (PIAAC) (see Table A.10). Even though one has to be careful in drawing conclusions from this comparison across age groups and generations, the similarity shows that the magnitude of the correlation observed in the data is not out of the ordinary. 
Figure 11 Correlation between mathematics scores and highest parental education level
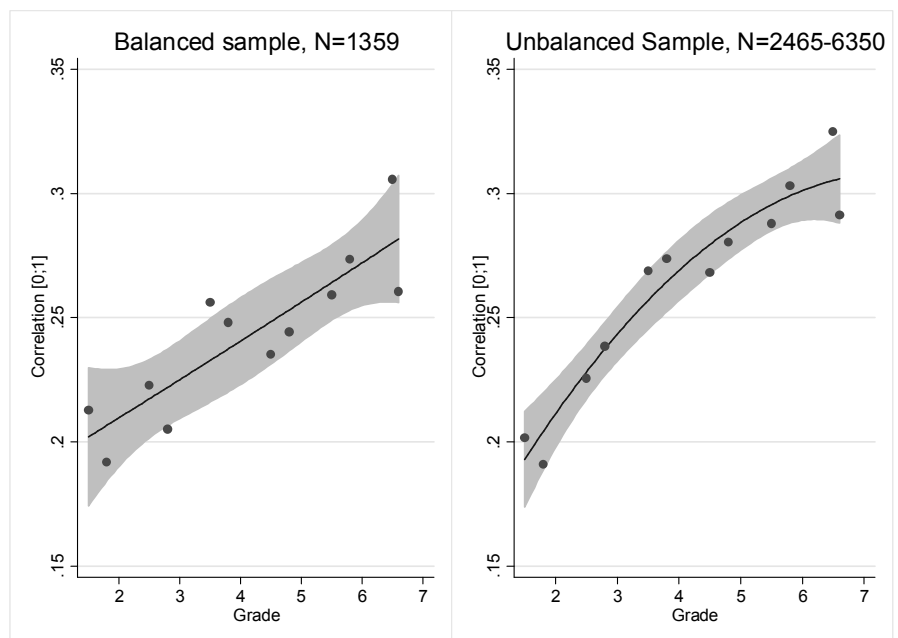

Notes: The graph shows the quadratic prediction plot of the correlations and the respective 95 percent confidence interval. The balanced sample consists of group (1) from Table 17. Since in this sample not every student took every test, the number of observation varies. The number of observations for each of the tests are reported in Table A.11. The changes in composition of the students in terms of their skill level, measured by the Cito test, are shown in Figure A.4. The variable "grade" captures the grade as well as the time during the school year, when the respective test is usually taken. For the result of the mid-year test in grade 1 it takes on the value 1.5 and for the end-year test in grade 1 it is 1.8 . The same scheme applies for grades 2 through 5 . In the final year, the grade for the mid-year test is 6.5 as usual, and since the Cito test is only taken shortly after the mid-year test, the grade assigned is 6.6.

Turning to the development over time, in both samples the correlation clearly increases over time, but there are some notable differences. Both prediction plots start with a similar correlation of about 2 in grade 1 . However, over the six years of primary school the correlations in the unbalanced sample rise steeper, leading to a higher correlation at the end of primary school (above .3, compared to around .28). Converting the increase in correlations into percent of explained variance of the linear relationship between test scores and parental education level, this development corresponds to an increase of about 4.3 percentage points for the balanced sample and respectively 5.5 percentage points for the unbalanced sample. ${ }^{54}$ The highest

\footnotetext{
${ }^{54} \mathrm{This}$ difference is not significant. Still, it points to potential differences between schools that test their students consequently and non-selectively and schools that test infrequently and/or selectively. Those differences could refer to many factors, for example student composition or teaching quality.
} 
Chapter 4: Measurement error and intergenerational mobility

correlation is in both cases observed for the last low stakes test, while the Cito test shows a slightly lower correlation closer to the correlations observed in grade 5.

Furthermore, the patterns during the first three years are quite different between the samples. In the balanced sample a decreasing within-year pattern can be observed - meaning that the correlation of the mid-year test score with parental education is higher than for the end-year test score. In the unbalanced sample the correlation increases from test to test, with only few exceptions. From grade 4 onwards the development is similar again for both samples: correlations increase monotonously across years until the last low stakes test.

To conclude, while observed within-year patterns are probably less reliable in the unbalanced sample, the overall developments are comparable in both samples. Most importantly, an increase towards the peak in the last low stakes test is observed. Additionally, the balanced sample shows a decreasing within-year pattern, for the first three school years. Based on a series of available tests scores, we are able to go beyond raw correlations. The results of the main analysis are shown for the balanced sample. Differences to the unbalanced sample are always considered, and the above mentioned observations are discussed in more detail in the results and discussion section.

\subsection{Results}

- Three ways to explore the role of measurement error in the relationship of parental education and test scores

The aim of the following analysis is to shed light on how the relationship of parental education and mathematics test scores develops in primary school, and to investigate which role measurement error plays in this. The analysis evolves around exploiting the advantages of our dataset: a series of comparable mathematics tests and panel-structured data. We proceed in three steps: First, correlations of consecutive test scores are presented. Based on a simple model, in which the test result depends on mathematic ability as well as parental education level, we distinguish two hypotheses of how an increase of the correlation could be explained. In a second step, a latent variable model allows us to investigate these hypotheses. In a final step, we consider an alternative model in which we relax less realistic assumptions. 


\subsubsection{Current test scores as predictors of future test scores}

Having a series of comparable mathematics test scores, means that we have several measures of the same skill. Assuming that each test score is determined by an individual's skill level as well as measurement error, which is independent across different tests, such a setting provides the opportunity to identify the skills more clearly by using one test to predict another one and remove measurement error. Based on this rational, we exploit the property that our dataset includes a long series of test scores and analyze how well each test score predicts the following one. In Figure 12, we plot the correlations of consecutive test scores (test one and two, test two and three, and so on) as well as a quadratic prediction plot of how they develop.

Figure 12 shows, as children grow older, current mathematics test results become increasingly better predictors of future test scores, reaching more than 65 per cent of explained variance in grade 5. Overall the correlation between tests following each other increases by more than a third. Towards the end of primary school it flattens out, seemingly approaching a constant power of prediction. Tests within each school year are higher correlated than across years. This observation is not surprising, considering teacher effects and similarities in content.

Figure 12 Correlations of scores in consecutive mathematics tests

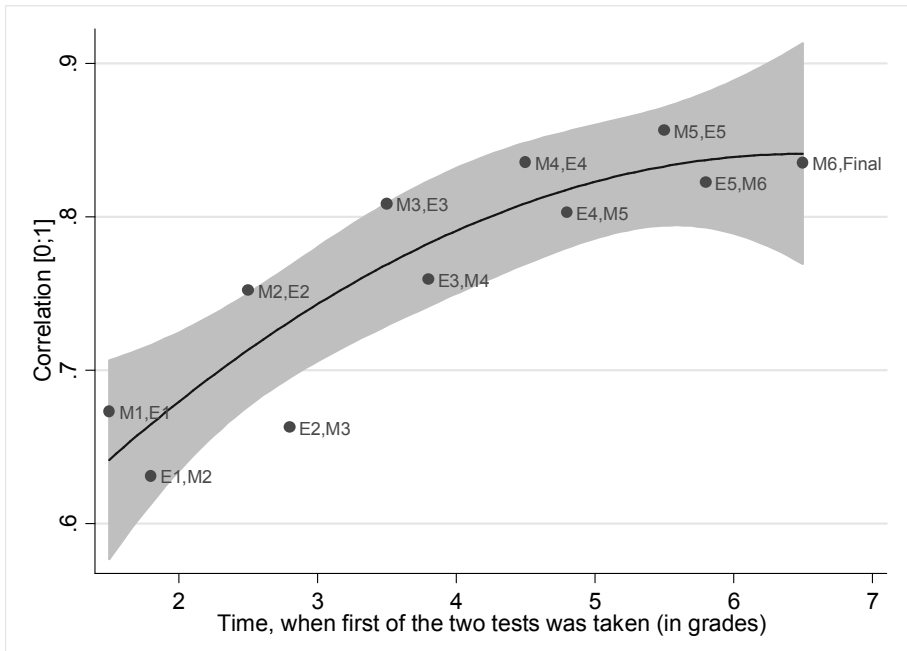

Notes: The graph shows the quadratic prediction plot of the correlations and the respective 95 percent confidence interval. The labels indicate which test scores have been correlated for that data point. M (for middle) and $\mathrm{E}$ (for end) denote the time of the school year when the test was taken and the number refers to the grade. "Final" stands for the mathematics section of the Cito test. The correlations displayed are calculated based on the balanced sample. Using the unbalanced sample leads to a very similar graph. 
Chapter 4: Measurement error and intergenerational mobility

The change in correlations between consecutive test scores points to some changes in the components determining success in mathematics tests across time. Technically, there are two potential explanations for the observed pattern: either a factor common to consecutive tests, attached to the individual, becomes more important in determining success or a component that differs between tests, for example the measurement error, decreases. In the following we develop a model to investigate the underlying developments closer.

\subsubsection{Model with constant mathematic ability}

\subsubsection{Model and reflections on the model parameters}

We propose a simple model in which the schooling outcome in each time period is determined by the individual's mathematic ability as well as highest parental education (PE). Equation 1 shows this for a single period. $Y_{\mathrm{i}}$ denotes the individual $i$ 's test score, $M A T H_{\mathrm{i}}$ the individual mathematic ability and $P E_{\mathrm{i}}$ the highest parental education level. The individual error term is denoted $\varepsilon_{\mathrm{i}}$.

$$
Y_{i}=c+\beta_{1} M A T H_{i}+\beta_{2} P E_{i}+\varepsilon_{i}
$$

Considering a series of test scores changes the equation in the following way: The test score varies with time, PE is arguably constant and for now we also assume MATH to be constant. From the age of eight onwards, the assumption of constant mathematic ability is supported by the results of the literature studying children's skill development (Cunha \& Heckman, 2008; Heckman, 2006). Based on our series of test scores starting at the age of six, we will relax this assumption in a next step (see Section 4.4.3).

Even though the ability and the parental education level do not change over time, still, their influence on the test score might differ from year to year. Practical reasons for this could be different types of tasks in the tests or changes in how the teacher reacts to the child's parental background. Therefore we allow the parameters to vary across periods, in our case, across tests taken at different points in time. The resulting model is presented in Equation 2. The parameters to be estimated are the coefficients of MATH and PE for each time period as well as the error term, which may also vary over time.

$$
Y_{i t}=c_{t}+\beta_{1 t} M A T H_{i}+\beta_{2 t} P E_{i}+\varepsilon_{i t}
$$


Here MATH is a latent variable, based on what all twelve test scores have in common. It can therefore be interpreted as an intra-individual constant, determining success in mathematics tests. In that sense it includes not only mathematic ability, based on innate ability and on outof-school training, but also test taking ability, influenced by non-cognitive skills, motivation, as well as additional factors that are constant over time within the individual. This being said, for reasons of simplicity, we will refer to it as MATH or mathematic ability. Estimates of $\beta_{1 \mathrm{t}}$ are measures of how important this composite is for success in that specific test and $\beta_{2 \mathrm{t}}$ captures the explanatory power that parental education has for the mathematics test score $Y$ in test $\mathrm{t}$ across individuals.

An important restriction is that with our dataset all the influence that PE has on mathematic ability before the children start school at the age of five cannot be measured. The ability that they bring to school might well be partly dependent on parental education. This is in line with the literature on the development of cognitive skills (Cunha \& Heckman, 2008; Heckman, 2006). With this model at hand, we cannot say anything about the cumulated influence of parental education when children start school. However, we can shed some light on the role that parental education plays during the time in primary school

In Section 4.4.1, we have shown that in the dataset of Dutch primary school students the correlation of $P E_{\mathrm{i}}$ and $Y_{\mathrm{i}}$, as well as the correlation between $Y_{\mathrm{it}}$ and $Y_{\mathrm{it}+1}$, increase over time. For a correlation to increase, the model outlined above provides two alternative reasons: (1) Either a common determinant of both measures, or the coefficient linking the measures, increases, or (2) a determinant they do not share decreases in magnitude. For both pairs $\left(Y_{\mathrm{it}}, P E_{\mathrm{i}}\right)$ and $\left(Y_{\mathrm{it}}\right.$, $\left.Y_{\mathrm{it}+1}\right)$ a common or connecting factor is $\beta_{2}$ and a distinguishing factor is $\varepsilon_{\mathrm{i}}$. Therefore, this framework provides two possible explanations for the observation of an increase in the correlation of PE with the test scores and an increase in the correlation between consecutive test scores: Either the parental education level becomes increasingly important for educational success over time, or the measurement error decreases. ${ }^{55}$

\subsubsection{Results for the full sample}

Based on the outlined model, we are interested in the development of the error term and the coefficient capturing the relationship with PE. The empirical problem in estimating the model

\footnotetext{
${ }^{55} \mathrm{We}$ are aware that a changing measurement error could be driven by different factors, e. g. systematic changes with age or increasing precision of the tests. We will mainly concentrate on the decomposition of the total variance and the general development of the different factors. In the final section potential underlying mechanisms are discussed.
} 
Chapter 4: Measurement error and intergenerational mobility

is that the students' mathematic ability is not directly observed. In order to estimate equation 2 with twelve independent variables simultaneously, we use a structural equation model (sem), treating MATH as a latent variable. Thus, the sem calculates a hypothetical mathematic ability for each individual out of all the tests taken, using their covariance. In the Appendix, we explain for a simple case of three tests how the estimation procedure of the sem uses the covariance matrix of several tests to assess unbiased coefficients. ${ }^{56}$

Figure 13 Coefficients of structural equation model, mathematic ability as latent variable

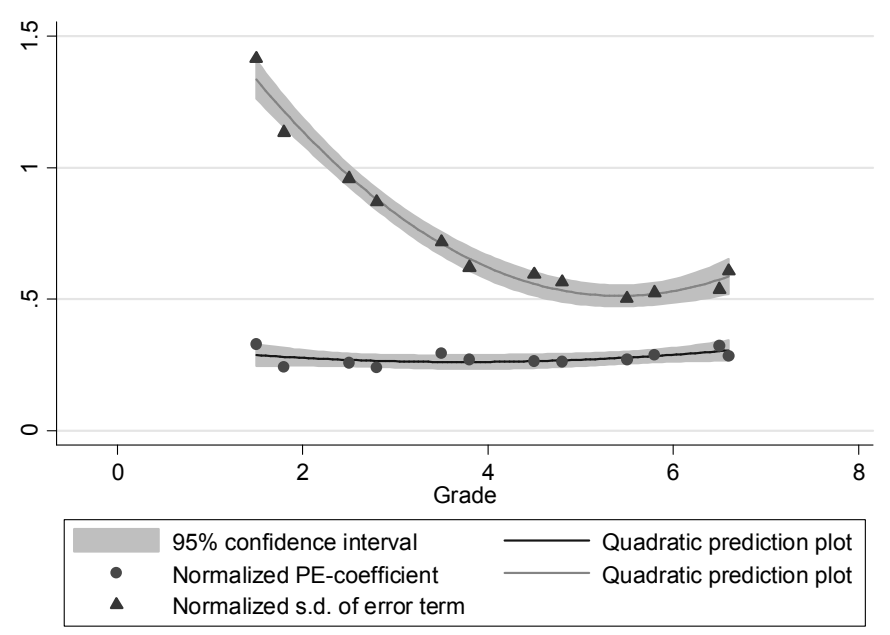

Notes: The structural equation model is based on the balanced sample. In order to account for teacher specific components of the error term, the model allows the error terms of tests to correlate within each school-year combination. Furthermore the mid-year test scores of consecutive years are may also correlate. Only the error term of the Cito test is assumed to be uncorrelated with all other error terms since the test differs in many respects from the others and it is graded externally. Standard errors are clustered at the school and year-combination level. The coefficients shown have been normalized by the respective coefficient for mathematic ability.

Figure 13 is based on the estimates of the sem outlined above, applied to the balanced sample. It shows the development of the PE coefficients as well as the standard deviation of the error term, which will in the following be referred to as the importance of the error term. Both measures are normalized by the MATH coefficient of the respective test. With regard to the overall development over the course of primary education, a clear decrease of the importance

\footnotetext{
${ }^{56}$ Alternatively to this simultaneous estimation approach, Equation 1 can be estimated twelve times with the Cito test as a measure for student ability (see Figure A.5). However, this approach makes no use of the series of test scores. A direct comparison between estimating Equation 1 with mathematical ability as a latent variable and based on all tests shows that this model provides a better fit (see Figure A.6).
} 
of the error term until the mid-year test in grade 5 becomes apparent. Its magnitude exceeds that of the PE coefficient by far. At the end of primary school, the errors' standard deviation is still twice as large as the PE coefficient. However, one has to keep in mind that the applied model is very simple and only includes mathematic ability and parental education background as explanatory variables.

Figure 14 Development of normalized PE coefficients (detail from Figure 13)

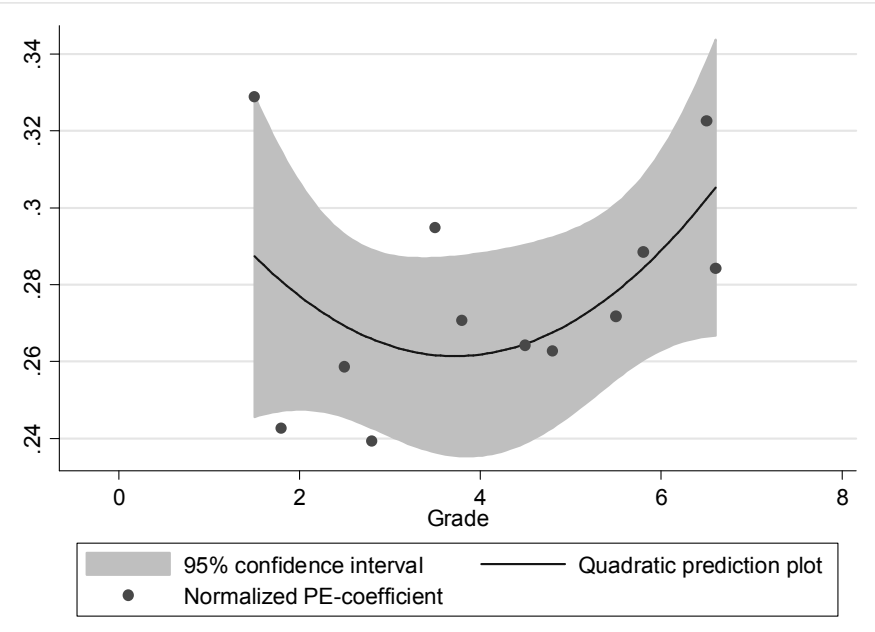

Notes: The graph shows the quadratic prediction plot of the normalized PE coefficients and the respective 95 percent confidence interval.

For the normalized PE coefficient smaller changes are observed than for the error term. When showing the development in more detail in Figure 14, a u-shape with a sharp decrease in the first year becomes apparent. In year two and three the within-year pattern is similar. The decrease in the size of the coefficient of parental education from the middle of the school year to the end of the school year are consistent with an equalizing effect of school. The coefficients in the third year stand out in the level, exceeding those in the second and fourth year. ${ }^{57} \mathrm{~A}$

\footnotetext{
${ }^{57}$ Grade 3 stands out in most of the figures, but it is not surprising. There are three ways in which the tests of that year differ from the other ones: Firstly, the biggest change in the primary school curriculum happens at that time. New tasks, such as multiplication and division as well as calculating with units, are introduced. Secondly, according to experts it is the only year with major discrepancies in the commonly used textbooks. Therefore, if some children are confronted with tasks they did not learn to solve at school, their prior knowledge and thereby their home environment is likely to play a larger role in determining success. Thirdly, it is likely that the children read the questions themselves for the first time. Until the mid-year test in grade 2 all tasks are read out by the
} 
Chapter 4: Measurement error and intergenerational mobility

monotone increase can only be observed for the last four low stakes tests, starting with the endyear test in grade 4 and continuing until the mid-year test in the final grade, when it reaches a level similar to the starting point.

While the pattern of correlations are very different for the balanced and the unbalanced sample, the coefficients calculated based on the sem are very similar. The results shown are based on the balanced sample. Comparable results for the unbalanced sample (not shown here) are almost indistinguishable.

\subsubsection{Heterogeneity across the test score distribution}

In this part we address potential heterogeneity in the development of the relationship between $\mathrm{PE}$ and test scores along the test score distribution. One way of doing this, would be to run separate regressions for different parts of the distribution. However, first of all, this weakens the estimations by having smaller samples. And secondly, specifically in our case of analyzing a series of test scores, children might move within the test score distribution. Therefore one would have to choose one of the twelve test score on which to base the groups.

We go around this problem, by applying a modification of quantile regression to repeat the main specification of our analysis for different parts of the distribution. Original quantile regression, first developed by Koenker and Bassett Jr (1978), is based on:

$$
y_{i}=x_{i}^{\prime} \beta_{\tau}+u_{\tau i} \text { with } \operatorname{Quant}_{\tau}\left(y_{i} \mid x_{i}\right)=x_{i}^{\prime} \beta_{\tau}
$$

where $\tau$ refers to the specific quantile of the distribution.

Diris (2012) modified this by also recoding the independent variable to ranks and then conducting separate analysis for different parts of the distribution.

We transfer this methodology to the structural equation approach and thereby extend it to the application in the context of a series of dependent variables. Based on the percentile scores also used in the main specifications, we generate four monotonic transformations of each test score:

$$
\begin{aligned}
& y_{1 j}=\min \left(25, \text { score }_{j}\right) \text { with } j \in[1,12] \\
& y_{2 j}=\max \left(25, \min \left(50, \text { score }_{j}\right)\right) \text { with } j \in[1,12]
\end{aligned}
$$

teacher. The end-year test in grade 2 already includes texts for the children, but it is likely that the teacher still supports the children during this first time. 


$$
\begin{aligned}
& y_{3 j}=\max \left(50, \min \left(75, \text { score }_{j}\right)\right) \text { with } j \in[1,12] \\
& y_{4 j}=\max \left(75, \text { score }_{j}\right) \text { with } j \in[1,12]
\end{aligned}
$$

where $j$ denotes the test number.

We then estimate our main specification with these four alternative outcome variables. The effects in each of the twelve simultaneously estimated equations for the whole distribution is the sum of the four separate effects. Each of the transformations only picks up the variation in one quartile of the distribution, while always using all observations. The transformed test score $y_{1 \mathrm{i}}$ for example resembles a test with an extreme ceiling effect, where all students above percentile 25 score the maximum number of points.

Figure 15 presents the estimated PE coefficients for the quartiles in the test score distribution, analogue to Figure 14 for the whole distribution. Only for the first test are the PE coefficients similarly large. After that, the developments are very distinct in the four quartiles:

Figure 15 Normalized PE coefficients for different test score quartiles
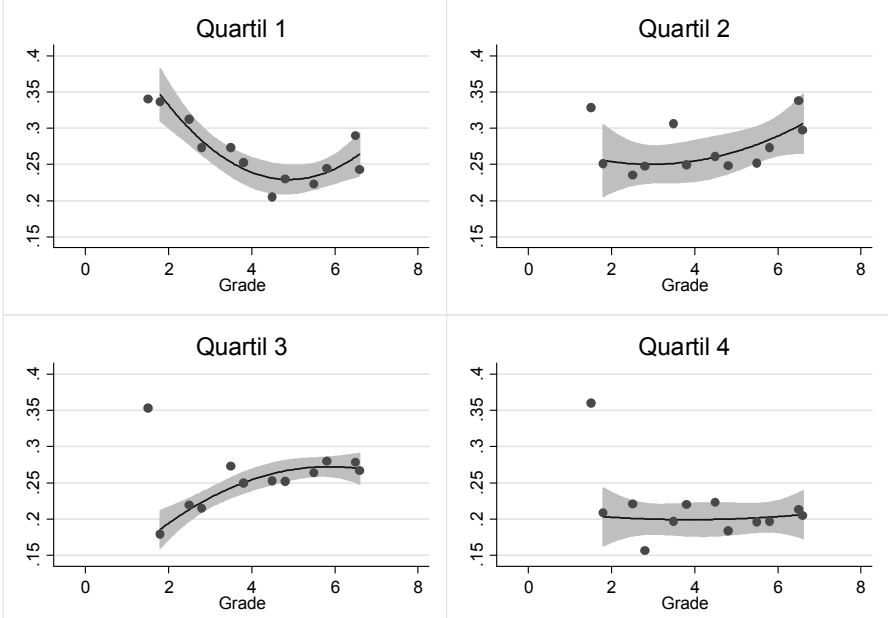

Notes: The underlying structural equation model is analogue to the main specification above (see Figure 14). Presented are the PE coefficients for the test score transformations $y_{1 \mathrm{j}}$ to $y_{4 \mathrm{j}}$, normalized by the respective coefficient for mathematic ability. The quadratic prediction plots and the related 95 percent confidence intervals are based on all but the first coefficient, because it is a clear outlier in three of the four cases. 


\section{Chapter 4: Measurement error and intergenerational mobility}

In quartile one, starting from a high level, the test outcomes' relationship with parental education weakens until grade 4 and only slightly increases towards the Cito test. So it looks as if primary school has an equalizing effect within the lowest quartile. In quartile two and three the PE coefficient decreases strongly after the first test, but then increases on different paths. In quartile two the relationship between test scores and parental education becomes stronger in the last three years. In quartile three this development concentrates on the first three years. The final level is largest for quartile two and second largest for quartile three. The estimated coefficients for quartile four are, leaving the first test out of the picture, all on a fairly low level around .2 , without a clear tendency to increase or decrease across the years.

As already mentioned in the main analysis, the first test is somewhat special, constituting an outlier for three of the four quartiles. It can be seen as a baseline measurement before curricular teaching and testing. Other characteristics of the results from the full sample are driven by parts of the test score distribution. The increasing dependence of test scores on parental education level is mostly driven by the two middle quartiles. Whereas the full sample is hiding that test scores become less dependent on parental education in the lowest quartile. Furthermore, the discrepancy in estimated coefficients between the last low stakes test and the Cito test is apparent in the lowest half of the test score distributions and disappears almost completely when looking at quartile three and four.

\subsubsection{Model with changing mathematic ability}

In order to keep the advantages of the structural equation model that estimates the latent variable based on several tests, but allowing for changes in mathematic ability we use a "rolling" structural equation model (sem). This means, that we use one test before and one test after the test of interest to estimate the model. For the second test for example we use tests one through three, for the third test we use test two through four, and so on. In consequence, based on this method, no estimates can be generated for the first and last test in the series. Since the development in the beginning is of special interest, we use tests on basic calculation and sorting skills in kindergarten to calculate a prior measure. ${ }^{58}$ Unfortunately, there is no similar opportunity for the last data point based on the Cito test.

\footnotetext{
58 Those test results are available only for a subset of our balanced sample. In order to keep the number of observations as large as possible, we combine two available tests. We use the percentile rank of a weighted sum of both test scores. If only one was available, that score was used instead of the weighted sum.
} 


\subsubsection{Results for the full sample}

The results of the rolling sem based on the full sample, shown in Figure 16, provide a similar picture of the overall developments as the results of the model assuming constant mathematic ability. In the details, there are still some notable differences. First, the importance of the error term is decreasing from a lower level, suggesting a better fit of this model. Furthermore, the increasing importance of parental education is more pronounced here. At least partly, this is caused by the missing last point in the series of test scores. In turn, the u-shape of the coefficient on parental education is less apparent (see Figure 17). The magnitude of estimated influence of parental education in the first test is now on the same level as in year four, and not as before in the last year of primary school.

\section{Figure 16 Coefficients of rolling structural equation model}

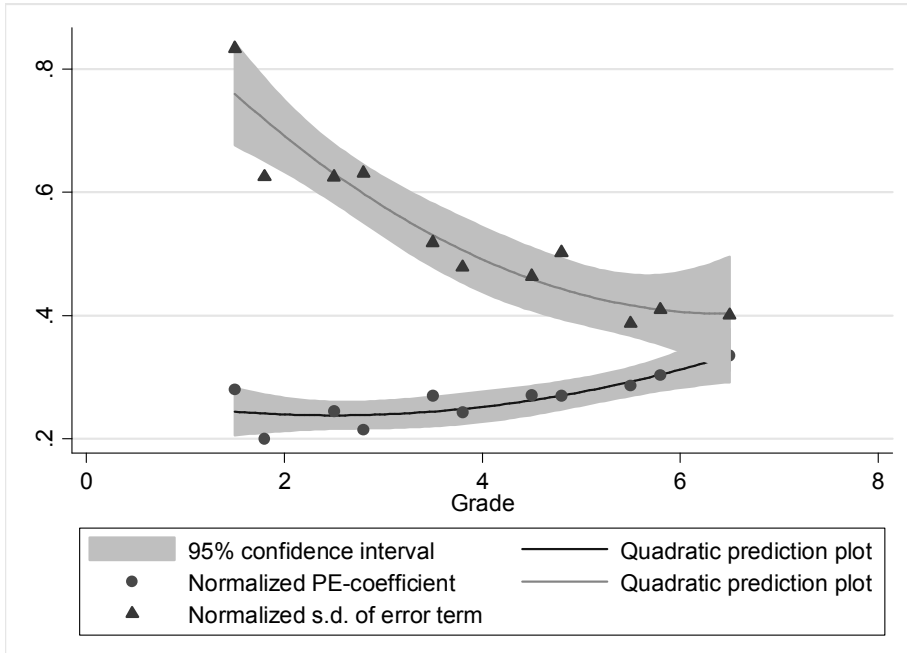

Notes: The underlying sample is a sub-sample $(\mathrm{N}=823)$ of balanced sample with all individuals for whom results from last year of kindergarten are available. The estimates for each test are based only on the data for the test of interest as well as the test directly before and after. 
Chapter 4: Measurement error and intergenerational mobility

Figure 17 Normalized PE coefficients based on rolling sem (detail from Figure 16)

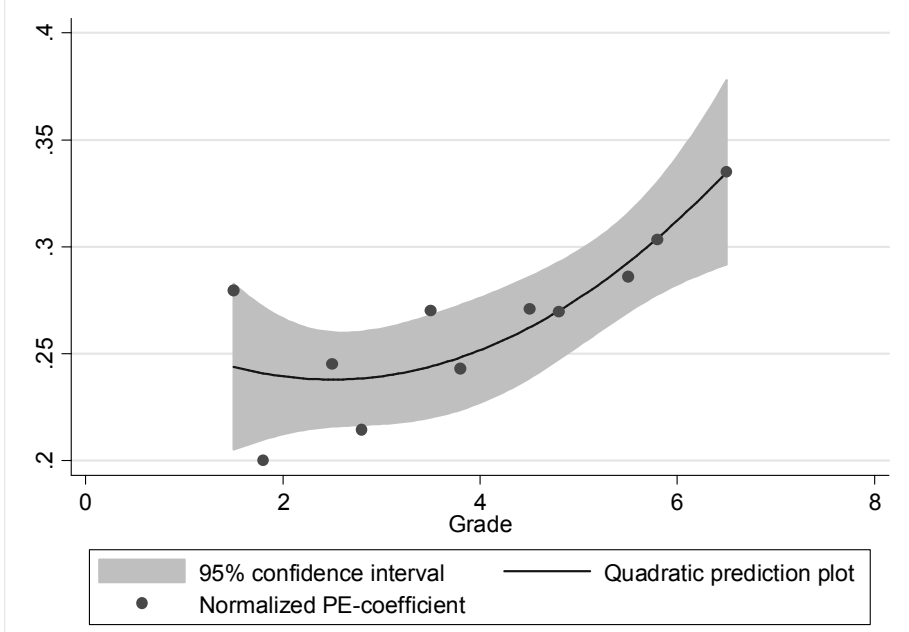

Notes: The graph shows the quadratic prediction plot of the normalized PE coefficients and the respective 95 percent confidence interval.

What stays are the qualitative implications that in the first three years within-year changes in the influence of parental education are dominating the development and only during the two years leading up the last low stakes test the dependence on parental education increases. In grade 6 the normalized PE coefficient is of similar magnitude as the standard deviation of the error, but the coefficient's increase over the complete six years is still only half of the decrease of the error's standard deviation.

\subsubsection{Variance decomposition}

The approach of the rolling structural equation model further allows us to make the results more tangible, by providing a decomposition of the overall variance in test scores based on the calculations, shown in Appendix: Chapter 4. Figure 18 shows the contributions to the variance of the three components: mathematic ability, parental education background, and the error term of this model. 
Figure 18 Decomposition of test score variance

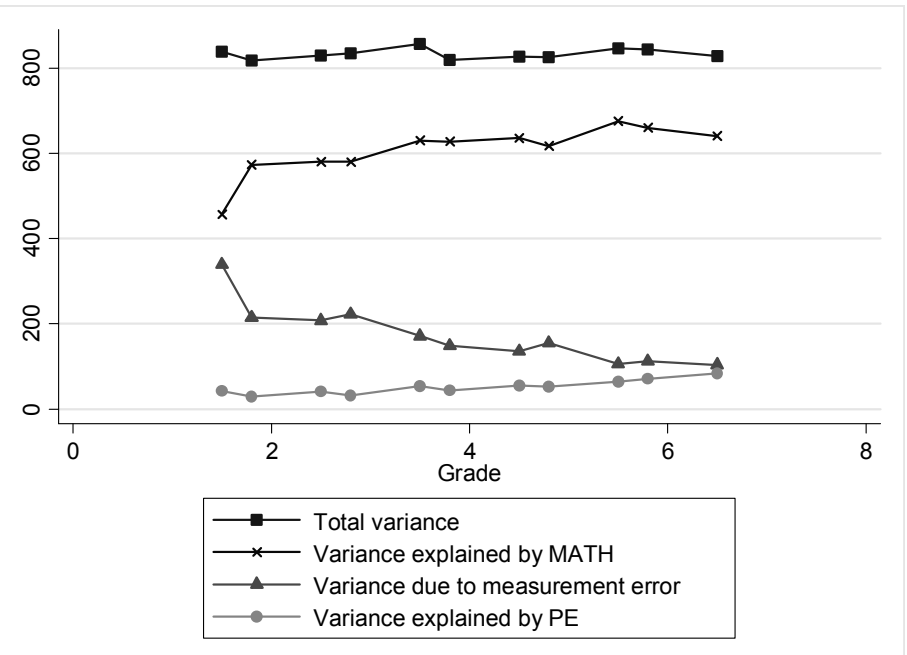

Notes: Plot of the total variance and the fractions explained by MATH and PE as well as the fraction due to measurement error.

The overall variance is constant due to using percentile ranks. The variance explained by both explanatory variables increases over time, but distinctively. In the first three years of primary school the variance explained by MATH increases relatively more, in the second half the relative fraction explained by parental education background increases more strongly.

\subsubsection{Heterogeneity across the test score distribution}

Analogue to Figure 15, the results for splitting up the test score distribution into quartiles are presented in Figure 19. The increasing importance of parental education for students' test scores towards the end of primary school, especially in the lowest half of the test score distribution, as well as the almost constantly low relationship in the highest quartile are confirmed. The main differences between the rolling structural equation model and the one assuming constant mathematic ability are apparent in the lowest quartile of the test score distribution. Allowing for changing mathematic ability almost completely takes away the decreasing importance of parental education for students' performance in the early years for the lowest quartile. 
Chapter 4: Measurement error and intergenerational mobility

Figure 19 Normalized PE coefficients for test score quartiles, based on rolling sem
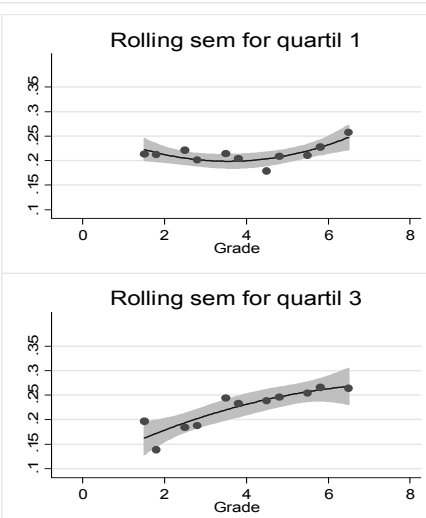
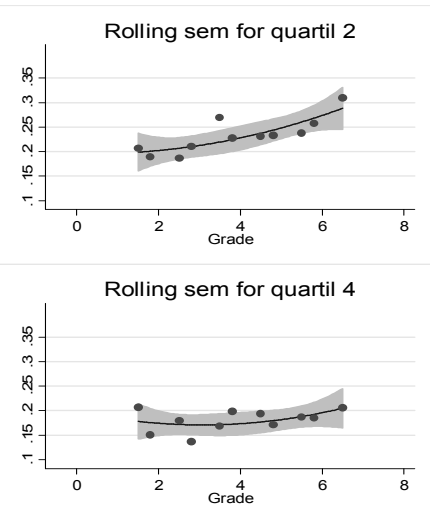

Notes: The graphs show the quadratic prediction plots of the normalized PE coefficients and the respective 95 percent confidence intervals. The estimates for each test are based only on the data for the test of interest as well as the test directly before and after. Presented are the values of the estimated normalized PE coefficients for the test score transformations $y_{1 \mathrm{j}}$ to $y_{4 \mathrm{j}}$.

\subsubsection{Robustness checks}

In the main analyses, we use percentiles of raw scores, which correspond to the number of correct items in the specific test and are therefore a relative performance measure for everyone participating in that test. For the low stakes mid- and end-year tests also skill scores are provided. These are a transformation of the raw scores, accounting also for item-difficulty. Skill scores, therefore, allow comparisons across different grades. We chose to base our main results on percentiles of raw scores, since there are two different ways of calculating the skill scores, depending on whether schools report the results item-based or only the overall number of correct answers. Nonetheless, robustness checks using the skill scores support the claim that the results are independent from this choice. Further, using directly the raw scores or skill scores instead of the percentiles only changes the scale of the y-axis, but not the relative development of the coefficients, and standard deviations.

Holding the definition of the test scores constant, the results are very robust against different specifications of the sem. Irrespective of whether we allow for correlation between the two independent variables or between error terms, both cases yield almost indistinguishable results to the ones shown above.

Another concern might be that the results are influenced by the composition of the sample. Apart from selective testing, which is already addressed by comparing the balanced and 
unbalanced sample, students might be tested at different points in time than it is meant to be. If students lack behind or if they are already ahead, teachers sometimes use tests that are supposed to be taken in a different grade. In our balanced sample, this concerns 70 of the 1.359 students, a little above 5 per cent. Excluding those students only changes the results minimally. In the graph comparable to Figure 13 this is indistinguishable.

As the robustness checks show, the structural equation model produces consistent results across samples, different definitions of the test scores, and across a range of model specifications.

\subsection{Discussion}

One of the major questions based on the analysis of test scores is how meritocratic an education system is, meaning how much success is determined by ability, compared to social class. Empirical studies (e. g. OECD, 2013) show big differences between countries with respect to the variance in performance that can be explained by differences in parental socio-economic status. Thus, in aiming for meritocratic fairness it is crucial for policy makers to understand the underlying mechanisms leading to the observed social dependency of outcome measures. However, as we show, the development of the correlation alone can be misleading. Furthermore, incentives and mechanisms might differ depending on the position in the performance distribution.

Using a series of comparable mathematics test scores over the course of six years of Dutch primary education, we study how the influence of socio-economic background, measured by the highest parental education level, develops, and how this relates to the measurement error. As we show, correlations are especially vulnerable to the sample composition, while our proposed structural equation model produces very robust estimates. Additionally, we use a modified quantile regression to analyze separate parts of the distribution. In the following, we discuss our main results as well as their implications.

\subsubsection{Overall development}

Increasing intergenerational dependence, measured as correlations of parental education (PE) and test scores, are during the first four years, mainly driven by more precise measurement. During that time, the influence of parental education is constant or even decreases. Though, it steeply increases towards the transition to secondary school. In the following, the detailed results are discussed. 
Chapter 4: Measurement error and intergenerational mobility

When assuming constant mathematic ability in our structural equation model, the influence of PE on test scores strongly decreases in the first year and then increases - first stepwise per year, later monotonous. However, even at the peak in the last low stakes mathematics test, the influence of parental education never exceeds the starting level in grade 1 . The main driver for the observed increase in the correlation of PE and the test results is therefore likely to be the strong decreasing importance of measurement error. Only in the last two to three years, when that decrease flattens out and even turns into a slight increase, the monotonous increase of the coefficient on parental education is likely to drive the higher correlations.

For the outcomes of the very first test, parental education plays a large role across the whole distribution of test scores and is very comparable in magnitude. Most likely this is due to being the first formal test, so that the result is most influenced by the before dominant home environment. After that the development of the estimated influence of parental education on test scores is very distinct across the distribution. Variation at the bottom part of the distribution in the beginning depends a lot on parental education. Later, this factor becomes less important, with the exception of the last low stakes test. At the top part of the distribution, parental education in general does not play a big role. After the first test, the estimated coefficients are almost stable at a very low level. The overall increasing influence of parental education is driven by the middle part of the test score distribution, for which also the relation of PE and the Cito test is most important at the end of primary school.

When allowing for changing math ability, the main difference to the more restrictive model is that the discrepancy between the estimated coefficients for the first and the second test disappears almost completely. Instead, a strong increase in explained variance through mathematic ability ${ }^{59}$ can be observed between the first and second test (Figure 18). In the first half of primary school, the variance explained by mathematic ability increases, and the error component decreases. In the second half of primary school, the variance component explained by parental education increases.

\subsubsection{Within-year patterns and the role of the Cito test}

Over the course of the first three years, the coefficient of parental education is always larger for the test score of the mid-year test than for that of the end-year test. This observation is the same for all model specifications, if using the full test score distribution and it is supported by most

\footnotetext{
${ }^{59}$ The concept as we use it in this analysis can be seen as mathematic ability plus test taking ability, where the latter of the two is likely to be influenced also by non-cognitive skills (Borghans \& Schils, 2012).
} 
year-quartile combinations, when exploring heterogeneous developments. From the end-year test in grade 4 onwards, the coefficient increases consistently from test to test across all model specifications. This pattern is very similar to the development of the correlation in the balanced sample in Figure 11.

The pattern in grade 1 to 3 is consistent with empirical evidence comparing the development of children from different backgrounds during school breaks and during school times. Investigating the effect of summer breaks Downey, Von Hippel, and Broh (2004) find support for school having an equalizing effect. Our analysis of the development over time confirms that on average school seems to reduce social-dependency of test outcomes during the first few years, especially for students at the lower end of the test score distribution. Later, in the last one and a half to two years before the Cito test, it increases again.

The change in this pattern, around the fourth year, could be explained by distinct reactions along the lines of parental educational background to approaching the high stakes Cito test at the end of primary school. The incentives to score high on this test are strong, since it is a main determinant of the teacher's recommendation for secondary schooling track. And this first track placement is very important.

While the low stakes tests leading up to the Cito test show an increasing trend in the relationship between the children's parental educational background, it peaks in the mid-year test in grade 6 and is clearly lower for the Cito test. This makes sense, when considering that the Cito test is not only based on the subject taught most recently. It focusses on a longer time span and is intended to measure the overall mathematic skills acquired during primary school. Furthermore, it is the only test among the ones considered, which is graded externally.

The observed pattern is consistent with additional support or pressure from parents with higher education levels or alternatively with increased effort by the children themselves. Furthermore, the low stakes tests allow for teaching to the test. They did not change for several years and are therefore known by many teachers. Differential effects of this teaching to the test, based on parental education, could therefore also explain the observations. Alternatively, the changes could also be related to the increasing test length. As Borghans and Schils (2012) show, the longer a test is, the more important are non-cognitive skills, which might also be correlated with parental educational background. These are of course only some possible explanations. More research regarding the underlying mechanisms is needed in order to support or reject these. 
Chapter 4: Measurement error and intergenerational mobility

The results from the different transformations, focusing on the variance in certain parts of the distribution, further support the hypothesis of background specific training effects in the second half of primary school. The increasing importance of parental education towards the end, as well as the large discrepancy between the last low stakes test and the Cito test, are most apparent for the transformations focusing on the two lowest quartiles of the distribution. For the upper part of the distribution, this increase is less pronounced and the coefficients estimated for the last low stakes test are no outliers to the top. It is logical to find this pattern for students in the lower half of the distribution since those are the ones at risk of attending a lower level secondary school.

\subsection{Conclusion}

Even when using more than one student outcome to measure the relation with parental education still exists. The development of the correlation between parental education and test scores provides a misleading picture of the underlying relationship, due to measurement error in the tests. Correlations between consecutive tests scores already point to potential developments in the error term. Using a structural equation model and conditional on mathematic ability, we show that, what looks like an almost monotone increase of intergenerational dependency from year to year, is in early years driven mostly by a decrease in measurement error. Only in later years, parental education becomes a stronger predictor of achievement tests. The first three years are dominated by a fluctuating within-year pattern, where the parental influence is larger in the test taken earlier in the school year. This observation is consistent with an equalizing influence of schools during the school year. When assuming constant mathematical ability from the age of six onwards, the influence of parental education is even largest in the very first test and is always lower after that. Only for the last two to three years of school, we observe an increasingly strong relationship between students' test scores and parental education.

Another reason for the misleading picture of correlations is that the developments are also very different across the test score distribution. The overall increase of the parental education coefficient is mostly driven by the middle 50 percent, while the increase towards the end is mostly driven by the lowest 50 percent of the distribution. The ones at the top of the distribution show a constant and low level of influence by parental education, and the ones at the bottom level show a more or less pronounced u-shape over time. 


\title{
Basic numeric competencies - its Measurement and Predictive Value ${ }^{60}$
}

\begin{abstract}
Distinguishing factors of basic numerical competencies, and how they predict mathematic performance at a later age, will improve the understanding of child development with respect to mathematic skills. Using longitudinal data for 3,037 Dutch students, we fill a gap in investigating the factor structure in a large sample, as well as providing results on longterm predictive power of basic numerical competencies. Among the items of a standardized test, conducted among kindergarten children of age five to six, we identify five distinct categories of number sense. Those predict about seventeen percent of the variance in a curricular mathematics tests conducted in grade 6 , even when controlling for general cognitive ability.
\end{abstract}

\footnotetext{
${ }^{60}$ This chapter is based on joint work with Katharina Lambert, Karien Coppens and Korbinian Moeller. We would like to thank Tyas Prevoo and Leo Kockelkorn for coordinating the collection of item-based data specifically for this project. Furthermore we thank Lex Borghans, Trudie Schils, Norman Rose, Roxanne Korthals, and Miriam Heijdendael as well as seminar participants at Maastricht University and University Tuebingen for valuable comments.
} 
Chapter 5: Basic numeric competencies - its Measurement and Predictive Value

\subsection{Introduction}

Numbers are virtually everywhere - from prices in the super market and quantities in a recipe to wages, and taxes. Thus, numerical competences are of great importance for labor market outcomes, as well as for everyday life in general (e. g. Butterworth, Varma, \& Laurillard, 2011; Dowker, 2005). Some empirical evidence suggests, mathematical skills might even be more important than language skills for life prospects (Parsons \& Bynner, 2005). Especially early mathematics concepts, as numbers, and ordinality, have been shown to be powerful predictors of mathematic as well as reading achievement in school (Duncan et al., 2007). Therefore, a basic level of numerical competencies is of economic and societal interest.

Number processing in young children has been suggested to be multi-dimensional (Dehaene, Piazza, Pinel, \& Cohen, 2003), and the development of numerical competencies to be hierarchical (Aunola, Leskinen, Lerkkanen, \& Nurmi, 2004; Okamoto \& Case, 1996). This implies that mastering basic numerical concepts in early childhood is essential for students' acquisition of more advanced mathematic skills later on. Furthermore Dowker (2008) showed that numerical cognition is not a unitary concept, suggesting that there are several factors contributing to successful number processing. Thus, understanding the precursors of numerical competencies is a precondition for developing effective interventions that go beyond curricular tasks, and specifically train underlying basic numerical competencies (Moeller, Pixner, Klein, Cress, \& Nuerk, 2009). Often, these precursor skills are referred to as number sense (e. g. Dehaene, 2011; Gersten \& Chard, 1999; Greeno, 1991; Okamoto \& Case, 1996). Gersten and Chard (1999, p. 18) describe number sense "an analog as important to mathematics learning as phonemic awareness has been to the reading research field".

\subsubsection{Number sense}

"Most broadly, number sense refers to understanding of numbers and number relationships." (Locuniak \& Jordan, 2008, p. 452) or "skills that provide a foundation for the acquisition of later mathematical abilities [...], resulting from both formal and informal experience with numbers during childhood" (Lago, 2007, p. 2). While these are two exemplary definitions of what is denoted by the term number sense, there is still no consensus on how to specifically define and operationalize number sense ${ }^{61}$ (Berch, 2005; Gersten, Jordan, \& Flojo, 2005).

\footnotetext{
${ }^{61}$ Alternative terms referring to similar concepts are basic number skills, preparatory arithmetic skills, concepts of numbers and counting and informal mathematical knowledge (as listed by Aunio et al., 2004), number understanding (Dowker, 2008) or preschool quantity-number competencies (Krajewski \& Schneider, 2009). In the remainder of the article we will use the term "number sense" for reasons of consistency.
} 
There are several reasons for a lack of clarity in the literature on number sense, amongst others: (1) the involvement of different fields of research, such as numerical cognition, and mathematics education; (2) different underlying assumptions (Berch, 2005), such as whether some kind of number sense is part of our genetic endowment or an acquired skill, and whether it is a low order sense of quantity or high order conceptual sense-making of mathematics. The latter question also relates to the age group focused at (e. g. Jordan, Glutting, \& Ramineni, 2010; Okamoto \& Case, 1996). What is defined as higher order conceptual sense-making cannot be measured in kindergarten children.

Because we used data from kindergarten, we specifically considered articles focusing on a similar age group for our operationalization of number sense. A definition along these lines has been provided by Geary et al. (2009, p. 412): “Children's number sense includes a non-verbal and implicit understanding of the absolute and relative magnitude of sets of small numbers of objects and of symbols (e. g., Arabic numerals) that represent these quantities".

Prior to describing the specificities of the current study, we briefly review the literature on number sense, with respect to its dimensionality, as well as its predictive power for later math achievement.

\subsubsection{Dimensionality of number sense}

A couple of articles have provided confirmatory factor analyses, analyzing dimensionality of number sense, and supporting specific operational definitions for children aged 4 to 6 (Aunio et al., 2004; Aunio \& Niemivirta, 2010; Cirino, 2011; Kolkman et al., 2013). The proposed factor structures vary between two, and five factors, and all confirmed the respective proposed structure. Aunio et al. (2004) as well as Aunio and Niemivirta (2010) distinguish the two factors relational, and counting skills, with each four aspects. Relational skills include tasks on nonsymbolic comparisons, classification, one-to-one correspondence, and seriation. Counting skills comprise counting forward as well as backward, structured counting, resultative counting, and simple story problems. Kolkman et al. (2013) distinguish non-symbolic and symbolic skills, broadly relating to relational, and counting skills. Non-symbolic skills are tested with nonsymbolic number lines, and comparing sets of dots. Symbolic skills are tested by number naming, and counting. They also test a three factor model with additionally including mapping skills. This third factor is referring to the mapping of number symbols, and non-symbolic comparison, for example measured by symbolic number line tasks or symbolic comparisons. Among children of age 4 or 5 , the three factor model is favored. However, the differences between the fit of the two, and three factor model are minor. Among older children of age 6, 
Chapter 5: Basic numeric competencies - its Measurement and Predictive Value

one integrated number sense factor provided the best fit. Cirino (2011) confirms the main distinction being between symbolic and non-symbolic tasks, but provides empirical evidence for a five factor structure. The author distinguishes non-symbolic comparison, symbolic comparison, symbolic labeling, rote counting, and counting knowledge. Cirino (2011) as well as Kolkman et al. (2013) conclude that symbolic skills play a predominant role as precursors of mathematic skills, potentially via the development of mapping skills.

The main distinction so far has been between symbolic, and non-symbolic skills. The only more detailed structure tested (Cirino, 2011) focuses mostly on differentiating symbolic skills, and missed out on differentiating non-symbolic skills. Aunio and Niemivirta (2010) measure several non-symbolic, and relational skills, but do not test a more detailed factor structure. Furthermore, all the above mentioned analyses are based on only small to medium-sized samples, ranging from below 100 (Kolkman et al., 2013), up to roughly 300 participants (Cirino, 2011).

\subsubsection{Prediction of later mathematic performance}

Many longitudinal studies analyze the relevance of specific operational definition of numbers sense for later mathematic achievement (e. g. Aubrey, Godfrey, \& Dahl, 2006; Aunio \& Niemivirta, 2010; Jordan et al., 2010; Jordan, Kaplan, Locuniak, \& Ramineni, 2007; Jordan,

Kaplan, Ramineni, \& Locuniak, 2009; Kolkman et al., 2013). Each article uses a different operationalization. However, all of the individual measures are among the ones mentioned above in the context of one of the factor analyses. All of the studies confirm a sizable predictive power for later mathematic achievement level above, and beyond demographic characteristics, and in the case of Jordan et al. (2010) controlling for general cognitive ability. Furthermore, Jordan et al. (2009) report a positive association of high number sense values with high growth rates in mathematic achievement. Additional results are again the major importance of early symbolic number knowledge (Jordan et al., 2009), as well as that the strength of prediction does not weaken over the first three years (Jordan et al., 2010).

Most of the studies cover a time span of one to two years only (Aunio \& Niemivirta, 2010; Jordan et al., 2006). Those studies that cover longer time-spans (Aubrey et al., 2006; Jordan et al., 2009) suffer from small sample sizes $(\mathrm{N}<200)$.

\subsubsection{The current study}

In this article, we aim at closing the gap of large scale evidence on the dimensionality, and operationalization of number sense, as well as long-term longitudinal evidence on the prediction 
of later mathematic performance. The analysis is based on $\mathrm{N}>3,000$ observations from a longitudinal large-scale panel study in the Netherlands. A longitudinal sub-sample of about 800 observations covers a time span of six years. The two research questions are answered stepwise.

Our first hypothesis is that several factors of early number sense can be empirically distinguished. We propose an empirically motivated internal structure of number sense, and conduct a confirmatory factor analysis. To operationalize number sense in this study, we use data from an actual kindergarten test widely applied in the Netherlands. Among the 42 items, we identified 30 that measure skills which have been considered as being part of number sense before. We propose a five factor structure, distinguishing: perceptual matching, seriation, nonsymbolic number knowledge, counting, and symbolic number knowledge.

Table 18 Articles with operationalization of number sense including similar competencies

\begin{tabular}{|c|c|}
\hline Five factors & Articles \\
\hline Perceptual matching & $\begin{array}{l}\text { Assel, Landry, Swank, Smith, and Steelman (2003); Aunio et al. } \\
\text { (2004); Aunio and Niemivirta (2010); Passolunghi and Lanfranchi } \\
\text { (2012) }\end{array}$ \\
\hline Seriation & $\begin{array}{l}\text { Aubrey et al. (2006); Howell and Kemp (2005); Krajewski and } \\
\text { Schneider (2009); Passolunghi and Lanfranchi (2012) }\end{array}$ \\
\hline $\begin{array}{l}\text { Non-symbolic number } \\
\text { knowledge }\end{array}$ & $\begin{array}{l}\text { Aubrey et al. (2006); Cirino (2011); Gebuis and Reynvoet (2015); } \\
\text { Howell and Kemp (2005); Kolkman et al. (2013); Krajewski and } \\
\text { Schneider (2009); Lago (2007); LeFevre et al. (2010); Lembke and } \\
\text { Foegen (2009); Malofeeva, Day, Saco, Young, and Ciancio (2004) }\end{array}$ \\
\hline Counting & $\begin{array}{l}\text { Aubrey et al. (2006); Cirino (2011); Dowker (2008, 2015); Jordan et } \\
\text { al. (2010); Jordan et al. (2007); Jordan et al. (2006); Jordan et al. } \\
\text { (2009); Lago (2007); Locuniak and Jordan (2008); Malofeeva et al. } \\
\text { (2004); Passolunghi and Lanfranchi (2012); Passolunghi, Vercelloni, } \\
\text { and Schadee (2007) }\end{array}$ \\
\hline $\begin{array}{l}\text { Symbolic number } \\
\text { knowledge }\end{array}$ & $\begin{array}{l}\text { Cirino (2011); De Smedt, Verschaffel, and Ghesquière (2009); } \\
\text { Göbel, Watson, Lervåg, and Hulme (2014); Howell and Kemp } \\
\text { (2005); Jordan et al. (2010); Jordan et al. (2007); Jordan et al. } \\
\text { (2006); Jordan et al. (2009); Kolkman et al. (2013); Lago (2007); } \\
\text { LeFevre et al. (2010); Lembke and Foegen (2009); Locuniak and } \\
\text { Jordan (2008); Malofeeva et al. (2004); Moeller et al. (2009); } \\
\text { Passolunghi and Lanfranchi (2012); Passolunghi et al. (2007); } \\
\text { Sasanguie, Göbel, Moll, Smets, and Reynvoet (2013) }\end{array}$ \\
\hline
\end{tabular}


Chapter 5: Basic numeric competencies - its Measurement and Predictive Value

Table 18 lists other studies using similar measures. This proposed five factor model is tested against a two factor model, analogue to the structure of earlier factor analytic studies, as well as to a model with a unitary factor. The two factor model distinguishes figurative and nonsymbolic skills from counting and symbolic skills.

The second hypothesis is that the identified factors predict mathematic achievement still six years later. To test this, we regress the results of a mathematic achievement test at the end of primary school, six years later on the identified number sense factors.

Our third hypothesis is that early numeracy predicts a more stable share of the variance in mathematic achievement tests than do early curricular-based tests. This is tested by comparing how the explained variance of a series of standardized mathematic test scores develops. Once the number sense factors are used as an independent variable to predict each test. Once the first test of the series is used to predict the following test scores.

\subsection{Method}

\subsubsection{Participants}

The sample consisted of 3,037 children, attending 44 primary schools in south Limburg. Limburg is the most southern province of the Netherlands. They belong to seven cohorts, who attended the sixth and last grade of Dutch primary school in the years 2009 to 2015. In this study, we use the data of a test assessing basic numerical competencies, administered when children were in their second, and last year of kindergarten. Additionally, mathematics achievement data, from a test taken in grade 6, are available for a sub-sample of 797 children. Every school was free to choose which of the standardized tests to use. About the same number of schools administered each of the two tests. The sub-sample consists of the overlap.

The data stem from an ongoing longitudinal study monitoring and aiming at improving education in the Province of Limburg in the south of the Netherlands. ${ }^{62}$ More than 95 percent of all primary schools in the south of Limburg participated in this project, called OnderwijsMonitor Limburg. The project was approved by the local school boards of Limburg. Test scores were processed by the MEMIC Maastricht (center for data and information management), and were provided for analysis in anonymized form.

\footnotetext{
${ }^{62}$ For a description of the education monitor see Educatieve Agenda Limburg (2016). Further, detailed descriptions of the dataset, as well as the Dutch education system are provided in Chapter 2.
} 


\subsubsection{Materials}

The underlying tests, considered in the analyses, are part of the most commonly administered series of standardized tests in Dutch kindergartens and primary schools.

Assessment in Kindergarten. We rely on data from a test on early numeracy, administered in the second, and last year of kindergarten, between January and March, when children are five to six years old (Cito, 1997; Van Kuyk, 1997). When conducting the test, kindergarten teachers are advised to read out the instructions, and questions in front of the class, repeating each question once. Each child has a test booklet, a piece of cardboard to cover the irrelevant parts on each page, and a pencil. The test comprises 42 items in two parts. Each part takes about 20 to 30 minutes to complete, and is set up as a power test without explicit time limit. Accordingly, answers are only coded as either correct or incorrect. ${ }^{63}$ The maximum raw score on the test is 42 points.

Thirty of the 42 items are categorized to reflect basic numerical competencies. Additionally, another 10 items are considered to reflect a measure of general cognitive ability. Two items are excluded from the analysis: one because of ambiguity of the answer ${ }^{64}$, and the second one because it did not fit into any category.

Basic numerical competencies. Thirty items of this pre-existing test are categorized into the following five basic numerical competencies: perceptual matching (four items), seriation (seven items), non-symbolic number knowledge (seven items), counting (six items), and symbolic number knowledge (six items). Generic examples for items of each category are given in the Appendix in Figure A.7, panels (a) to (e), respectively.

General cognitive ability. Ten items reflect a measure of general cognitive ability, rather than basic numerical competencies. These items are very similar to items used in tests of nonverbal intelligence, such as the CFT 1-R (Weiß \& Osterland, 2013). Generic examples of the respective items are provided in the Appendix in Figure A.7, Panels (f) to (i).

Mathematic achievement in sixth grade. Mathematic achievement is assessed by the last standardized mathematics test administered in primary school. Most students are 11 to 12 years old at the point of testing. Each student receives a booklet with questions that she/he has to

\footnotetext{
${ }^{63}$ Questionable answers are considered incorrect (at most .13 percent per item).

${ }^{64}$ This is confirmed by a two parameter item response model. The discrimination parameter for this item is very low in comparison, and only significantly different from zero at the five percent level, while all others are significant at the .1 percent level.
} 
Chapter 5: Basic numeric competencies - its Measurement and Predictive Value

read, and answer independently. The test comprises 96 items in three parts. The parts can be administered at different days. Each part takes about 45 minutes to complete. The test is conducted as a power test without explicit time limit (Janssen, Scheltens, \& Kraemer, 2009). The answers can only be correct or incorrect. Questionable answers are considered incorrect (at most .45 percent). The maximum raw score on the test is 96 points.

The test covers the complete national curriculum for primary schools (SLO - nationaal expertisecentrum leerplanotwikkeling, 2006), including: numbers, and number relations; mental arithmetic; handwritten arithmetic (addition, subtraction, multiplication and division); approximate arithmetic; calculations with fractions, and percentages; as well as using units, and measurements, (e. g., such as time, money, length, circumference, surface area, volume, weight, speed, and temperature). The type of question varies: there are calculation tasks; word problems; tasks where some information for the calculation has to be extracted from tables, graphs, pictures or documents like recipes; geometric tasks; and tasks on visual perception and perspective. While most of the questions are in an open question format, a little less than one fifth are multiple choice questions.

\subsubsection{Data analyses}

Prior to any analyses data were checked for anomalies, and deviation from testing instructions. Only first attempts of each test, and only attempts made in the correct grade are considered. In case of the mathematic achievement test, we create a control variable, indicating whether the respective student took the test at the beginning (44.68 percent) or at the end of the school year. All analyses are either based on raw scores or normalized raw scores.

In this study, we propose a theory-led categorization of how to structure number sense into basic numerical competencies and evaluated this categorization in two steps. First, we run a confirmatory factor analysis on early numeracy test data from kindergarten. We compare our proposed five factor structure of number sense to an earlier proposed two factor, as well as a unitary structure. In a second step, we use a longitudinal sub-sample to test the long-term predictive value of those basic numerical competencies for mathematic achievement in sixth grade, while controlling for general cognitive ability. 


\subsection{Results}

\subsubsection{Step 1: Empirical evaluation of the proposed number sense structure}

We propose a decomposition of number sense into five basic numerical competencies: perceptual matching, seriation, non-symbolic number knowledge, counting, and symbolic number knowledge. Summary statistics, and correlations between the different basic numerical competencies are presented in Table 19. Polychoric correlations are used to account for the binary nature of the items, and thus the discrete nature of the sum scores used for the categories (Holgado-Tello, Chacón-Moscoso, Barbero-García, \& Vila-Abad, 2010). The largest correlation amounts to .38 , and is observed between counting, and symbolic number knowledge. Overall, over half of the correlations are below .30. This already suggested distinct concepts.

Table 19 Descriptive statistics and correlations between all measures

\begin{tabular}{|c|c|c|c|c|c|c|c|c|c|c|c|c|}
\hline \multirow[b]{2}{*}{ Variable name } & \multirow[t]{2}{*}{ \# items } & \multicolumn{2}{|c|}{ Full sample } & \multicolumn{2}{|c|}{$\begin{array}{l}\text { Longitudinal } \\
\text { sub-sample }\end{array}$} & \multirow[t]{2}{*}{ Sign. } & \multicolumn{6}{|c|}{ Correlations } \\
\hline & & Mean & SD & Mean & SD & & (1) & (2) & (3) & (4) & (5) & (6) \\
\hline (1) Perceptual matching & 4 & 3.79 & .49 & 3.78 & .48 & & - & & & & & \\
\hline (2) Seriation & 7 & 5.85 & 1.27 & 5.88 & 1.28 & & .29 & - & & & & \\
\hline (3) Non-symbolic number knowledge & 7 & 4.91 & 1.28 & 4.91 & 1.31 & & .21 & .28 & - & & & \\
\hline (4) Counting & 6 & 5.06 & 1.13 & 5.08 & 1.14 & & .24 & .37 & .35 & - & & \\
\hline (5) Symbolic number knowledge & 6 & 5.09 & 1.23 & 5.02 & 1.29 & * & .23 & .31 & .29 & .38 & - & \\
\hline (6) General cognitive ability & 10 & 7.38 & 1.66 & 7.47 & 1.68 & * & .20 & .28 & .26 & .29 & .23 & - \\
\hline (7) Mathematic achievement, grade 6 & 96 & - & - & 67.43 & 15.92 & - & .20 & .30 & .31 & .32 & .30 & .22 \\
\hline
\end{tabular}

$\begin{array}{lll}\mathrm{N} & 3.037 & 797\end{array}$

Notes: Significance asterisks $(* \mathrm{p}<.1, * * \mathrm{p}<.05, * * * \mathrm{p}<.01)$ indicate the result of a t-test comparing the means in two sub-samples: children who only took the kindergarten test and children who took the kindergarten test as well as the mathematic achievement test in grade 6 . The correlations for (1) to (5) are polychoric correlations to account for the discrete nature of the sum scores (Kolenikov \& Angeles, 2004). For (6) and (7) Pearson correlations are shown. The latter two variables are also sum scores. Since both have 10 or more possible outcomes they are treated as continuous. All correlations are significant at the one percent level.

The confirmatory factor analysis corroborates the proposed structure. We compare a five factor model (see Figure 20) to a two factor model, as proposed earlier in the literature (Aunio et al., 2004; Aunio \& Niemivirta, 2010; Cirino, 2011; Kolkman et al., 2013), and a simple one factor model, pooling all 30 items of numerical competence. Estimates are obtained by applying a robust weighted least square estimation using MPlus (Muthén \& Muthén, 2012). The sum score 
Chapter 5: Basic numeric competencies - its Measurement and Predictive Value

of general cognitive ability was included as a covariate. In all models the contribution of all items to the respective latent variables is highly significant (all $p<.001$ ).

Figure 20 Confirmatory factor analysis for five factor model of number sense

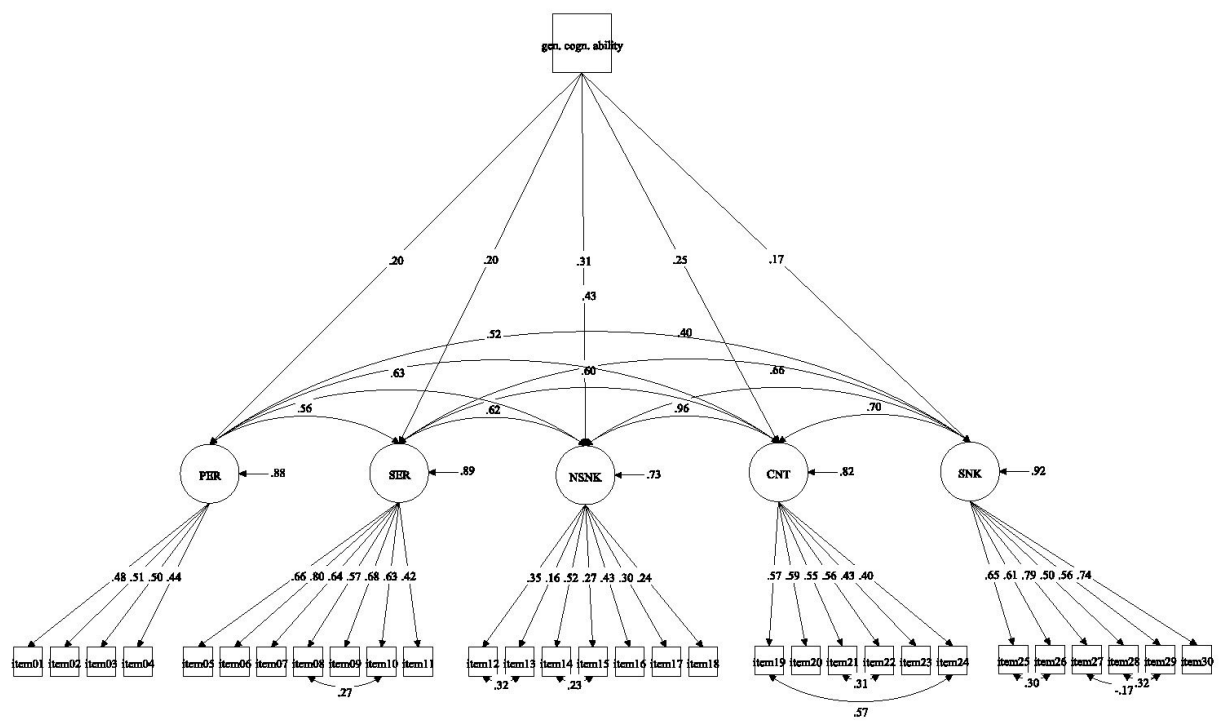

Notes: The figure shows the structure of the confirmatory factor analysis of the five factor model of number sense run on the 3,037 children in the full sample. The model distinguished the factors perceptual matching (PER), seriation (SER), non-symbolic number knowledge (NSNK), counting (CNT), symbolic number knowledge (SNK). The only covariate used was general cognitive ability (gen. cogn. ability). The items have been relabeled for the purpose of this analysis. The shown order does not correspond to the order in which the items appeared in the test. The reported coefficients are standardized and all of them are significant at 1 percent.

The fit is evaluated based on several indices, including the Chi-square $\left(\chi^{2}\right)$ test, comparing the model against the saturated model, also relative to the degrees of freedom $\left(\chi^{2} / \mathrm{df}\right)$, the root mean square error of approximation (RMSEA), the comparative fit index (CFI), and the TuckerLewis index (TLI). Schermelleh-Engel, Moosbrugger, and Müller (2003) discuss those indices, and provide the following recommendations for good fit: $\chi^{2} / \mathrm{df}(\leq 2)$, RMSEA $(\leq .05)$, CFI $(\geq$ $.97)$, and TLI $(\leq .97)$. The large sample size, and number of variables provide an inherent disadvantage with respect to most absolute goodness of fit indices (e. g. $\chi^{2}, \chi^{2} / \mathrm{df}$ ). As suggested by Bollen (1990) and Schermelleh-Engel et al. (2003), we therefore place more emphasis on the reported non-centrality-based indices (CFI, and TLI). 
Table 20 Fit indices of the confirmatory factor analysis

\begin{tabular}{rrrrrrrrr}
\hline & & \multicolumn{7}{c}{ Goodness-of-fit index } \\
\cline { 3 - 8 } Model & Error terms & $\chi^{2}$ & df & $\chi^{2} / \mathrm{df}$ & RMSEA & CFI & TLI \\
\hline one factor & uncorrelated & 2293.29 & 434 & 5.28 & .038 & .77 & .75 \\
two factors & uncorrelated & 1822.63 & 432 & 4.22 & .033 & .83 & .82 \\
five factors & uncorrelated & 1277.48 & 420 & 3.04 & .026 & .90 & .89 \\
one factor & correlated & 1233.35 & 426 & 2.90 & .025 & .90 & .89 \\
two factors & correlated & 984.98 & 424 & 2.32 & .021 & .93 & .93 \\
five factors & correlated & 634.07 & 412 & 1.54 & .013 & .97 & .97 \\
\hline
\end{tabular}

Notes: $\mathrm{Chi}^{2}$ (testing model versus saturated model), RMSEA (root mean squared error of approximation), CFI (comparative fit index), TLI (Tucker-Lewis index).

Table 20 presents the different indices for all three models. All indices confirm a better fit of the more complex five factor model of numerical competencies, compared to the model with two broader factors, as well as to the one factor model, reflecting a general number sense factor. This is the case, irrespective of whether correlations between error terms of structurally similar items are accounted for. The best fit is obtained for the five factor model, allowing for correlations between the error terms of similar items within each category. All indices lay within the above mentioned boundaries of good fit. A RMSEA of .013, a CFI of .97, and a TLI of .97 are found.

\subsubsection{Step 2: Confirming long-term relevance of basic numerical competencies}

After having confirmed our proposed structure of number sense, we aim at evaluating how relevant the identified factors are for mathematical achievement six years later. For that purpose we use a longitudinal sub-sample, comprising 797 students. Those students took the early numeracy test in their last year of kindergarten, as well as a mathematic achievement test in their last year of primary school.

Table 19, above, shows that the sub-sample is very similar to the full sample; in terms of early numerical competencies, and general cognitive ability. None of the differences are significant at the 5 percent level. 
Chapter 5: Basic numeric competencies - its Measurement and Predictive Value

Table 21 Regression results, longitudinal sample

\begin{tabular}{|c|c|c|c|c|c|}
\hline & \multicolumn{5}{|c|}{ Mathematic achievement, grade 6} \\
\hline & $(1)$ & $(2)$ & (3) & (4) & (5) \\
\hline Basic numeric cognition (total sum) & $\begin{array}{l}.119^{\text {*** }} \\
(.009)\end{array}$ & & & & \\
\hline \multicolumn{6}{|l|}{ Number sense } \\
\hline Perceptual matching & & $\begin{array}{r}.083 \\
(.069)\end{array}$ & $\begin{array}{r}.073 \\
(.069)\end{array}$ & $\begin{array}{r}.069 \\
(.069)\end{array}$ & $\begin{array}{r}.068 \\
(.069)\end{array}$ \\
\hline Seriation & & $\begin{array}{l}.109 \text { *** } \\
(.027)\end{array}$ & $\begin{array}{l}.100 * * * \\
(.028)\end{array}$ & $\begin{array}{l}.103^{* * *} \\
(.028)\end{array}$ & $\underbrace{.107}{ }^{* * *}$ \\
\hline Non-symbolic number knowledge & & $\begin{array}{l}.147^{* * *} \\
(.027)^{*}\end{array}$ & $\begin{array}{l}.1411^{* * *} \\
(.027)^{2}\end{array}$ & $\begin{array}{l}.1422^{* * *} \\
(.027)\end{array}$ & \\
\hline Counting & & $\begin{array}{l}.126 \text { *** } \\
(.032)\end{array}$ & $\begin{array}{l}.119^{* * *} \\
(.032)\end{array}$ & $\begin{array}{l}.1233^{* * *} \\
(.032)\end{array}$ & \\
\hline Symbolic number knowledge & & $\begin{array}{l}.101 \\
(.028)\end{array}$ & $\begin{array}{l}.0966^{* * *} \\
(.028)\end{array}$ & $\begin{array}{l}.102 \text { *** } \\
(.028)\end{array}$ & \\
\hline \multicolumn{6}{|l|}{ Number sense (by type of question) } \\
\hline Non-symbolic magnitude, abstract (MC4) & & & & & $\left.{ }_{(.055)}^{.141}\right)^{* * *}$ \\
\hline Non-symbolic relations / magnitude (MC3) & & & & & $\begin{array}{l}.139^{* * *} \\
(.031)^{* *}\end{array}$ \\
\hline Counting items (MC) & & & & & $\begin{array}{r}-.061 \\
(.085)\end{array}$ \\
\hline Counting, drawing items (open format) & & & & & $\begin{array}{l}.164^{* * *} \\
(.036)\end{array}$ \\
\hline Symbolic number knowledge (MC4) & & & & & 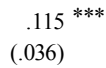 \\
\hline Symbolic number knowledge (MC3) & & & & & $\begin{array}{r}.083 \\
(.069)\end{array}$ \\
\hline General cognitive ability (total sum) & & & $\begin{array}{l}.036 * \\
(.021)\end{array}$ & & \\
\hline \multicolumn{6}{|l|}{ General cognitive ability } \\
\hline Similarity & & & & 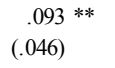 & $\begin{array}{l}.092 * * \\
(.047)\end{array}$ \\
\hline Categorization & & & & $\begin{array}{r}-.058 \\
(.047)\end{array}$ & $\begin{array}{r}-.058 \\
(.047)\end{array}$ \\
\hline Extending sequences & & & & $\begin{array}{l}-.014 \\
(.043)\end{array}$ & $\begin{array}{r}-.019 \\
(.043)\end{array}$ \\
\hline Matrices & & & & $\begin{array}{l}.1111^{* * *} \\
(.041)^{2}\end{array}$ & )$_{(.041)}^{.109 \text { *** }}$ \\
\hline Mathematic achievement test early & $\begin{array}{r}-.086 \\
(.065)\end{array}$ & $\begin{array}{c}-.081 \\
(.066)\end{array}$ & $\begin{array}{r}-.078 \\
(.066)\end{array}$ & $\begin{array}{r}-.086 \\
(.065)\end{array}$ & $\begin{array}{r}-.075 \\
(.066)\end{array}$ \\
\hline Constant & $\begin{array}{l}-2.887^{* * *} \\
(.228)\end{array}$ & $\begin{array}{l}-2.787^{* * *} \\
(.291)\end{array}$ & $\begin{array}{l}-2.878 * * * \\
(.296)\end{array}$ & $\begin{array}{l}-2.715^{* * *} \\
(.306)\end{array}$ & $\begin{array}{l}-2.549 \text { *** } \\
(.315)\end{array}$ \\
\hline $\mathrm{N}$ & 797 & 797 & 797 & 797 & 797 \\
\hline $\mathrm{R}^{2}$ & .178 & .180 & .183 & .190 & .198 \\
\hline adjusted $\mathrm{R}^{2}$ & .176 & .173 & .175 & .180 & .185 \\
\hline
\end{tabular}


Notes: The table reports OLS regressions of children's achievement test scores in grade 6 (age 12) on the five number sense factors and controls. The dependent variable are achievement test scores, standardized to a mean of zero, and a standard deviation of one. General cognitive ability is measured as a sum score of 10 items with a maximum of 10. The grade 6 achievement test could be taken at two different points in the school year. "Mathematic achievement test early" takes on the value of 1 in case the student took the test early in the school year. Standard errors are reported in parentheses. Significance levels are reported as follows: .1*,.05**, and .01 ***.

We test the relevance of the identified structure of number sense by regressing students' performance in a mathematical achievement test in the sixth, and last year of primary school on the different measures of number sense. The results are presented in Table 21.

First of all, number sense, defined as a total sum score on all numeric competence items (model 1 ), is relevant for later mathematics skills. It explains 17.6 percent of the variance in a mathematic achievement test six years later. Defining number sense as five basic numeric mathematics competencies (model 2) does not increase the share of explained variance. However, the five factor model allows to distinguish the contribution of each basic numeric competence. The coefficients of all factors except for perceptual matching are significant (all $\mathrm{p}$ $<.01){ }^{65}$ The coefficients of the other factors vary, but do not differ significantly.

The influence of number sense factors remains significant, even when controlling for general cognitive ability (model 3). The estimated coefficients change only slightly. Distinguishing the different types of items within general cognitive ability (model 4), further increases the explained variance to 18 percent. However, only the scores in "similarity", and "matrices" significantly predict mathematical achievement.

Furthermore, we compare the predictive power of the early numeracy test, used for the analysis above, to that of the first curricular test, taken in the middle of the first year in primary school. All later mathematic achievement tests are, one by one, regressed once on the sum score of the first curricular test, once on the sum score of the early numeracy test, and once on the five number sense factors from above. The results in Figure 21 show how the predictive power of each measure changes with the time lag. As expected, the curricular test explains a larger part of the variance of other curricular tests (starting from $\mathrm{R}^{2}=.55$ ). Yet, also the decrease in the fraction of explained variance is more pronounced for the curricular test. The $\mathrm{R}^{2}$ of the early

\footnotetext{
${ }^{65}$ Perceptual matching also relates positively to later mathematic achievement. However, as soon as any three of the other categories are included, the coefficient becomes insignificant (stepwise results not shown here).
} 
Chapter 5: Basic numeric competencies - its Measurement and Predictive Value

numeracy sum score, and the five number sense factors are very similar, and almost constant, starting around .2 and ending at .18 .

Figure 21 Comparing predictive power of early numeracy test and curricular test

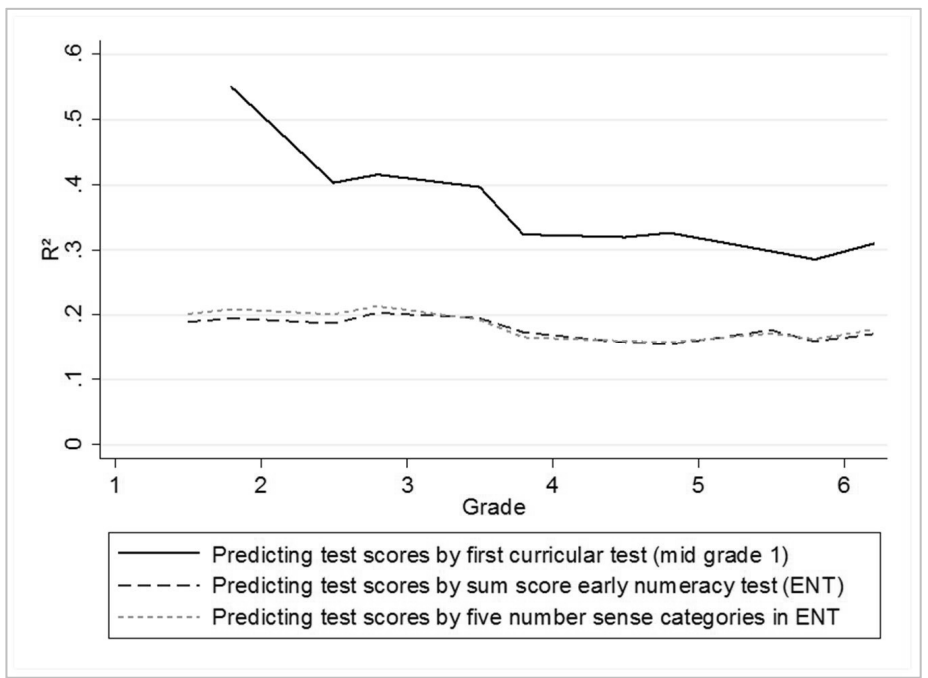

Notes: The line referring to the regressions with the first curricular test as the predictor is based on 10 regressions, one for each of the other mathematic achievement tests in primary school (two per year in grades 1 to 5, one in grade 6). The lines referring to the regressions with the early numeracy test as the predictor are based on 11 regressions, including one for predicting the first curricular test. Tests taken in the middle of the school year are coded as .5 on the grade scale, and tests taken at the end of the school year are coded as .8.

\subsubsection{Robustness check}

The downside of using a pre-existing test is being restricted by the available items. Specifically, the early numeracy test mixes items with different item structures: multiple choice items with three or four options, and open formats, where the children had to draw or underline a certain number of objects. This leads to distinct probabilities with which an answer can be guessed correctly. Theoretically, the answers to items with three answer options are more likely to be guessed correctly, than the answers to items with four provided options. The easier it is to guess correctly, the lower should be the predictive value for later outcomes, considering everything else remaining equal. Since this could distort the analysis, ideally all items, at least within one category, should be kept comparable.

The competencies perceptual matching, and seriation are measured with items of perfectly similar structure. Therefore this concern is solely relevant for non-symbolic number knowledge, 
counting, and symbolic number knowledge. The item characteristic curves based on a twoparameter item response analysis (not shown here) confirm the differences between each two types of questions within each category. Combining them violates the specific objectivity. As a robustness check, we therefore distinguish the different types of questions within each of the three categories, and rerun the regression (Table 21, model 5). This specification further increases the explained variance. In the cases of counting, and symbolic number knowledge only one of the two types of questions remained significant. The observed pattern fits the theoretical predictions perfectly; the sets of items remaining significant predictors have either more answer options, or are open format questions.

\subsection{Concluding discussion}

In two steps, we propose and evaluate the fit, and relevance of a model distinguishing five basic numerical competencies to reflect number sense. Using an existing test, which was administered in Dutch kindergartens, provides us with a strong empirical basis. It enables us to analyze a large sample of more than 3,000 kindergarten children, and a longitudinal sub-sample of 797 children.

First, a confirmatory factor analysis indicates that the proposed theoretical structure fits the empirical data. It clearly supports a more complex five factor model, compared to a simple two, or even one factor model. To our knowledge, this is the first large-scale empirical analysis specifying the internal structure of number sense at the end of kindergarten.

In a second step, we then evaluated the developmental relevance of the internal structure in a longitudinal sub-sample. As our results revealed, basic numerical competencies are relevant in the long-term. Six years after the initial assessment at the end of kindergarten, children's performance in this test on basic numerical competencies still explains more than 17 percent of the variance of a standardized mathematic achievement test. Importantly, this predictive value remains, even when controlling for general cognitive ability, or when distinguishing different types of items. This confirms that the findings of earlier studies (Aunio et al., 2004; Aunio \& Niemivirta, 2010; Jordan et al., 2010; Jordan et al., 2007; Kolkman et al., 2013) extend to longer time spans, larger samples, as well as a natural test setup.

The differentiation of number sense into separate competencies allows to distinguish their specific predictive value. In addition to the other factors, perceptual matching is not significant, indicating that many other studies disregarding it, did not miss an important factor. On the other hand, none of the other coefficients are significantly different from each other. Thus, our results 
Chapter 5: Basic numeric competencies - its Measurement and Predictive Value

do not confirm the dominant role of symbolic, compared to non-symbolic number knowledge, as found in earlier studies (e. g. Kolkman et al., 2013).

While the five factor structure can be confirmed, overall the differentiation does not provide an advantage in predicting later outcomes, compared to the sum score. Thus, sum scores on number skill measures can be well used to predict later overall mathematics outcomes.

Using a pre-existing test provides us with advantages, such as a large number of participants, and six years of longitudinal coverage. However, there are also some downsides to this. First of all, we are restricted by the available items. Because it is a pen, and paper test, some measures, used in the literature to measure number sense in kindergarteners, are not available. This holds for any measures that rely on direct one-on-one interaction with the child, or that assess processes. Especially, counting out loud (e. g. Aubrey et al., 2006; Cirino, 2011; Jordan et al., 2009; Kolkman et al., 2013; Krajewski \& Schneider, 2009; Malofeeva et al., 2004; Passolunghi \& Lanfranchi, 2012; Passolunghi et al., 2007), other tasks of distinguishing different counting principles (e. g. Jordan et al., 2006), or number line tasks on the spatial representation of magnitude (e. g. Geary et al., 2009; Kolkman et al., 2013; Lembke \& Foegen, 2009; Moeller et al., 2009; Nuerk, Geppert, van Herten, \& Willmes, 2002; Sasanguie et al., 2013) are often assessed or theoretically considered. Although not exactly the same, the available items cover all the factors of number sense, which have been identified before (see e. g. Aunio et al., 2004; Aunio \& Niemivirta, 2010; Cirino, 2011; Kolkman et al., 2013).

Thus, even though not constructed for the purpose of measuring number sense, the test used covers many important aspects of number sense. Our results provide a start into large-scale assessment of the number sense structure, as well as its predictive value. To sum up: We propose a theory-led five factor structure for number sense, and confirm it with a factor analysis, based on results of more than 3,000 participants. Furthermore, we showed that four of the five identified factors have predictive value for mathematic achievement at least six years later.

A remaining question is, to what extent specific aspects of number sense predict specific mathematics difficulties later on. For example, Aunio and Niemivirta (2010) point to differential prediction, when further distinguishing later mathematic skills. This could be a path to further investigate the dynamic between number sense factors, and specific mathematic skills, as well as mathematics difficulties. In the long run, such knowledge could help to develop specific interventions based on assessed number sense skills, which help prevent or reduce later mathematic difficulties. 
Conclusion 
Chapter 6: Conclusion

"Aren't you out of place? You are the only one presenting something methodological."

Conference participant, 30th Annual Conference of the European Society of Population Economics

(Berlin, 2016)

Large and very large datasets are becoming more and more normal, in the field of education same as in other fields. This might make us forget that even those data are not perfect. First, large does not mean complete (see Chapter 2 and 3). Second, the more specific the research question is, the higher the data requirements are, and the more selective the sample becomes (see Chapter 2), especially the data collection depends on the collaboration of different actors (Chapter 3). Third, the validity of research findings depends at least as much on the analysis as on the data quality (see Chapter 4 and 5). With the large data that we have now at hand, the remaining datasets after attrition, non-response, and other additional restrictions are still large. Thus, statistically these restrictions do not pose a problem. However, external validity might still be threatened.

Each of the studies compiled in this thesis focuses on the consequences of nuisances in data collected in and via schools. Particularly, it is investigated how the conclusions on research questions regarding intergenerational mobility and skill development might be affected. Issues, such as attrition and non-response bias, are often addressed by the institution administering a survey or a panel, but less often by education researchers themselves. However, as the studies in this thesis show, these issues can also alter the obtained research results. This makes them highly relevant for empirical researchers, as well as policy makers, aiming for evidence-based practice. Thus, despite the above mentioned quote, I felt very much in the right place, when presenting the study in Chapter 2 at the empirically focused Conference of the European Society of Population Economics.

This thesis does not provide "the" answer to avoid distortions in empirical education research. In fact, the data of the OML, which were used in all chapters, are far from perfect themselves. However, the particular strengths of the dataset were used to study some specific aspects in detail. Namely, those strengths include: the close to full coverage population, the longitudinal nature, the detailed information down to results on item-level, the combination of many different data sources, and the opportunity to link the data to administrative information. Many of these features could only be maintained based on good collaboration between researchers, 
supervisory authorities, school boards, and schools. These advantages have been exploited in the four studies. The result are some specific conclusions, regarding the development and assessment of intergenerational mobility, and the skill development, in the age range from 5 to 12. The developed methodologies could be used as a basis for replications and further development

In the following the results of the studies, presented in the four main chapters, are summarized and implications are presented.

\subsection{Main findings and implications}

\subsubsection{Representativeness and selective testing in education data}

In Chapter 2, the data used in the analyses of all the other chapters are introduced and explored. With a yearly coverage rate of 97 percent of regular primary schools in the target region, the OML can be considered an education monitor with close to full population coverage. Combining administrative data, students' test scores, as well as parental and student surveys, makes it a rich dataset. Only, if information from all data sources are required, the data availability reduces to about 40 percent of the cohort. The data source missing most often are parental surveys. In Chapter 3, different types of non-response are distinguished and assessed with respect to their impact on estimates of intergenerational mobility.

General collaboration and data provision on the school level is good. Most fluctuation, with respect to the data provided, is observed across years. Some patterns with respect to data availability can be observed. As a rule of thumb, the more data are available for an individual student, the better the school performance of that student. There are specific regional differences, regarding whether schools provide test score data. This could be either due to a lack of testing, or to the fact that these schools use a computer program with more timeconsuming export options. Roman Catholic schools tend to provide data on a broad basis, while public schools provide less data.

An analysis of potential selective testing in the field of mathematics shows that most schools test more than 80 percent of their student population. Also, the overall time trend points towards more consistent testing. However, in the covered years, between 15 and 38 percent of the schools still do not test all students. An open question is, whether this is due to strategic behavior. Less consistent testing of the student population concentrates in the east and the south of Limburg. On the individual level, about 40 percent of the students take almost all tests, 31 
percent take no test at all. Here as well, problems in the data transmission cannot be excluded as a partial explanation. Students taking all tests perform best, students only taking some tests perform worst. These two groups are referred to in Chapter 4 as the balanced sample and the unbalanced sample (excluding the balanced sample). While some of the questions raised in Chapter 2 are picked up in Chapter 3 and 4, others remain unanswered (see Section 6.2).

At first sight, Chapter 2 might be most useful to researchers that want to work with the OML. However, it is an exemplary analysis and the issues raised are relevant for other datasets as well, particularly in education. In that respect, this chapter can be considered as providing a non-conclusive list of questions regarding the processes underlying of data collection, transmission, and analysis that, once answered, provide deeper insights into a dataset. Furthermore, it could also be helpful to consider these issues when planning the data collection for new surveys.

\subsubsection{Non-response and intergenerational mobility}

In Chapter 3, it is investigated how non-response might bias estimates of intergenerational mobility, specifically the correlation between parental income and school performance of children, at the age of 12 and 15. In a first step, different sources of non-response are uncovered: school non-collaboration in the process of data collection, parental survey non-response, and parental item non-response on the income question. The specific setting and combination with administrative data allowed assessing the biases induced to the estimates. School non-response significantly attenuates the estimated relationship. The bias induced by parental survey nonresponse goes in the same direction, but is not significant at this sample size. Item non-response on the income question, on the other hand, biases the estimates upward. The following nonparticipation patterns can be observed: Especially, schools with high average test scores, but also high intergenerational dependence, do not collaborate in sending out surveys to parents. These schools show on average a lower fraction of students from low socio-economic background, but a higher fraction of first- or second-generation immigrants. Parental survey response on average goes along with a higher school performance of children. Additionally, it relates positively to children speaking the local dialect, and in secondary school, to measures of socio-economic background. Item non-response on income is particularly high for low income families with untypical characteristics, such as high education levels.

The fact that non-response on several levels can bias the estimates of intergenerational mobility raises awareness that this could also be the case for other research results. There are several measures which survey conductors and researchers can take to minimize such distortions. 
Higher level non-response, such as that of schools, can be eliminated by approaching participants as directly as possible. Reminders and offering different means to complete the survey could further help to increase the response rate. Regarding missing item data, it has been recommended in the past to impute missing data based on aggregate characteristics at postal code level. Based on the results shown, this should only be applied after careful consideration, because item non-responders might be untypical residents. In order to make positive recommendations of how to avoid or deal with item non-response, further research is needed (see Section 6.2). In any case, the minimum should be to report openly about the level of nonresponse, as for example, Björklund et al. (2006). In case anything is known about nonresponders compared to responders, this can help to specify for which group the results hold. This is specifically important for policy effects, differentiated by sub-group.

\subsubsection{Measurement error and intergenerational mobility}

Chapter 4 investigates how measurement error might influence correlations between parental education and test scores, and how the influence of measurement error changes with age. Using a series of mathematics tests, we find increasing correlations over the six years of primary education, covering the time span of age 6 to 12. With a structural equation model we investigate in how far this increasing intergenerational dependency is simply driven by changes in measurement error in the tests. In the first four years, the main driver is more precise measurement. While the influence of parental education is first constant or even decreases, it steeply increases shortly before the transition to secondary school. A quantile analysis provides more detailed insights: The overall increase of the parental education coefficient is mostly driven by the middle 50 percent. The specific increase towards the end is mostly driven by the lowest 50 percent of the distribution. An observed reoccurring pattern within the school years suggests an equalizing influence of school during the first three years.

The first and main result, that measurement error is an important driver of increasing correlations strengthens the point, that single correlations are not enough to judge schools and education systems on their contribution to counteract socio-economic dependency of educational outcomes. The applied structural equation model shows robustness with respect to transformations of the test scores as well as the definition of the sample. Uplifting is, that the study is consistent with earlier evidence on school's potential of equalizing socio-economic differences, mostly at the beginning, but also throughout each school year. The finding of a decreasing importance of the error term over the course of primary school urges researchers not to put too much emphasize on early estimates of intergenerational dependence. Furthermore, 
Chapter 6: Conclusion

the results draw policy-makers' attention to the differential importance of incentives induced by high stakes tests, depending on the socio-economic status.

\subsubsection{Number sense and its prediction of mathematic achievement}

In Chapter 5 we investigate an early numeracy test regarding whether several skills can be distinguished, and how later mathematic achievement can be predicted. Based on a confirmatory factor analysis, five factors of number sense can be distinguished: perceptual matching, seriation, counting, non-symbolic, and symbolic number knowledge. This is a more differentiated factor structure than in earlier studies. Regressions show that early numeracy matters for mathematic achievement 6 years later, explaining about 18 percent of the variance. However, the distinction of number sense factors does not add to the predictive power compared to sum-scores. Furthermore, a systematic difference between the analyzed early numeracy test, conducted in kindergarten, and the first curricular test, conducted in primary school, can be confirmed. They show distinct patterns of predicting later curricular achievement tests in mathematics.

The study has implications for economic as well as psychological research. Economists often use simple sum scores of mathematics tests as performance measures, instead of distinguishing more detailed competencies. The results support that this approach is valid for predicting later mathematic achievement and that it does not lead to a loss in explained variance. The implications for psychological research concern the concept of number sense. As the findings strongly suggest, number sense should not be treated as a unitary concept. Further, the factor structure is even more refined than proposed in earlier studies. Based on the identified factors, it might be possible to develop more targeted interventions preventing or diminishing mathematic difficulties (see Section 6.2).

\subsection{Future research}

All the chapters answer some, while raising other questions. Selected aspects of future research based on or related to the different studies are presented in the following.

There are a lot of different reasons why data can be missing in the end. Chapter 2 identified and differentiated several points of decision and technical challenges. However, the downside of this broad focus is the lack of detailed analysis on the individual processes. Non-response in the parental survey, as one identified reason for missing data, has already been answered in Chapter 3. Other questions remain open. One basic question regarding data availability, which 
should be answered first is which schools test more than it is visible in the dataset so far. Such a discrepancy could for example be due to technical difficulties in the data transmission. This requires detailed follow-up with the individual schools. Furthermore, decision-making structures within schools, regarding more or less extensive participation in the OML, could help explaining differences across years. Additionally, the above mentioned results raise two specific research questions: First, whether schools behave strategically, purposely excluding specific students from tests. Second, whether there is a causal relationship between consistent testing and later performance, or whether this observation is the result of selection.

To our knowledge, the study in Chapter 3 is the first to directly assess the impact of nonresponse on estimates of intergenerational mobility. Thus, replications of our approach in different empirical contexts are needed to see whether our results regarding the impact of school, parental, and item non-response generalize. In countries which already provide the opportunity to link administrative data to other data, this should be viable even without new data collections. Furthermore, more research on who answers and who does not answer surveys at all or not completely and under which conditions could help gaining insight in how to prevent or minimize non-response. Our findings suggest, that reminders and different mediums are at least two aspects to consider.

Similarly, regarding Chapter 4, it would be interesting to see comparable results from other empirical contexts or other tests using structural equation modelling to investigate developments of intergenerational dependency. Alternatively, the analysis could be replicated for tests in the domain of language tests. The biggest challenge for both replications will be to find similar series of tests. To see how the observed development continues, the longitudinal coverage would have to be extended to secondary school. Furthermore, the results point to a differential effect of high stakes tests on incentives for students and parents from a high and low socio-economic background. This could be investigated based on the recent policy change in the Netherlands, which led to a decrease in the importance of the Cito test for secondary school placement.

A logical follow-up to Chapter 5 would be to investigate whether performance in aspects of number sense, measured at an early age, relate to difficulties in specific areas of mathematic achievement later. The OML data would be suited for this analysis. Based on these results, targeted interventions for mathematical difficulties could be designed and evaluated. 



\section{Addendum}

Summary and Valorization 
Summary and Valorization

"At this point in our history, [...] we can process exabytes of data at lightning speed, we have the potential to make bad decisions far more quickly, efficiently, and with far greater impact than we did in the past."

Susan Etlinger. What do we do with all this big data? TED@IBM

(San Francisco, 2014)

As stated in the introduction, the aim of this thesis is to understand nuisances and specific features in education data better, as a means to improve empirical research and evidence-based policy making. In the above mentioned quote, Susan Etlinger stresses the importance of being careful not to decouple data generation from data analysis, and therewith, from evidence-based decision-making. This is all the more important, since more and more data become available. However, data out of context lose their value. This holds generally as well as in education.

This thesis investigates the advantages as well as the pitfalls of the broad availability of test scores over the course of a school career and of combining data from different sources. The economics of education research group at Maastricht University and the OnderwijsMonitor Limburg provided the perfect conditions for this purpose. The researchers involved in the design and the realization of the panel study are members of the research group. In the course of writing this thesis, they could answer also detailed questions regarding the local context as well as the process of data collection; some of them were involved as co-authors for a specific study. Strong relationships with the participating schools as well as policy institutions are maintained until today. Additionally, researchers of different disciplines were involved and provided diverse perspectives on the topics. All this allowed to carefully consider and analyze in how far more or less detailed knowledge of the context or more or less extensive series of test scores matter for the results reached. This is what is meant by the sub-title "Test Scores and Beyond".

This addendum provides a summary of the thesis and the implications arising from the results. The overarching research question is in how far we can trust empirical research results in the economics of education field to reflect relationships and in the best case causal links that apply to the whole population. In order to get closer to answering this question, the different chapters investigate several potential flaws of data: selective participation in research and testing (Chapter 2), non-response bias (Chapter 3), measurement error (Chapter 4) or the diverse content of a test and how using sum scores of tests differs from item level data (Chapter 5). 
At first sight this might be quite technical. At a second thought, knowledge about these potential flaws are essential for the link between research and practice via evidence-based innovations or reforms. In the following, the results of the studies compiled in this thesis are summarized and their specific contribution to link research and practice are discussed. The implications are distinguished by relevance for different groups, especially researchers, policy makers, and schools. To end with the most general implications, the order of the chapters is reversed, starting with Chapter 5 and ending with Chapter 2.

Chapter 5 combines economic and psychological research interests in early numeracy skills and has two research questions. It investigates how important it is to have detailed knowledge about the content of an early numeracy test in kindergarten, when predicting later mathematic achievement. This is particularly important, since economists often only use one score as the outcome of a test and disregard differences between items. In order to test, whether differentiation matters, it is first tested, how many different skills can be distinguished. Using an existing test, which was administered in Dutch kindergartens, provides us with a strong empirical basis for this analysis. It enables us to analyze a large sample of more than 3,000 kindergarten children, and a longitudinal sub-sample of 797 children. As a result, five different skills can be distinguished. This differentiation is more detailed than the ones proposed in earlier studies. Taken together, these five early numeracy skills matter for mathematic achievement 6 years later, explaining about 18 percent of the variance. However, whether one sum score or sub-scores for each factor are used for prediction makes almost no difference.

In Math, compared to reading, a lot less is known about early precursors of later achievement. In that sense, the differentiation of early numeracy skills in this study is basic research. Further research could help identify a connection between certain early numeracy skills and later mathematic difficulties. In a third step, this might allow to design targeted and potentially earlier interventions for students with mathematics difficulties.

Beyond this, the study has some direct implications as well. In the economic approach to investigating educational questions tests outcomes are often measured by one sum score. Whether this score adequately represents the skill of interest is rarely empirically supported. The results of Chapter 5 show that, even though a distinction of different early numeric competencies can be made, it does not improve predictive power for a mathematic achievement test six years later. Thus, the results support the practice of using sum scores in early numeric tests to predict later achievement tests. 
Summary and Valorization

Another more general implication stems from the collaborative interdisciplinary approach. The research project, which was the foundation for the data set, was run by an economic research group. The research question and the methodology stem from psychology. Before collaborating, economic researchers did not think about using the data in this way and looking at test scores on item level. Conversely, in this specific field of psychology, researchers had not considered using data of existing tests, rather than conducting their own specific study before. Thus, this study shows how collaboration can open up new opportunities and safe time and money by sharing resources.

Chapter 4 focusses on using test score series to draw conclusions on the development of social mobility. Using a series of comparable mathematics test scores over the course of six years of Dutch primary education, we study how the influence of socio-economic background, measured by the highest parental education level, develops, and how this relates to measurement error. We find that the relationship of parental education level and test scores becomes stronger, measured in terms of increasing correlations. Our results suggest that in the first four years the main driver of this stronger relationship is more precise measurement. When correcting for this, the influence of parental education is first constant or even weakens. However, towards the transition to secondary school it steeply increases. The results of the last regular low stakes test depend most strongly on parental education levels. Performance in the final objective and external test is less dependent on socio-economic background. As we show, correlations are especially vulnerable to the sample composition, while our proposed structural equation model produces very robust estimates. Furthermore, we provide evidence for an equalizing influence of school during the first three years. Additionally, we analyze separate parts of the distribution. Thereby, we uncover that the increase of social inequality later on is mostly driven by students performing below average.

The main implication for researchers and policy makers is to be careful with the identification and attribution of changes in social inequality and social mobility. Not every increase in correlations between the socio-economic background and children's performance relates to an increased dependency. Especially in the first few years of school such an observation is likely to be driven by increased precision in measurement. There are different potential reasons for this: students getting used to the testing situation, ongoing skill development or changes in test length and content, just to name some. Before holding schools responsible for such developments, researchers and policy makers should consider and test these alternative explanations. Otherwise, they might unintentionally punish schools with a disproportionately high fraction of students from a low socio-economic background. 
The study has further implications regarding the design of transitions in education systems. Shortly before the transition to secondary school, students take one more low stakes test, which is graded internally, and one high stakes test, which is graded externally and unknown to the teachers. We find that students' socio-economic background plays a smaller role in determining performance in the latter than in the former test. This supports using objective tests for important transition decisions, rather than tests known, conducted and graded by the teachers. Just recently, Dutch policy makers made the internally graded test more important for the transition decision than the externally graded one. Based on our results, this will likely lead to an increase in social inequality in secondary school placement.

Finally, schools aiming to foster social mobility can use some of the results on the overall development and the within-year pattern of social inequality. Social-inequality seems to evolve in the years before transitions. Thus, this is the time when badly performing students of low socio-economic backgrounds need most support. Additionally, schools could counteract the identified within-year pattern of increasing social inequality over the summer. They could improve social mobility by targeting students from low socio-economic backgrounds directly after the summer holidays or even during the summer holidays, by offering summer programs.

In Chapter 3, we investigate whether and how the fact that not all parents respond to surveys sent out for research purposes influence estimates of intergenerational mobility. Many studies on intergenerational mobility are survey-based and parents' or schools' participation in surveys may be non-random. Additionally, only a specific subset of the responding parents fills in the questions of interest. This holds specifically for sensitive data, such as their income. The problem is that, when the characteristic, in which the survey participation is non-random, is correlated with the relationship of interest, this selection cannot be corrected for by weights. However, usually this issue cannot be investigated, because non-responders are not observed. Linking Dutch survey data to administrative income data, we investigate whether selective response behavior biases the estimated relationship between parental income and children's schooling. We find that the relationship is attenuated because specific schools refuse to participate in the data collection endeavors. Parental survey non-response shifts coefficients in the same direction, but not significantly. Parental item non-response on income questions, on the contrary, biases the estimates upward.

To our knowledge, this is the first study to unveil the effect of non-response on estimates of intergenerational mobility. Thus, it is not clear whether the same results would be found in different contexts. Keeping this in mind, some implications are presented in the following. 


\section{Summary and Valorization}

Our first contribution to survey-based research in intergenerational mobility is, that we identify three different sources of non-response: parental non-response, school non-response and item non-response. We show that they have to be considered separately, because the effects on the estimates of intergenerational mobility are distinct. Contrary to what is often assumed, researchers do not need to worry too much about individual non-response. It leads to an underestimation of the relationship between parental income and student performance. However, the magnitude of the underestimation is smaller than for institutional non-response and in our sample the bias induced by individual non-response is insignificant. This holds, as long as the studies are based on objective income measures, such as administrative information. If subjective measures of income are used, item non-response will likely lead to a severe overestimation of social mobility.

The non-response rates of published studies on intergenerational mobility are substantial (among the ones cited in Chapter 3 up to 42 percent) and also access to administrative data is no guarantee for a full sample. If biases due to non-response are not taken into account, the results might be misleading. Our results give insights in whether to expect an over- or underestimation and provide an order of magnitude. In conclusion, this study helps to judge empirical evidence on social mobility with respect to parental income. If the parents report their income themselves, the results should be considered to be a lower bound. If an objective measure of parental income is available, the estimated relationship between parental income and student performance is more likely an upper bound.

Chapter 2 provides the introduction to the data set used in all other chapters, the education monitor Limburg, to be exemplary for complex data sets in education. As often in education, it relies on a number of different data sources. Among them are test scores, which are increasingly used to assess and compare student and school performance. As is shown, the completeness of survey and test score data depends crucially on the collaboration of a number of different actors. However, with a specific research question in mind, quality and representativeness of the data often fade into the background. In particular, we examine how representative the participating schools and the covered student population are, as well as how selective schools test and provide test scores.

The main implication is not to take data as granted. The first step should always be understanding the data. We provide an example analysis and a framework to start with. What is the context (region, education system)? How were the data collected? Which different data sources were combined? What is the population of interest? How well is it covered? How 
representative is the coverage? What are reasons for missing values - do they not exist, have they not been collected? If the latter is the case, who did not participate? We also cannot not answer all these questions in detail. However, we show that posing them contributes to a better understanding of the data and sometimes even raises new research questions on its own. Every data analysis is only as good as the contextual knowledge it is based upon.

Thus, organizations who conduct surveys should provide extensive contextual information. However, they have an incentive to promote their product as best as possible. Admitting high non-response rates or other flaws, which are important for the interpretation, collides with this. Consequently, those who pay for the surveys (government agencies, universities or in other contexts foundations or corporations) should ask for these details and those who use the data (researchers, policy-makers) should do the same. Researchers, if involved in the design of the survey, can also directly contribute to this.

Another important set of contributors to good data in education are schools. Testing and participating in research and doing this fully increases the validity and thereby the value of that research. However, there is a limit to what schools can do beyond their primary task. Thus, along with this goes an appeal to researchers and policy makers to collaborate in data collection, to bundle their efforts for data quality and to share the resulting data. 



\section{Appendices}

\section{Appendix: Chapter 2}

Table A.1 Availability of data on school level

\begin{tabular}{|c|c|c|c|c|c|c|c|c|c|c|c|c|c|c|}
\hline \multicolumn{3}{|c|}{ Admin. } & \multicolumn{3}{|c|}{ Cito } & \multicolumn{3}{|c|}{ LVS } & \multicolumn{3}{|c|}{ Parent Q. } & \multicolumn{3}{|c|}{ Student Q. } \\
\hline & $\mathrm{N}$ & $\%$ & & $\mathrm{~N}$ & $\%$ & & $\mathrm{~N}$ & $\%$ & & $\mathrm{~N}$ & $\%$ & & $\mathrm{~N}$ & $\%$ \\
\hline \multirow[t]{16}{*}{ yes } & 224 & $97.39 \%$ & yes & 214 & $93.04 \%$ & yes & 199 & $86.52 \%$ & yes & 198 & $86.09 \%$ & yes & 197 & $85.65 \%$ \\
\hline & & & & & & & & & & & & no & 1 & $0.43 \%$ \\
\hline & & & & & & & & & no & 1 & $0.43 \%$ & yes & 1 & $0.43 \%$ \\
\hline & & & & & & & & & & & & no & 0 & $0.00 \%$ \\
\hline & & & & & & no & 15 & $6.52 \%$ & yes & 15 & $6.52 \%$ & yes & 15 & $6.52 \%$ \\
\hline & & & & & & & & & & & & no & 0 & $0.00 \%$ \\
\hline & & & & & & & & & no & 0 & $0.00 \%$ & yes & 0 & $0.00 \%$ \\
\hline & & & & & & & & & & & & no & 0 & $0.00 \%$ \\
\hline & & & no & 10 & $4.35 \%$ & yes & 3 & $1.30 \%$ & yes & 3 & $1.30 \%$ & yes & 3 & $1.30 \%$ \\
\hline & & & & & & & & & & & & no & 0 & $0.00 \%$ \\
\hline & & & & & & & & & $\overline{\text { no }}$ & 0 & $0.00 \%$ & yes & 0 & $0.00 \%$ \\
\hline & & & & & & & & & & & & no & 0 & $0.00 \%$ \\
\hline & & & & & & no & 7 & $3.04 \%$ & yes & 2 & $0.87 \%$ & yes & 2 & $0.87 \%$ \\
\hline & & & & & & & & & & & & no & 0 & $0.00 \%$ \\
\hline & & & & & & & & & no & 5 & $2.17 \%$ & yes & 1 & $0.43 \%$ \\
\hline & & & & & & & & & & & & no & 4 & $1.74 \%$ \\
\hline \multirow[t]{17}{*}{ no } & 6 & $2.61 \%$ & yes & 6 & $2.61 \%$ & yes & 0 & $0.00 \%$ & yes & 0 & $0.00 \%$ & yes & 0 & $0.00 \%$ \\
\hline & & & & & & & & & & & & no & 0 & $0.00 \%$ \\
\hline & & & & & & & & & no & 0 & $0.00 \%$ & yes & 0 & $0.00 \%$ \\
\hline & & & & & & & & & & & & no & 0 & $0.00 \%$ \\
\hline & & & & & & no & 6 & $2.61 \%$ & yes & 0 & $0.00 \%$ & yes & 0 & $0.00 \%$ \\
\hline & & & & & & & & & & & & no & 0 & $0.00 \%$ \\
\hline & & & & & & & & & no & 6 & $2.61 \%$ & yes & 0 & $0.00 \%$ \\
\hline & & & & & & & & & & & & no & 6 & $2.61 \%$ \\
\hline & & & no & 0 & $0.00 \%$ & yes & 0 & $0.00 \%$ & yes & 0 & $0.00 \%$ & yes & 0 & $0.00 \%$ \\
\hline & & & & & & & & & & & & no & 0 & $0.00 \%$ \\
\hline & & & & & & & & & no & 0 & $0.00 \%$ & yes & 0 & $0.00 \%$ \\
\hline & & & & & & & & & & & & no & 0 & $0.00 \%$ \\
\hline & & & & & & no & 0 & $0.00 \%$ & yes & 0 & $0.00 \%$ & yes & 0 & $0.00 \%$ \\
\hline & & & & & & & & & & & & no & 0 & $0.00 \%$ \\
\hline & & & & & & & & & no & 0 & $0.00 \%$ & yes & 0 & $0.00 \%$ \\
\hline & & & & & & & & & & & & no & 0 & $0.00 \%$ \\
\hline & 224 & $97.39 \%$ & & 220 & $95.65 \%$ & & 202 & $87.83 \%$ & & 218 & $94.78 \%$ & & 219 & $95.22 \%$ \\
\hline Total & & & & & & & & & & & & & 230 & \\
\hline
\end{tabular}


Appendices

Table A.2 Availability of data on school-year level

\begin{tabular}{|c|c|c|c|c|c|c|c|c|c|c|c|c|c|c|}
\hline & \multicolumn{2}{|c|}{ Admin. } & \multicolumn{3}{|c|}{ Cito } & \multicolumn{3}{|c|}{ LVS } & \multicolumn{3}{|c|}{ Parent Q. } & \multicolumn{3}{|c|}{ Student Q. } \\
\hline & $\mathrm{N}$ & $\%$ & & $\mathrm{~N}$ & $\%$ & & $\mathrm{~N}$ & $\%$ & & $\mathrm{~N}$ & $\%$ & & v & $\%$ \\
\hline \multirow[t]{16}{*}{ yes } & 1,355 & $94.16 \%$ & yes & 1,289 & $89.58 \%$ & yes & 1,002 & $69.63 \%$ & yes & 955 & $66.37 \%$ & yes & 955 & $66.37 \%$ \\
\hline & & & & & & & & & & & & no & 0 & $0.00 \%$ \\
\hline & & & & & & & & & no & 47 & $3.27 \%$ & yes & 0 & $0.00 \%$ \\
\hline & & & & & & & & & & & & no & 47 & $3.27 \%$ \\
\hline & & & & & & no & 287 & $19.94 \%$ & yes & 266 & $18.49 \%$ & yes & 266 & $18.49 \%$ \\
\hline & & & & & & & & & & & & no & 0 & $0.00 \%$ \\
\hline & & & & & & & & & no & 21 & $1.46 \%$ & yes & 0 & $0.00 \%$ \\
\hline & & & & & & & & & & & & no & 21 & $1.46 \%$ \\
\hline & & & no & 66 & $4.59 \%$ & yes & 24 & $1.67 \%$ & yes & 20 & $1.39 \%$ & yes & 20 & $1.39 \%$ \\
\hline & & & & & & & & & & & & no & 0 & $0.00 \%$ \\
\hline & & & & & & & & & no & 4 & $0.28 \%$ & yes & 0 & $0.00 \%$ \\
\hline & & & & & & & & & & & & no & 4 & $0.28 \%$ \\
\hline & & & & & & no & 42 & $2.92 \%$ & yes & 28 & $1.95 \%$ & yes & 28 & $1.95 \%$ \\
\hline & & & & & & & & & & & & no & 0 & $0.00 \%$ \\
\hline & & & & & & & & & no & 14 & $0.97 \%$ & yes & 0 & $0.00 \%$ \\
\hline & & & & & & & & & & & & no & 14 & $0.97 \%$ \\
\hline \multirow[t]{17}{*}{ no } & 84 & $5.84 \%$ & yes & 79 & $5.49 \%$ & yes & 48 & $3.34 \%$ & yes & 0 & $0.00 \%$ & yes & 0 & $0.00 \%$ \\
\hline & & & & & & & & & & & & no & 0 & $0.00 \%$ \\
\hline & & & & & & & & & no & 48 & $3.34 \%$ & yes & 0 & $0.00 \%$ \\
\hline & & & & & & & & & & & & no & 48 & $3.34 \%$ \\
\hline & & & & & & no & 31 & $2.15 \%$ & yes & 0 & $0.00 \%$ & yes & 0 & $0.00 \%$ \\
\hline & & & & & & & & & & & & no & 0 & $0.00 \%$ \\
\hline & & & & & & & & & no & 31 & $2.15 \%$ & yes & 0 & $0.00 \%$ \\
\hline & & & & & & & & & & & & no & 31 & $2.15 \%$ \\
\hline & & & no & 5 & $0.35 \%$ & yes & 5 & $0.35 \%$ & yes & 0 & $0.00 \%$ & yes & 0 & $0.00 \%$ \\
\hline & & & & & & & & & & & & no & 0 & $0.00 \%$ \\
\hline & & & & & & & & & no & 5 & $0.35 \%$ & yes & 0 & $0.00 \%$ \\
\hline & & & & & & & & & & & & no & 5 & $0.35 \%$ \\
\hline & & & & & & no & 0 & $0.00 \%$ & yes & 0 & $0.00 \%$ & yes & 0 & $0.00 \%$ \\
\hline & & & & & & & & & & & & no & 0 & $0.00 \%$ \\
\hline & & & & & & & & & no & 0 & $0.00 \%$ & yes & 0 & $0.00 \%$ \\
\hline & & & & & & & & & & & & no & 0 & $0.00 \%$ \\
\hline & 1,355 & $94.16 \%$ & & 1,368 & $95.07 \%$ & & 1,079 & $74.98 \%$ & & 1,269 & $88.19 \%$ & & 1,269 & $88.19 \%$ \\
\hline Tota & & & & & & & & & & & & & 1,439 & \\
\hline
\end{tabular}


Appendix: Chapter 2

Table A.3 Availability of data on individual student level

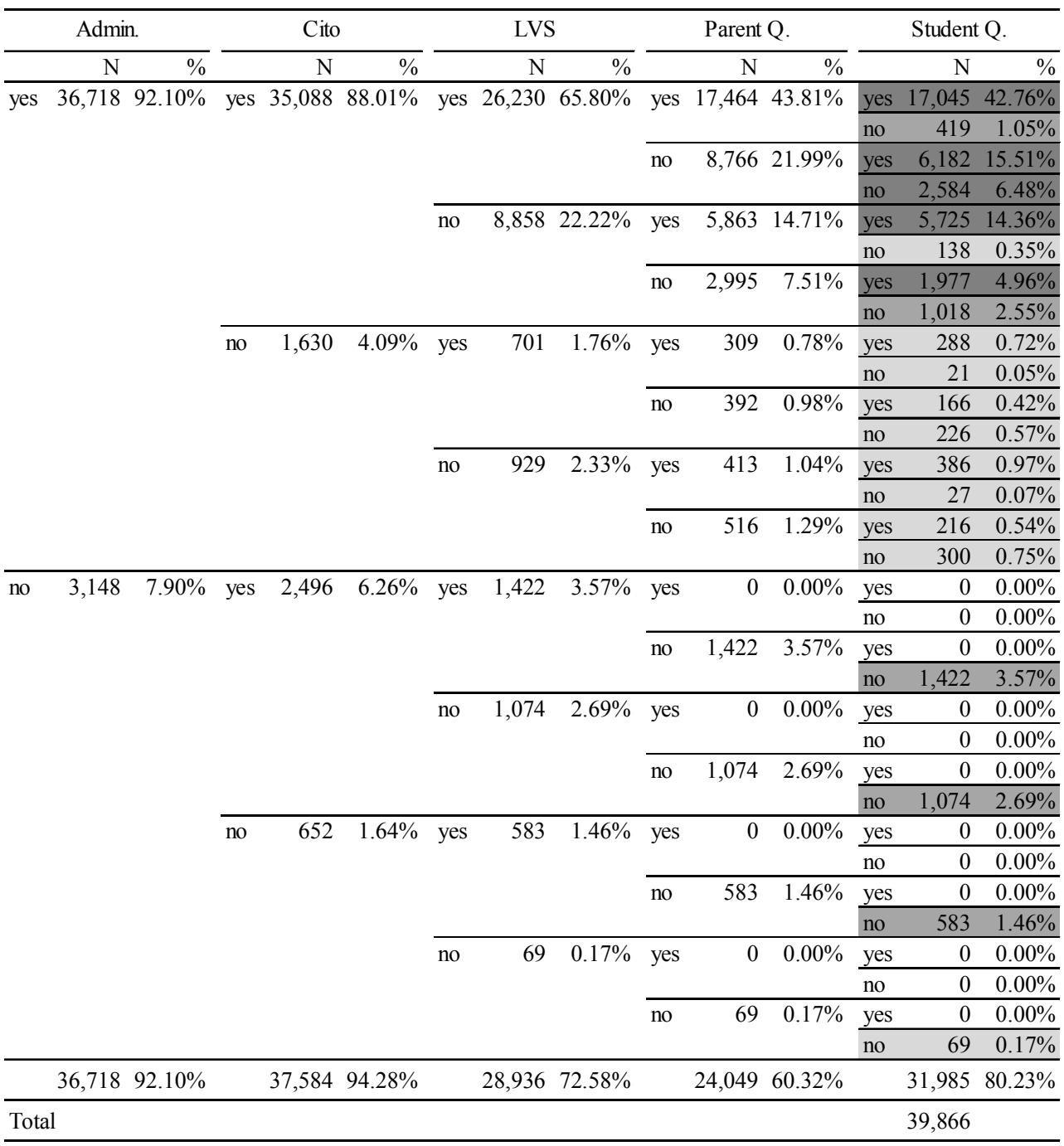



Appendix: Chapter 3

\section{Appendix: Chapter 3}

Table A.4 Descriptive statistics for students without administrative data

\begin{tabular}{|c|c|c|c|c|c|c|c|c|c|}
\hline \multirow[b]{4}{*}{ Variable } & \multicolumn{9}{|c|}{ Survey participation status } \\
\hline & \multirow{2}{*}{\multicolumn{3}{|c|}{$\begin{array}{c}\text { (1) } \\
\text { Survey participation }\end{array}$}} & \multicolumn{3}{|c|}{ (2) } & \multicolumn{3}{|c|}{ (3) } \\
\hline & & & & Schoo & non-resp & onse & Parent & 1 non-res & ponse \\
\hline & $\mathrm{N}$ & mean & $\mathrm{sd}$ & $\mathrm{N}$ & mean & $\mathrm{sd}$ & $\mathrm{N}$ & mean & $\mathrm{sd}$ \\
\hline Age (in years in grade six) & 510 & 12.26 & .59 & 50 & 12.28 & .64 & 277 & 12.36 & .62 \\
\hline Gender (fraction male) & 511 & .51 & .50 & 50 & .63 & .49 & 278 & .60 & .49 \\
\hline Low ses (fraction) & 512 & .19 & .39 & 50 & .02 & .14 & 279 & .18 & .38 \\
\hline Migration background (fraction) & 511 & .18 & .38 & . & . & . & . & . & \\
\hline Highest parental education (1-5) & 491 & 3.04 & 1.06 & . & . & . & . & . & \\
\hline Total Income (1-5) & . & . & . & . & . & . & . & . & \\
\hline Corrected Income (1-5) & . & . & . & . & . & . & . & . & \\
\hline Cito test score $(500-550)$ & 512 & 534.16 & 9.24 & 50 & 536.36 & 8.67 & 279 & 533.42 & 10.00 \\
\hline Language test, grade 9 (stand.) & 512 & 74.00 & 11.71 & 50 & 76.52 & 10.42 & 279 & 71.83 & 13.12 \\
\hline Mathematics test, grade 9 (stand.) & 512 & 69.17 & 17.74 & 50 & 73.66 & 17.27 & 279 & 68.25 & 18.37 \\
\hline \multirow[t]{2}{*}{ General cognitive ability $(0-43)$} & 499 & 31.84 & 4.84 & - & - & - & 166 & 31.39 & 4.67 \\
\hline & 512 & & & 50 & & & 229 & & \\
\hline
\end{tabular}

Notes: The table reports the number of observations, the mean values and the standard deviations for the listed variables by response status on the parental survey in grade 6 at age 12 for all students who could not be merged to administrative data from the income registry. The different sub-samples (1), (2), and (3) are mutually exclusive. Age is based on the students' month-exact age at the beginning of grade 6, their final year in primary education. Gender takes on the value 1 for male students. "Low ses" is an indication used and provided by the school administration. Schools receive extra funding in case the fraction of students indicated as "low ses" exceeds a certain threshold. It is 1 if one or both of the parents did not complete secondary education (this indication is comparable to the "free lunch" indication in the US). A child is considered to have a migration background if at least one parent has not been born in the Netherlands. Parental education level relies on a self-reported measure and is therefore only available when the parental survey was filled in. It is coded in terms of the five levels defined in the International Standard Classification of Education (ISCED). Corrected income is reported on the household level in terms of quintiles relative to the complete Dutch population. It is based on the income register at 31 December 2008. The Cito test score reflects the overall score including sections on language, mathematics and study skills. The information provided on the sub-sections language and mathematics are reported in percent of questions answered correctly. Blanks indicate that the data source of this variable is not available for that particular group. Dashes indicate that the values are not reported due to privacy regulations of Statistics Netherlands. 


\section{Appendices}

Table A.5 Regression results for full sample with interactions, baseline sample grade 6

\begin{tabular}{|c|c|c|c|c|c|c|}
\hline & \multicolumn{6}{|c|}{ Test scores } \\
\hline & $\begin{array}{c}(1) \\
\text { Cito test }\end{array}$ & $\begin{array}{c}\text { (2) } \\
\text { Cito test }\end{array}$ & $\begin{array}{c}\text { (3) } \\
\text { Language } \\
\text { (sub-section) }\end{array}$ & $\begin{array}{c}\text { (4) } \\
\text { Language } \\
\text { (sub-section) }\end{array}$ & $\begin{array}{c}\text { (5) } \\
\text { Mathematics } \\
\text { (sub-section) }\end{array}$ & $\begin{array}{c}\text { (6) } \\
\text { Mathematics } \\
\text { (sub-section) }\end{array}$ \\
\hline School (S) non-response & $\begin{array}{l}-.231 * \\
(.133)\end{array}$ & $\begin{array}{l}-.231 \\
(.145)\end{array}$ & $\begin{array}{l}-.193 \\
(.134)\end{array}$ & $\begin{array}{l}-.193 * \\
(.110)\end{array}$ & $\begin{array}{l}-.224 * \\
(.134)\end{array}$ & $\begin{array}{l}-.224 \\
(.143)\end{array}$ \\
\hline Parental (P) non-response & $\begin{array}{l}-.165 * \\
(.092)\end{array}$ & $\begin{array}{l}-.165 \\
(.106)\end{array}$ & $\begin{array}{l}-.172 * \\
(.093)\end{array}$ & $\begin{array}{l}-.172 * \\
(.099)\end{array}$ & $\begin{array}{r}-.108 \\
(.094)\end{array}$ & $\begin{array}{l}-.108 \\
(.096)\end{array}$ \\
\hline Income quintile & $\begin{array}{l}.147^{* * *} \\
(.014)\end{array}$ & $\begin{array}{l}.147^{* * *} \\
(.014)\end{array}$ & $\begin{array}{l}.143 * * * \\
(.014)\end{array}$ & $\begin{array}{l}.143 * * * \\
(.014)\end{array}$ & $\begin{array}{l}.124 * * * \\
(.014)\end{array}$ & $\begin{array}{l}.124 * * * \\
(.014)\end{array}$ \\
\hline Income * S non-response & $\begin{array}{l}.086 * * \\
(.038)\end{array}$ & $\begin{array}{l}.0866^{* * *} \\
(.032)\end{array}$ & $\begin{array}{l}.081 * * \\
(.039)\end{array}$ & $\begin{array}{l}.081 * * * \\
(.029)\end{array}$ & $\begin{array}{l}.073 * \\
(.039)\end{array}$ & $\begin{array}{l}.073 * * \\
(.033)\end{array}$ \\
\hline Income * $\mathrm{P}$ non-response & $\begin{array}{r}.007 \\
(.029)\end{array}$ & $\begin{array}{r}.007 \\
(.031)\end{array}$ & $\begin{array}{r}.013 \\
(.029)\end{array}$ & $\begin{array}{r}.013 \\
(.030)\end{array}$ & $\begin{array}{l}-.004 \\
(.029)\end{array}$ & $\begin{array}{l}-.004 \\
(.028)\end{array}$ \\
\hline Controls & $\mathrm{X}$ & $\mathrm{X}$ & $\mathrm{X}$ & $\mathrm{X}$ & $\mathrm{X}$ & $\mathrm{X}$ \\
\hline Clustered s. e. & & $\mathrm{X}$ & & $\mathrm{X}$ & & $\mathrm{X}$ \\
\hline $\mathrm{R}^{2}$ & .152 & .152 & .136 & .136 & .130 & .130 \\
\hline $\mathrm{N}$ & 3,699 & 3,699 & 3,699 & 3,699 & 3,699 & 3,699 \\
\hline
\end{tabular}

Notes: The table reports OLS regressions of children's Cito test scores on parental income. The dependent variables are (1) overall Cito test scores and respectively sub-scores on the (2) language and (3) mathematics section, standardized to a mean of zero and a standard deviation of one. Income refers to the corrected income. Each regression includes controls for a number of gender, students' month-exact age, and indicators of low socioeconomic status as well as of being a first or second generation immigrant. Standard errors are reported in parentheses. Significance levels are reported as follows: .1 $*, .05 * *$, and $.01 * * *$. 
Table A.6 Regression results for full sample with interactions, sub-sample grade 9

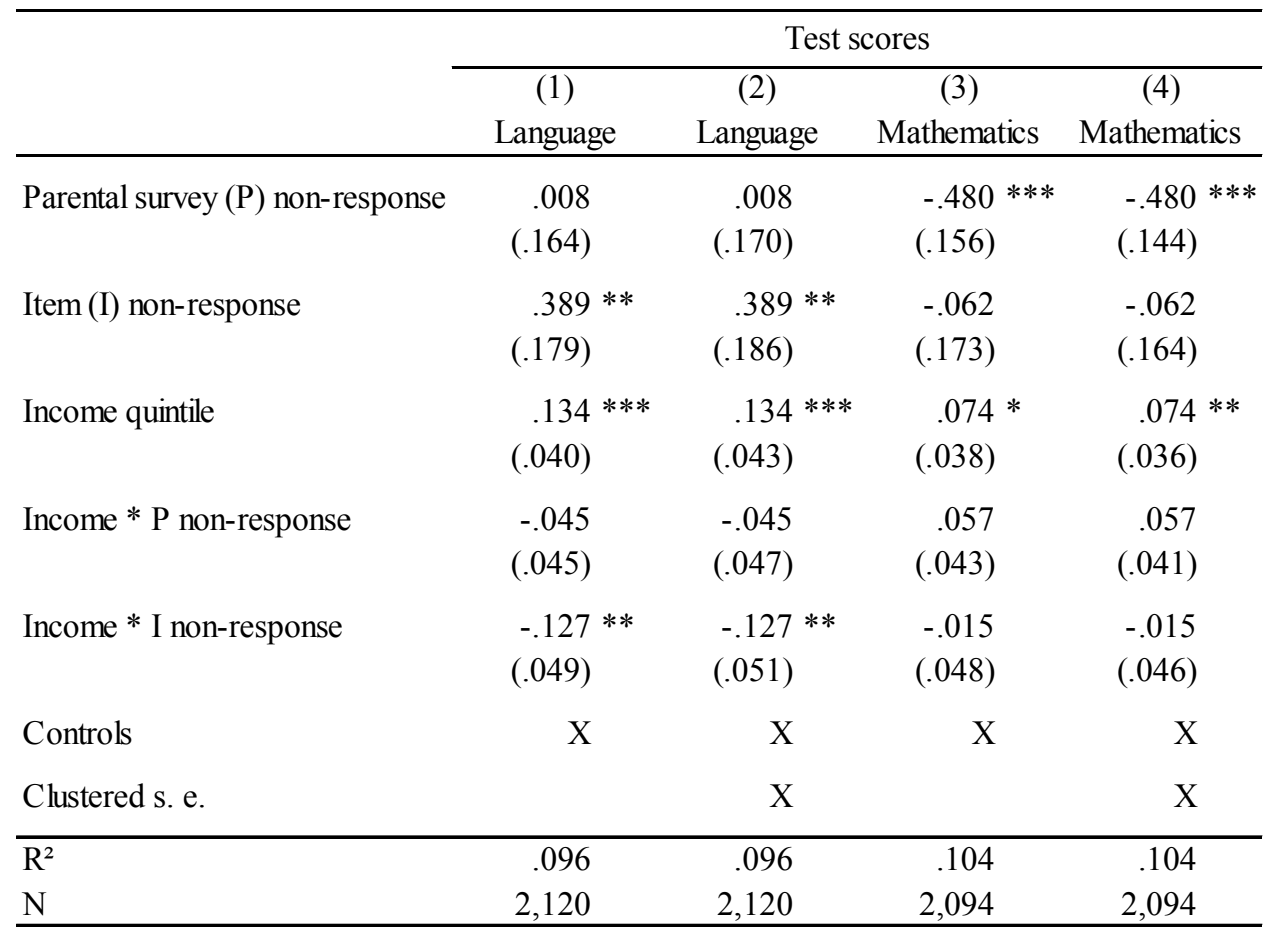

Notes: The table reports OLS regressions of children's Cito test scores on parental income. The dependent variables are (1) overall Cito test scores and respectively sub-scores on the (2) language and (3) mathematics section, standardized to a mean of zero and a standard deviation of one. Income refers to the corrected income. Each regression includes controls for a number of gender, students' month-exact age and indicators of low socioeconomic status as well as of being a first or second generation immigrant. Standard errors are reported in parentheses. Significance levels are reported as follows: .1 $* .05 * *$, and $.01 * * *$. 


\section{Appendices}

Table A.7 Regression of school survey response on aggregate characteristics

\begin{tabular}{|c|c|c|c|}
\hline & \multicolumn{3}{|c|}{ School survey response } \\
\hline & $(1)$ & $(2)$ & (3) \\
\hline Gender (fraction, males) & $\begin{array}{r}-.292 \\
(1.194)\end{array}$ & $\begin{array}{r}-.696 \\
(1.321)\end{array}$ & $\begin{array}{r}-.943 \\
(1.381)\end{array}$ \\
\hline Low ses (fraction) & $\begin{array}{r}1.470 \\
(1.481)\end{array}$ & $\begin{array}{r}1.974 \\
(1.829)\end{array}$ & $\begin{array}{r}1.599 \\
(1.834)\end{array}$ \\
\hline Migration background (fraction) & $\begin{array}{r}-.977 \\
(1.595)\end{array}$ & $\begin{array}{r}-.921 \\
(1.765)\end{array}$ & $\begin{array}{r}-.696 \\
(1.864)\end{array}$ \\
\hline Income quintile 2 (fraction) & $\begin{array}{r}3.019 \\
(2.114)\end{array}$ & $\begin{array}{c}4.868 * \\
(1.555)\end{array}$ & $\begin{array}{c}5.171 \text { * } \\
(2.676)\end{array}$ \\
\hline Income quintile 3 (fraction) & $\begin{array}{r}-.249 \\
(1.788)\end{array}$ & $\begin{array}{r}.191 \\
(2.010)\end{array}$ & $\begin{array}{r}.427 \\
(2.162)\end{array}$ \\
\hline Income quintile 4 (fraction) & $\begin{array}{r}1.111 \\
(1.835)\end{array}$ & $\begin{array}{r}1.118 \\
(2.088)\end{array}$ & $\begin{array}{r}1.135 \\
(2.214)\end{array}$ \\
\hline Income quintile 5 (fraction) & $\begin{array}{r}.548 \\
(1.946)\end{array}$ & $\begin{array}{r}.164 \\
(2.166)\end{array}$ & $\begin{array}{r}.348 \\
(2.230)\end{array}$ \\
\hline Cito test score (500-550), average & $\begin{array}{r}-.007 \\
(.061)\end{array}$ & $\begin{array}{r}.006 \\
(.065)\end{array}$ & $\begin{array}{r}.004 \\
(.066)\end{array}$ \\
\hline Cito test score (500-550), standard deviation & $\begin{array}{c}-.029 \\
(.106)\end{array}$ & $\begin{array}{l}-.036 \\
(.117)\end{array}$ & $\begin{array}{l}-.026 \\
(.119)\end{array}$ \\
\hline Correlation: income quintile \& Cito test score & & & $\begin{array}{l}-.502 \\
(.673)\end{array}$ \\
\hline Location: Westelijke Mijnstreek & & $\begin{array}{l}2.179 * * \\
(.995)\end{array}$ & $\begin{array}{l}2.353 * * \\
(1.033)\end{array}$ \\
\hline Location: Parkstad & & $\begin{array}{l}1.278 \\
(.872)\end{array}$ & $\begin{array}{l}1.412 \\
(.891)\end{array}$ \\
\hline Location: Maastricht / Heuvelland & & $\begin{array}{l}2.049 * * * \\
(.933)\end{array}$ & $\begin{array}{l}2.194 * * \\
(.966)\end{array}$ \\
\hline Pseudo $\mathrm{R}^{2}$ & .069 & .163 & .170 \\
\hline $\mathrm{N}$ & 174 & 171 & 170 \\
\hline
\end{tabular}

Notes: The table reports coefficients of probit regressions. The dependent variable is school survey response. The independent variables include: the fraction of male students, the fraction of students with at least one parent, who did not complete secondary education; the fraction of students, who are first or second generation immigrants; the fraction of students, belonging to households of the indicated income quintile, based on the corrected income; the average, the standard deviation of the Cito score and the correlation between income quintile and Cito test scores within each school; and indicators for the location of the school (the baseline being north Limburg). Standard errors are reported in parentheses. Significance levels are reported as follows: .1*,.05**, and .01***. 
Appendix: Chapter 3

Table A.8 Regression of parental survey response on individual characteristics

\begin{tabular}{|c|c|c|c|c|c|c|}
\hline & \multicolumn{6}{|c|}{ Parental survey response } \\
\hline & \multicolumn{3}{|c|}{ Baseline survey, grade 6 (age 12) } & \multicolumn{3}{|c|}{ Sub-sample, grade 9 (age 15) } \\
\hline & $(1)$ & $(2)$ & (3) & (4) & $(5)$ & $(6)$ \\
\hline Gender $($ male $=1)$ & $\begin{array}{l}-.013 \\
(.049)\end{array}$ & $\begin{array}{l}-.013 \\
(.049)\end{array}$ & $\begin{array}{r}.002 \\
(.055)\end{array}$ & $\begin{array}{l}-.053 \\
(.049)\end{array}$ & $\begin{array}{l}-.008 \\
(.049)\end{array}$ & $\begin{array}{l}-.027 \\
(.055)\end{array}$ \\
\hline Low ses & $\begin{array}{l}-.099 \\
(.077)\end{array}$ & $\begin{array}{l}-.072 \\
(.077)\end{array}$ & $\begin{array}{l}-.132 \\
(.085)\end{array}$ & $\begin{array}{l}-.431 * * * \\
(.088)\end{array}$ & $\begin{array}{l}-.377 \text { *** } \\
(.090)\end{array}$ & $\begin{array}{l}-.440 * * * \\
(.100)\end{array}$ \\
\hline Migration background & $\begin{array}{l}-.241 * * * \\
(.069)\end{array}$ & $\begin{array}{l}-.237 * * * \\
(.069)\end{array}$ & $\begin{array}{l}-.131 * \\
(.078)\end{array}$ & $\begin{array}{l}-.327 * * * \\
(.075)\end{array}$ & $\begin{array}{l}-.355 * * * \\
(.075)\end{array}$ & $\begin{array}{l}-.329 * * * \\
(.086)\end{array}$ \\
\hline Income quintile 2 & $\begin{array}{r}.091 \\
(.078)\end{array}$ & $\begin{array}{r}.097 \\
(.079)\end{array}$ & $\begin{array}{r}.079 \\
(.088)\end{array}$ & $\begin{array}{l}.256 * * * \\
(.086)\end{array}$ & $\begin{array}{l}.262 * * * \\
(.086)\end{array}$ & $\begin{array}{l}.307^{* * *} \\
(.094)\end{array}$ \\
\hline Income quintile 3 & $\begin{array}{r}.071 \\
(.081)\end{array}$ & $\begin{array}{r}.062 \\
(.081)\end{array}$ & $\begin{array}{r}.045 \\
(.090)\end{array}$ & $\begin{array}{l}.159^{*} \\
(.085)\end{array}$ & $\begin{array}{l}.151 \\
(.086)\end{array}$ & $\begin{array}{r}.085 \\
(.095)\end{array}$ \\
\hline Income quintile 4 & $\begin{array}{r}.103 \\
(.082)\end{array}$ & $\begin{array}{r}.087 \\
(.083)\end{array}$ & $\begin{array}{r}.041 \\
(.092)\end{array}$ & $\begin{array}{l}.354 \text { *** } \\
(.086)\end{array}$ & $\begin{array}{l}.298 * * * \\
(.087)\end{array}$ & $\begin{array}{l}.306 \text { *** } \\
(.096)\end{array}$ \\
\hline Income quintile 5 & $\begin{array}{r}.125 \\
(.091)\end{array}$ & $\begin{array}{r}.112 \\
(.092)\end{array}$ & $\begin{array}{r}.125 \\
(.104)\end{array}$ & $\begin{array}{l}.342 * * * \\
(.092)\end{array}$ & $\begin{array}{l}.272 * * * \\
(.093)\end{array}$ & $\begin{array}{l}.321 \text { *** } \\
(.103)\end{array}$ \\
\hline Cito test score (500-550) & $\begin{array}{l}.011 \text { *** } \\
(.003)\end{array}$ & $\begin{array}{l}.012 \text { *** } \\
(.003)\end{array}$ & $\begin{array}{l}.010 \text { *** } \\
(.003)\end{array}$ & $\begin{array}{l}.0144^{* * *} \\
(.003)\end{array}$ & $\begin{array}{l}-.012 * * \\
(.005)\end{array}$ & $\begin{array}{l}-.014 * * \\
(.005)\end{array}$ \\
\hline Language \& mathematics, grade 9 & & & & & $\begin{array}{r}.247 \\
(.163)\end{array}$ & $\begin{array}{l}.267 * * \\
(.181)\end{array}$ \\
\hline Track: pre-vocational (VMBO g / t) & & & & & $\begin{array}{l}.162 * \\
(.086)\end{array}$ & $\begin{array}{r}.128 \\
(.095)\end{array}$ \\
\hline Track: higher general (HAVO) & & & & & $\begin{array}{l}.533 * * * \\
(.100)\end{array}$ & $\begin{array}{l}.554^{* * *} \\
(.110)\end{array}$ \\
\hline Track: academic (VWO) & & & & & $\begin{array}{l}.698 * * * \\
(.121)\end{array}$ & $\begin{array}{l}.739 * * * \\
(.133)\end{array}$ \\
\hline Location: Westelijke Mijnstreek & & $\begin{array}{l}-.493 * * \\
(.232)\end{array}$ & $\begin{array}{l}-.256 \\
(.250)\end{array}$ & & & $\begin{array}{l}-.093 \\
(.172)\end{array}$ \\
\hline Location: Parkstad & & $\begin{array}{l}-.507 * * \\
(.230)\end{array}$ & $\begin{array}{l}-.396 \\
(.247)\end{array}$ & & & $\begin{array}{c}-.096 \\
(.170)\end{array}$ \\
\hline Location: Heuvelland & & $\begin{array}{l}-.280 \\
(.234)\end{array}$ & $\begin{array}{l}-.174 \\
(.252)\end{array}$ & & & $\begin{array}{r}.005 \\
(.173)\end{array}$ \\
\hline Location: Maastricht & & $\begin{array}{l}-.502 * * \\
(.238)\end{array}$ & $\begin{array}{l}-.470 * \\
(.256)\end{array}$ & & & $\begin{array}{r}-.180 \\
(.184)\end{array}$ \\
\hline Speaking dialect well & & & $\begin{array}{l}.255^{* * *} \\
(.059)\end{array}$ & & & $\begin{array}{l}.1311^{* *} \\
(.058)\end{array}$ \\
\hline Pseudo $\mathrm{R}^{2}$ & .015 & .020 & .031 & .043 & .055 & .071 \\
\hline $\mathrm{N}$ & 3,328 & 3,321 & 3,034 & 2,813 & 2,813 & 2,349 \\
\hline
\end{tabular}

Notes: The table reports coefficients of probit regressions. The dependent variable is parental survey response. The independent variables included for both samples are: a variable indicating the student to be male, an indicator for students, having at least one parent, who did not complete secondary education; an indicator for students being first or second generation immigrants; indicators for the quintile of corrected income the households belongs to; the student's Cito test score; indicators for the location of the school (with the baseline being north Limburg); and an indicator for speaking the local dialect well. Additionally, for the sub-sample of secondary school students, a combined performance measure of the language and mathematics test in grade 9, as well as indicators for the attended track level (the baseline being the two lower pre-vocational tracks, VMBO b/k), are included. Standard errors are reported in parentheses. Significance levels are reported as follows: .1*,.05**, and .01***. 


\section{Appendices}

Table A.9 Regression of parental item response on individual characteristics

\begin{tabular}{|c|c|c|c|c|}
\hline & \multicolumn{4}{|c|}{ Parental item response } \\
\hline & $(1)$ & $(2)$ & (3) & $(4)$ \\
\hline Gender $($ male $=1)$ & $\begin{array}{r}-.135 \\
(.104)\end{array}$ & $\begin{array}{l}-.127 \\
(.105)\end{array}$ & $\begin{array}{r}-.061 \\
(.116)\end{array}$ & $\begin{array}{c}-.098 \\
(.137)\end{array}$ \\
\hline Low ses & $\begin{array}{r}-.067 \\
(.224)\end{array}$ & $\begin{array}{r}-.034 \\
(.230)\end{array}$ & $\begin{array}{r}.041 \\
(.257)\end{array}$ & $\begin{array}{r}-.273 \\
(.313)\end{array}$ \\
\hline Migration background & $\begin{array}{r}.053 \\
(.175)\end{array}$ & $\begin{array}{r}.044 \\
(.175)\end{array}$ & $\begin{array}{r}.017 \\
(.195)\end{array}$ & $\begin{array}{r}.061 \\
(.233)\end{array}$ \\
\hline Income quintile 2 & $\begin{array}{r}.130 \\
(.201)\end{array}$ & $\begin{array}{r}.113 \\
(.202)\end{array}$ & $\begin{array}{r}.200 \\
(.222)\end{array}$ & $\begin{array}{r}.333 \\
(.275)\end{array}$ \\
\hline Income quintile 3 & $\begin{array}{r}.310 \\
(.199)\end{array}$ & $\begin{array}{r}.299 \\
(.199)\end{array}$ & $\begin{array}{l}.471 \text { ** } \\
(.222)\end{array}$ & $\begin{array}{l}.609 \text { ** } \\
(.276)\end{array}$ \\
\hline Income quintile 4 & $\begin{array}{r}.258 \\
(.192)\end{array}$ & $\begin{array}{r}.229 \\
(.193)\end{array}$ & $\begin{array}{r}.321 \\
(.214)\end{array}$ & $\begin{array}{r}.274 \\
(.261)\end{array}$ \\
\hline Income quintile 5 & $\begin{array}{l}.559 * * * \\
(.200)\end{array}$ & $\begin{array}{l}.5344^{* * *} \\
(.201)\end{array}$ & $\begin{array}{l}.663 * * * \\
(.223)\end{array}$ & $\begin{array}{l}.972 * * * \\
(.271)\end{array}$ \\
\hline Cito test score (500-550) & $\begin{array}{l}.018 * * \\
(.007)\end{array}$ & $\begin{array}{r}.010 \\
(.011)\end{array}$ & $\begin{array}{r}.012 \\
(.012)\end{array}$ & $\begin{array}{r}.010 \\
(.014)\end{array}$ \\
\hline Language test, grade 9 (stand.) & $\begin{array}{r}-.040 \\
(.061)\end{array}$ & $\begin{array}{l}-.047 \\
(.062)\end{array}$ & $\begin{array}{l}-.040 \\
(.068)\end{array}$ & $\begin{array}{r}-.070 \\
(.082)\end{array}$ \\
\hline Mathematics test, grade 9 (stand.) & $\begin{array}{r}-.020 \\
(.061)\end{array}$ & $\begin{array}{c}-.038 \\
(.064)\end{array}$ & $\begin{array}{l}-.045 \\
(.071)\end{array}$ & $\begin{array}{r}-.119 \\
(.086)\end{array}$ \\
\hline Track: pre-vocational (VMBO g / t) & & $\begin{array}{r}.145 \\
(.208)\end{array}$ & $\begin{array}{r}.169 \\
(.223)\end{array}$ & $\begin{array}{r}.085 \\
(.276)\end{array}$ \\
\hline Track: higher general (HAVO) & & $\begin{array}{r}.134 \\
(.232)\end{array}$ & $\begin{array}{r}.129 \\
(.250)\end{array}$ & $\begin{array}{r}.226 \\
(.305)\end{array}$ \\
\hline Track: academic (VWO) & & $\begin{array}{r}.299 \\
(.274)\end{array}$ & $\begin{array}{r}.202 \\
(.297)\end{array}$ & $\begin{array}{r}.272 \\
(.363)\end{array}$ \\
\hline Location: Westelijke Mijnstreek & & & $\begin{array}{r}.122 \\
(.326)\end{array}$ & $\begin{array}{r}.489 \\
(.403)\end{array}$ \\
\hline Location: Parkstad & & & $\begin{array}{r}.023 \\
(.320)\end{array}$ & $\begin{array}{r}.365 \\
(.397)\end{array}$ \\
\hline Location: Heuvelland & & & $\begin{array}{r}-.078 \\
(.325)\end{array}$ & $\begin{array}{r}.046 \\
(.399)\end{array}$ \\
\hline Location: Maastricht & & & $\begin{array}{l}-.054 \\
(.353)\end{array}$ & $\begin{array}{r}.107 \\
(.430)\end{array}$ \\
\hline Speaking dialect well & & & $\begin{array}{l}-.061 \\
(.123)\end{array}$ & $\begin{array}{r}.096 \\
(.148)\end{array}$ \\
\hline Response to first / online survey & & & & $\begin{array}{l}1.982 \text { *** } \\
(.149)\end{array}$ \\
\hline$\overline{\text { Pseudo } \mathrm{R}^{2}}$ & .028 & .030 & .032 & .350 \\
\hline $\mathrm{N}$ & 650 & 650 & 548 & 548 \\
\hline
\end{tabular}

Notes: The table reports coefficients of probit regressions. The dependent variable is parental item response. The independent variables included are: a variable indicating male students, an indicator for students, having at least one parent, who did not complete secondary education; an indicator for students being first or second generation immigrants; indicators for the quintile of corrected income the households belongs to; the student's Cito test score; z-standardized performance measures of the language and mathematics tests in grade 9; indicators for the attended track level (the baseline being the two lower pre-vocational tracks, VMBO b/k); indicators for the location of the school (with the baseline being north Limburg); and an indicator for speaking the local dialect well. Standard errors are reported in parentheses. Significance levels are reported as follows: .1 $*, .05 * *$, and $.01 * * *$. 
Appendix: Chapter 3

Figure A.1 Language test distributions by survey response status, sub-sample grade 9

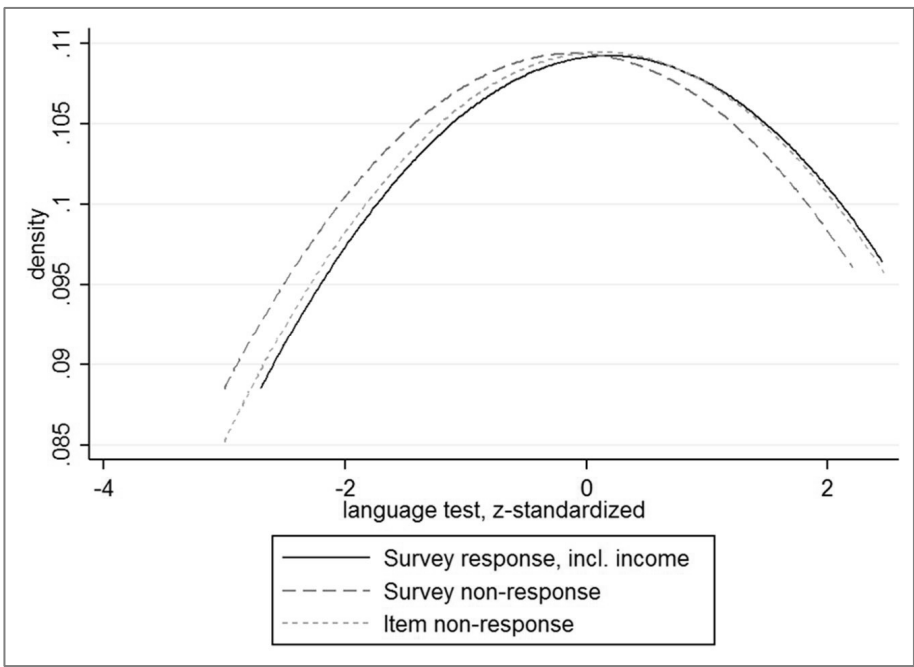

Notes: This graph shows the distribution of students' language achievement test, standardized to a mean of zero and a standard deviation of one. It is based on all students for whom data could be merged with administrative household information, who could be found back in grade 9 and took the language achievement test. The group with responding parents who answered the income question relates to column (1) from Table 13, the group with non-responding parents correspond to column (2), and responding parents who did not answer the income question, the item non-response group, relate to column (3). 


\section{Appendices}

Figure A.2 Mathematics test distributions by survey response status, sub-sample grade 9

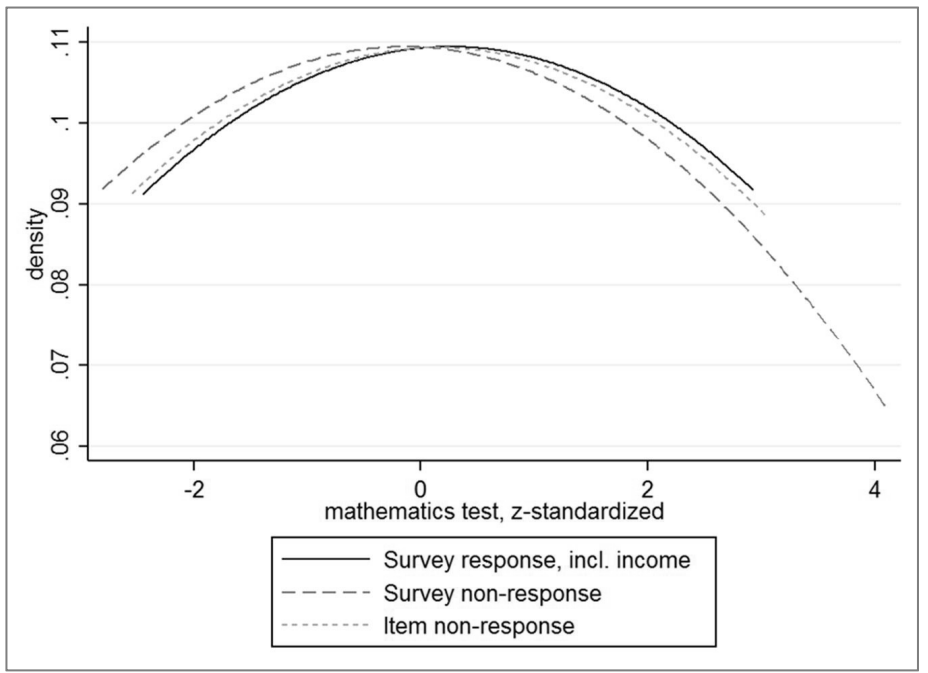

Notes: This graph shows the distribution of students' mathematics achievement test, standardized to a mean of zero and a standard deviation of one. It is based on all students for whom data could be merged with administrative household information, who could be found back in grade 9 and took the language achievement test. The group with responding parents who answered the income question relates to column (1) from Table 13, the group with responding parents who did not answer the income question, non-responding parents correspond to column (2), and the item non-response group, relates to column (2). 
Appendix: Chapter 3

Figure A.3 Box plots of mathematics test by survey response and income, sample grade 9

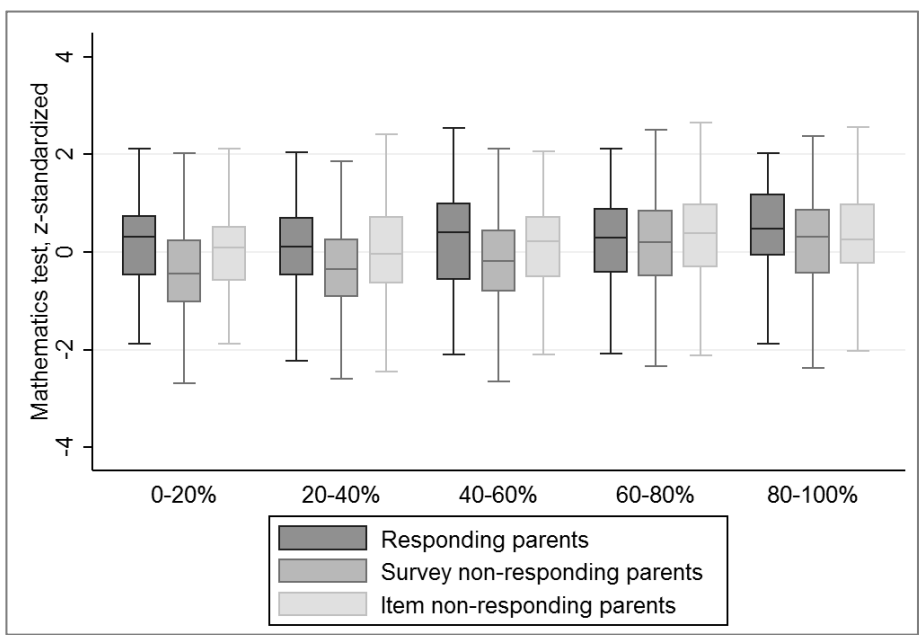

Notes: Box plots for mathematics test results in grade 9 , displayed by survey response status and income quintile. The boxes are drawn around the median, indicated by the line in the box, and show the interquartile range, from the 25 th percentile to the 75 th percentile. The whiskers show the span of the data points. Their maximum length is 1.5 times the interquartile range. Data points outside this span are usually displayed separately. In accordance with the policy on non-disclosure of individual data by Statistics Netherlands the Figure does not include those outside values. In this case those were 20 observations. The graph is based on 425 students whose parents participated in the survey, including the income question, 717 students whose parents responded to the survey without reporting the household income and 1,527 students whose parents did not return the survey. 

Appendix: Chapter 4

\section{Appendix: Chapter 4}

Table A.10 Correlations of parental education level with Cito and PIAAC test

\begin{tabular}{lcrr}
\hline & \multicolumn{3}{c}{ Sub-sections of the tests } \\
\cline { 2 - 4 } Test, sample & Language / literacy & Mathematics & $\begin{array}{r}\text { Problem solving / } \\
\text { study skills }\end{array}$ \\
\hline Cito test, population of OLM & .326 & .276 & .301 \\
PIAAC test, Dutch adults & .330 & .290 & .318 \\
\hline
\end{tabular}

Table A.11 Descriptive statistics for tests, based on unbalanced sample

\begin{tabular}{lrrrrr}
\hline Test & $\mathrm{N}$ & mean & sd & $\min$ & $\max$ \\
\hline Grade 1, mid-year & 5,216 & 36.79 & 4.87 & 10 & 42 \\
Grade 1, end-year & 5,214 & 45.06 & 6.31 & 11 & 53 \\
Grade 2, mid-year & 4,291 & 47.19 & 7.81 & 3 & 58 \\
Grade 2, end-year & 4,163 & 46.56 & 8.29 & 4 & 60 \\
Grade 3, mid-year & 4,259 & 53.00 & 9.61 & 6 & 79 \\
Grade 3, end-year & 3,899 & 58.39 & 11.21 & 11 & 78 \\
Grade 4, mid-year & 3,868 & 74.43 & 14.36 & 14 & 100 \\
Grade 4, end-year & 3,614 & 77.37 & 14.94 & 18 & 104 \\
Grade 5, mid-year & 3,570 & 81.51 & 15.78 & 12 & 109 \\
Grade 5, end-year & 2,367 & 76.85 & 15.29 & 11 & 105 \\
Grade 6, mid-year & 3,125 & 79.88 & 17.02 & 9 & 107 \\
Grade 6, cito math section & 6,350 & 73.92 & 17.03 & 15 & 100 \\
$\quad$ (in percentiles) & & & & & \\
\hline
\end{tabular}




\section{Appendices}

Figure A.4 Average Cito mathematics score for changing part of the unbalanced sample

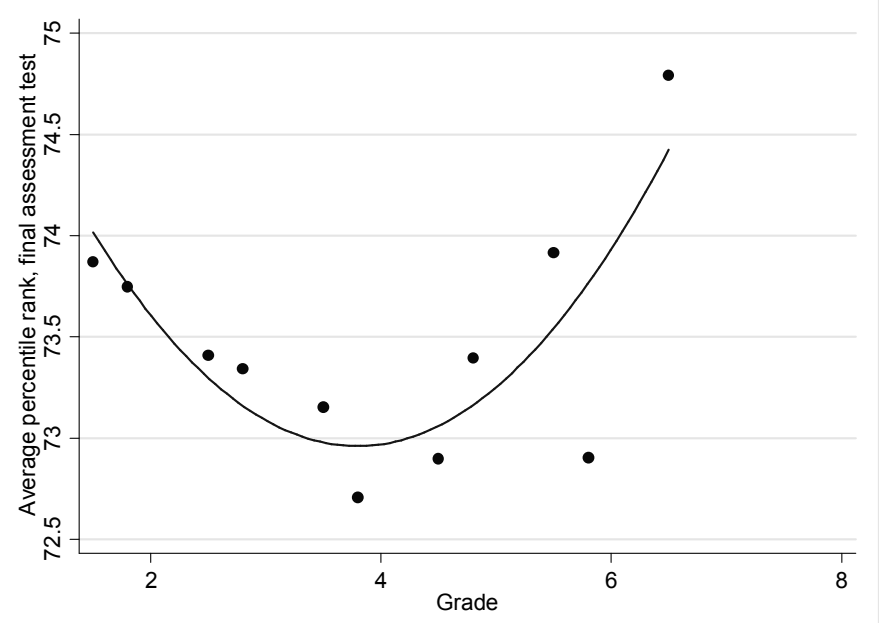

Notes: Each data point denotes the average Cito mathematics score of a different group: for each of the eleven low stakes tests the data basis consists of all students participating in that test, while not participating in all tests. 
Appendix: Chapter 4

Figure A.5 Coefficients of separate regressions, mathematic ability from Cito test

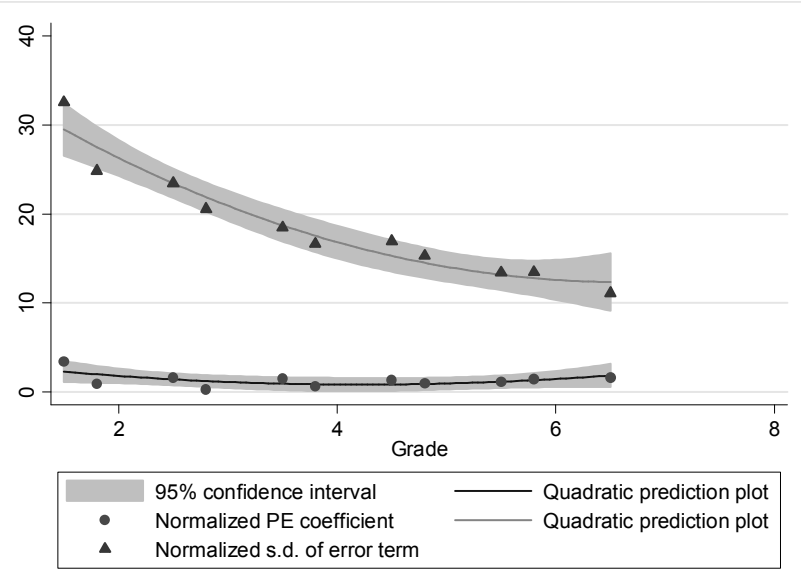

Notes: All regressions are based on the balanced sample. Each mathematics score was regressed on PE and mathematic ability. Mathematic ability was defined as percentile rank in the Cito test mathematics section. The coefficients have been normalized by the respective coefficient for mathematic ability. The graphs only show eleven coefficients each. The Cito test was left out, because it was used as a measure for mathematic ability.

Figure A.6 Coefficients of separate regressions, mathematic ability from sem

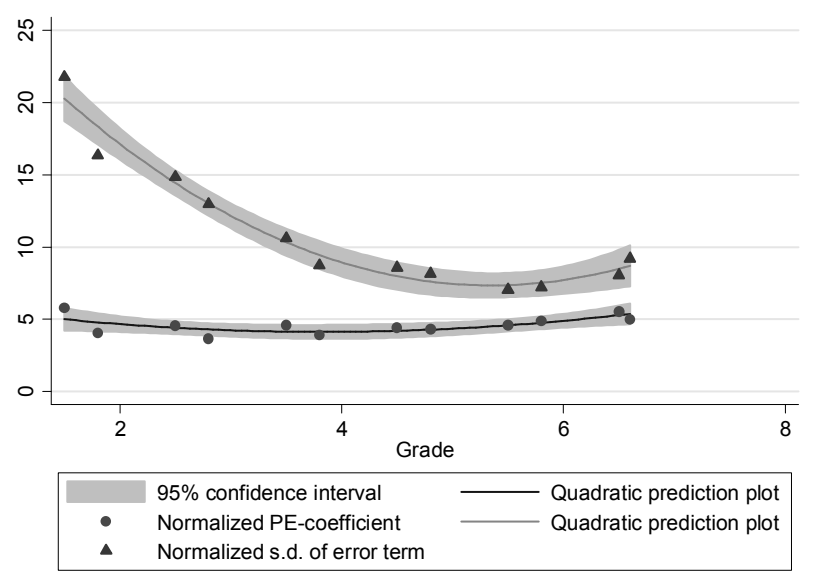

Notes: All regressions are based on the balanced sample. Each mathematics score was regressed on PE and mathematic ability. Mathematic ability was calculated beforehand in a structural equation model (sem). The coefficients have been normalized by the respective coefficient for mathematic ability. 


\section{Appendices}

The structural equation model (sem) introduced to estimate the coefficients for all twelve equations simultaneously uses, in addition to the within test score variance, also the covariances between the different dependent variables. In our case this allows the estimation of the latent variable MATH based on all available tests and improves the estimates of the magnitude of the error term. For the simple case of three tests and with some assumptions, the coefficients can be easily calculated by hand, using only the observed values from the variance-covariance matrix.

For convenience we simplify Equation 2 as follows: The subscript $i$ for the individual is left out and the variable names were simplified to $m$ for mathematic ability and $s$ for highest parental education level.

$$
Y_{t}=\alpha_{t}+\beta_{t} m+\gamma_{t} s+\varepsilon_{t}
$$

In addition we assume mathematic ability and parental education background not to be independent and we also do not allow the error terms of different tests to be correlated. Irrespective of whether these assumptions are realistic or not, here they serve the purpose of having a simple model for demonstrating the underlying calculations of the structural equation model. In the model used in the analysis we relaxed these assumptions.

Table 12 shows how the variance-covariance matrix of the test scores and the variable for parental education level relate to the coefficients, error terms, and variances of $m$ and $s$ under these assumptions. 
Table A.12 Variance-covariance matrix of test scores and socio-economic background

\begin{tabular}{|c|c|c|c|c|}
\hline & Y1 & Y2 & Y3 & S \\
\hline Y1 & $\begin{array}{l}\beta_{1}^{2} \operatorname{var}(m) \\
+\gamma_{1}^{2} \operatorname{var}(s) \\
+\operatorname{var}\left(\varepsilon_{1}\right)\end{array}$ & & & \\
\hline Y2 & $\begin{array}{l}\beta_{1} \beta_{2} \operatorname{var}(m) \\
+\gamma_{1} \gamma_{2} \operatorname{var}(s)\end{array}$ & $\begin{array}{l}\beta_{2}^{2} \operatorname{var}(m) \\
+\gamma_{2}^{2} \operatorname{var}(s) \\
+\operatorname{var}\left(\varepsilon_{2}\right)\end{array}$ & & \\
\hline Y3 & $\begin{array}{l}\beta_{1} \beta_{3} \operatorname{var}(m) \\
+\gamma_{1} \gamma_{3} \operatorname{var}(s)\end{array}$ & $\begin{array}{l}\beta_{2} \beta_{3} \operatorname{var}(m) \\
+\gamma_{2} \gamma_{3} \operatorname{var}(s)\end{array}$ & $\begin{array}{l}\beta_{3}^{2} \operatorname{var}(m) \\
+\gamma_{3}^{2} \operatorname{var}(s) \\
+\operatorname{var}\left(\varepsilon_{3}\right)\end{array}$ & \\
\hline $\mathrm{S}$ & $\gamma_{1} \operatorname{var}(s)$ & $\gamma_{2} \operatorname{var}(s)$ & $\gamma_{3} \operatorname{var}(s)$ & $\operatorname{var}(s)$ \\
\hline
\end{tabular}

Setting the variance of $m$ to unity and observing the variance of $s$ directly nine variables remain to be calculated based on nine equations.

$$
\begin{gathered}
\operatorname{var}(m)=1 \\
\operatorname{var}(s)=\operatorname{var}(s) \\
\gamma_{1}=\frac{\operatorname{cov}\left(Y_{1}, s\right)}{\operatorname{var}(s)}, \gamma_{2}=\frac{\operatorname{cov}\left(Y_{2}, s\right)}{\operatorname{var}(s)}, \gamma_{3}=\frac{\operatorname{cov}\left(Y_{3}, s\right)}{\operatorname{var}(s)} \\
\beta_{1} \beta_{2}=\operatorname{cov}\left(Y_{1} Y_{2}\right)-\frac{\operatorname{cov}\left(Y_{1}, s\right) \operatorname{cov}\left(Y_{2}, s\right)}{\operatorname{var}(s)}
\end{gathered}
$$

Under the assumption of $\operatorname{var}(m)=1$, Equation 7 denotes the part of $\operatorname{cov}\left(Y_{1}, Y_{2}\right)$ that is based on the variance in mathematic ability. This holds for $\beta_{1} \beta_{2}$ and $\beta_{1} \beta_{2}$ respectively. These three measures can then be used to calculate the mathematic ability component of the test variance $\operatorname{var}\left(Y_{1}\right)$ (see Equation 8). The square root of this measure provides is the coefficient for mathematic ability. 
Appendices

$$
\beta_{1}^{2}=\frac{\beta_{1} \beta_{2} * \beta_{1} \beta_{3}}{\beta_{2} \beta_{3}}
$$

The parental education component of the test variance can be calculated directly from the covariance of the test with $s$ and the variance of $s$, which both can be found in the variance covariance matrix. The remaining error component is what is left of the overall test variance after accounting for the components going back to mathematic ability and parental education level.

$$
\begin{aligned}
& \gamma_{1}^{2} \operatorname{var}(s)=\frac{\operatorname{cov}\left(Y_{1}, s\right)^{2}}{\operatorname{var}(s)} \\
& \operatorname{var}\left(\varepsilon_{1}\right)=\operatorname{var}\left(Y_{1}\right)-\gamma_{1}^{2} \operatorname{var}(s)-\beta_{1}^{2}
\end{aligned}
$$

Applying those formulas to the data yields exactly the same results as running a structural equation model under the assumptions made. 


\section{Appendix: Chapter 5}

Figure A.7 Generic item examples

$$
\text { a) }
$$

Look at the figure with the line below. Which figure is exactly the same? Draw a line below.
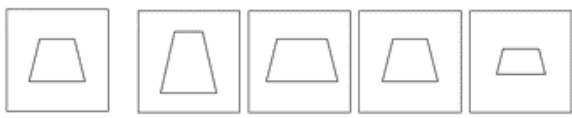

b)

Here you see three sets of trees. In which set are the trees sorted from small to large? Draw a line below.

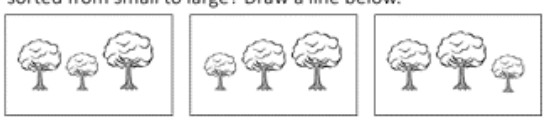

c)

Look at the box with the line below. In which of the other boxes are more clouds? Draw a line below that box.

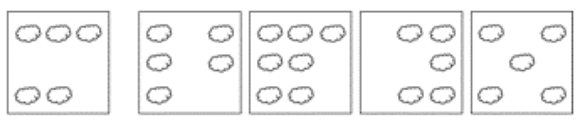

f)

Look at the figure with the line below. This figure is hidden in one of the other line drawings. If you find the line drawing with this figure, draw a line below.
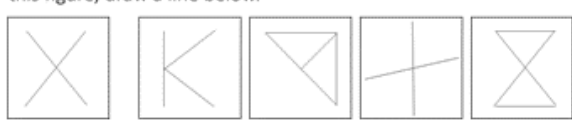

g)

Here you see different objects. Which object does not belong to the others? Draw a line below that object.

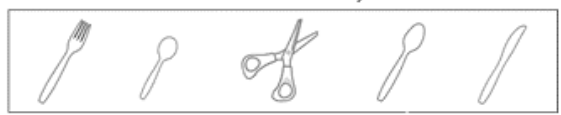

d)

Draw a line below the third bell.

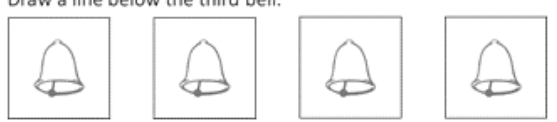

e)

Draw a line below the six.

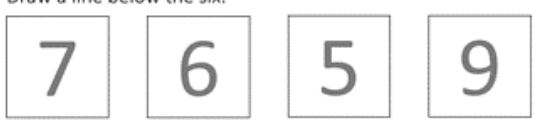

h)

Here you see a neclace. It is not complete yet. Which bead do I have to add next? Draw a line below that bead.

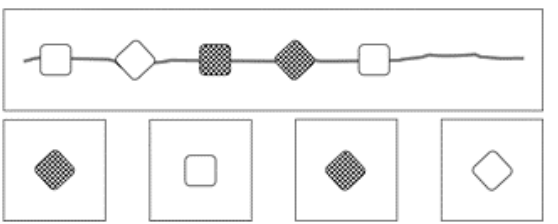

i)

Look at the stars. Which box has to be in the empty spot? Draw a line below the box.

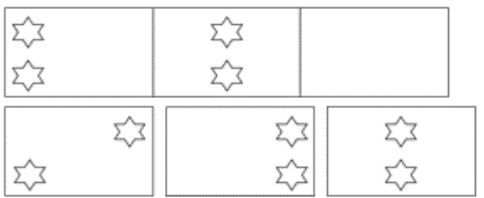

Notes: Items a to $g$ are generic examples for items measuring the following basic numerical competencies: perceptual matching (a), seriation (b), non-symbolic number knowledge (c), counting (d), symbolic number knowledge (e). Items (f) to (i) are generic examples for items measuring general cognitive abilities: similarity (f), classification (g), extending sequences (h), matrices (i). 



\section{References}

Assel, M. A., Landry, S. H., Swank, P., Smith, K. E., \& Steelman, L. M. (2003). Precursors to mathematical skills: Examining the roles of visual-spatial skills, executive processes, and parenting factors. Applied Developmental Science, 7(1), 27-38.

Aubrey, C., Godfrey, R., \& Dahl, S. (2006). Early mathematics development and later achievement: Further evidence. Mathematics Education Research Journal, 18(1), 27-46.

Aunio, P., Ee, J., Lim, S. E. A., Hautamäki, J., \& Van Luit, J. (2004). Young children's number sense in Finland, Hong Kong and Singapore. International Journal of Early Years Education, 12(3), 195-216.

Aunio, P., \& Niemivirta, M. (2010). Predicting children's mathematical performance in grade one by early numeracy. Learning and Individual Differences, 20(5), 427-435.

Aunola, K., Leskinen, E., Lerkkanen, M.-K., \& Nurmi, J.-E. (2004). Developmental Dynamics of Math Performance From Preschool to Grade 2. Journal of Educational Psychology, 96(4), 699-713.

Bee, C. A., Gathright, G., \& Meyer, B. D. (2016). Non-Response Bias in the measurement of income: Evidence from Address Linked Tax Records. Unpublished manuscript, presented at SOLE 2016.

Berch, D. B. (2005). Making sense of number sense implications for children with mathematical disabilities. Journal of Learning Disabilities, 38(4), 333-339.

Bielby, W. T., Hauser, R. M., \& Featherman, D. L. (1977). Response errors of black and nonblack males in models of the intergenerational transmission of socioeconomic status. American Journal of Sociology, 82(6), 1242-1288.

Björklund, A., Lindahl, M., \& Plug, E. (2006). The origins of intergenerational associations: Lessons from Swedish adoption data. The Quarterly Journal of Economics, 121(3), 999-1028.

Black, S. E., \& Devereux, P. J. (2011). Recent developments in intergenerational mobility. Handbook of labor economics, 4, 1487-1541.

Black, S. E., Devereux, P. J., \& Salvanes, K. G. (2005). Why the Apple Doesn't Fall Far: Understanding Intergenerational Transmission of Human Capital. American Economic Review, 95(1), 437-449.

Blau, D. M. (1999). The effect of income on child development. Review of Economics and Statistics, 81(2), 261276.

Bollen, K. A. (1990). Overall fit in covariance structure models: two types of sample size effects. Psychological Bulletin, 107(2), 256-259.

Bond, T. N., \& Lang, K. (2013). The evolution of the Black-White test score gap in grades K-3: The fragility of results. Review of Economics and Statistics, 95(5), 1468-1479.

Borghans, L., Korthals, R., \& Schils, T. (2015). The effect of track placement on cognitive and non-cognitive skills. Unpublished Manuscript. Maastricht University.

Borghans, L., \& Schils, T. (2012). The leaning tower of Pisa: decomposing achievement test scores into cognitive and noncognitive components. Paper presented at the 2012 NBER Summer Institute in Education Economics, Cambridge.

Buitelaar, R., Ros, B., Vink, A., \& van der Kroft, L. (2013). Eindtoets PO: Het verdriet van Cito. Retrieved from http://www.didactiefonline.nl/actueel-dossier-cito/47-uncategorised/11688-eindtoets-po-het-verdrietvan-cito

Butterworth, B., Varma, S., \& Laurillard, D. (2011). Dyscalculia: from brain to education. Science, 332(6033), 1049-1053. 


\section{References}

Central Bureau voor de Statistiek. (2011). Inpassing van het Nederlandse onderwijs in ISCED 2011. Internatnional Standard Classification of Education. Retrieved from http://www.cbs.nl/nl$\mathrm{NL} / \mathrm{menu} / \mathrm{methoden} /$ classificaties/overzicht/isced/default.htm

Chevalier, A., Harmon, C., O'Sullivan, V., \& Walker, I. (2013). The impact of parental income and education on the schooling of their children. IZA Journal of Labor Economics, 2(1), 1-22.

Cirino, P. T. (2011). The interrelationships of mathematical precursors in kindergarten. Journal of Experimental Child Psychology, 4(108), 713-733.

Cito. (1997). Leerlingvolgsysteem: Ordenen - Platenoek Oudste Kleuters (Cito Ed.). Arnhem, Netherlands: Cito.

College voor Toetsen en Examens. (2015). Interpretatie van het leerlingrapport bij de centrale eindtoets PO 2015. Utrecht: College voor Toetsen en Examens.

Couch, K. A., \& Lillard, D. R. (1998). Sample selection rules and the intergenerational correlation of earnings. Labour Economics, 5(3), 313-329.

Cunha, F., \& Heckman, J. J. (2008). Formulating, identifying and estimating the technology of cognitive and noncognitive skill formation. Journal of Human Resources, 43(4), 738-782.

De Smedt, B., Verschaffel, L., \& Ghesquière, P. (2009). Journal of Experimental Child Psychology. Journal of Experimental Child Psychology, 103, 469-479.

Dehaene, S. (2011). The Number Sense: How the Mind Creates Mathematics: Oxford University Press.

Dehaene, S., Piazza, M., Pinel, P., \& Cohen, L. (2003). Three parietal circuits for number processing. Cognitive Neuropsychology, 20(3-6), 487-506.

Diekmann, A., \& Schmidheiny, K. (2004). Do Parents of Girls Have a Higher Risk of Divorce? An EighteenCountry Study. Journal of Marriage and Family, 66(3), 651-660.

Dienst Uitvoering Onderwijs. (2016). Open onderwijsdata. Retrieved from https://duo.nl/open onderwijsdata/databestanden/

Diris, R. E. M. (2012). The economics of the school curriculum. Maastricht University.

Dowker, A. (2005). Early Identification and Intervention for Students With Mathematics Difficulties. Journal of Learning Disabilities, 38(4), 324-332.

Dowker, A. (2008). Individual differences in numerical abilities in preschoolers. Developmental Science, 11(5), 650-654.

Dowker, A. (2015). Individual differences in arithmetical abilities. In R. C. Kadosh \& A. Dowker (Eds.), The Oxford handbook of numerical cognition (pp. 878-894). USA: Oxford University Press.

Downey, D. B., Von Hippel, P. T., \& Broh, B. A. (2004). Are schools the great equalizer? Cognitive inequality during the summer months and the school year. American Sociological Review, 69(5), 613-635.

Dronkers, J., \& Korthals, R. (2016, forthcoming). Tracking in the Netherlands - Ability selection or social reproduction? In H.-P. Blossfeld, S. Buchholz, J. Skopek, \& M. Triventi (Eds.), Models of Secondary Education and Social Inequality - An International Comparison (pp. 149-165). Cheltenham, UK and Northampton, MA, USA: Edward Elgar Publishing.

Duncan, G. J., Dowsett, C. J., Claessens, A., Magnuson, K., Huston, A. C., Klebanov, P., . . Brooks-Gunn, J. (2007). School Readiness and Later Achievement. Developmental Psychology, 43(6), 1428-1446.

Educatieve Agenda Limburg. (2016). The OnderwijsMonitor Limburg. Retrieved from www.educatieveagendalimburg.nl/onderwijsmonitor-p/english

EUROSTAT. (2009). Task force on the quality of the Labour Force Survey. Retrieved from Luxembourg:

Frohne, E. (2009). Netherlands Limburg location map. Retrieved from https://commons.wikimedia.org/wiki/File:Netherlands_Limburg_location_map.svg?uselang=de 
Fryer Jr, R. G., \& Levitt, S. D. (2004). Understanding the black-white test score gap in the first two years of school. Review of Economics and Statistics, 86(2), 447-464.

Geary, D. C., Bailey, D. H., Littlefield, A., Wood, P., Hoard, M. K., \& Nugent, L. (2009). First-grade predictors of mathematical learning disability: A latent class trajectory analysis. Cognitive Development, 24(4), 411429.

Gebuis, T., \& Reynvoet, B. (2015). Number representations and their relation with mathematical ability. In R. C. Kadosh \& A. Dowker (Eds.), The Oxford handbook of numerical cognition (pp. 331-344). USA: Oxford University Press.

Gersten, R., \& Chard, D. (1999). Number sense rethinking arithmetic instruction for students with mathematical disabilities. The Journal of Special Education, 33(1), 18-28.

Gersten, R., Jordan, N. C., \& Flojo, J. R. (2005). Early identification and interventions for students with mathematics difficulties. Journal of Learning Disabilities, 38(4), 293-304.

Göbel, S. M., Watson, S. E., Lervåg, A., \& Hulme, C. (2014). Children's arithmetic development:: it is number knowledge, not the approximate number sense, that counts. Psychological Science, 25(3), 789-798.

Greeno, J. G. (1991). Number Sense as Situated Knowing in a Conceptual Domain. Journal for Research in Mathematics Education, 22(3), 170-218.

Hauser, R. M. (2005). Survey response in the long run: The Wisconsin Longitudinal Study. Field Methods, 17(1), 3-29.

Heckman, J. J. (2006). Skill formation and the economics of investing in disadvantaged children. Science, 312(5782), 1900-1902.

Holgado-Tello, F. P., Chacón-Moscoso, S., Barbero-García, I., \& Vila-Abad, E. (2010). Polychoric versus Pearson correlations in exploratory and confirmatory factor analysis of ordinal variables. Quality \& Quantity, 44(1), 153-166.

Howell, S., \& Kemp, C. (2005). Defining early number sense: A participatory Australian study. Educational Psychology, 25(5), 555-571.

Inspectie van het Onderwijs. (2014). De staat van het onderwijs, onderwijsverslag 2012/2013. Utrecht: Insepctie van het Onderwijs, Nederland.

Janssen, J., Scheltens, F., \& Kraemer, J.-M. (2009). Primair onderwijs Cito Volgsysteem (LOVS): RekenenWiskunde groep 8 - Handleiding. Arnhem, Netherlands: Cito.

Jordan, N. C., Glutting, J., \& Ramineni, C. (2010). The Importance of Number Sense to Mathematics Achievement in First and Third Grades. Learning and Individual Differences, 20(2), 82-88.

Jordan, N. C., Kaplan, D., Locuniak, M. N., \& Ramineni, C. (2007). Predicting first-grade math achievement from developmental number sense trajectories. Learning Disabilities Research \& Practice, 22(1), 36-46.

Jordan, N. C., Kaplan, D., Nabors Oláh, L., \& Locuniak, M. N. (2006). Number sense growth in kindergarten: A longitudinal investigation of children at risk for mathematics difficulties. Child Development, 77(1), 153175 .

Jordan, N. C., Kaplan, D., Ramineni, C., \& Locuniak, M. N. (2009). Early math matters: kindergarten number competence and later mathematics outcomes. Developmental Psychology, 45(3), 850-867.

Koenker, R., \& Bassett Jr, G. (1978). Regression quantiles. Econometrica, 46(1), 33-50.

Kolenikov, S., \& Angeles, G. (2004). The use of discrete data in principal component analysis with applications to socio-economic indices. MEASURE Working paper No. WP-04-85. Carolina Population Center, University of North Carolina. Chapel Hill.

Kolkman, M. E., Kroesbergen, E. H., \& Leseman, P. P. (2013). Early numerical development and the role of nonsymbolic and symbolic skills. Learning and Instruction, 25, 95-103. 


\section{References}

Krajewski, K., \& Schneider, W. (2009). Early development of quantity to number-word linkage as a precursor of mathematical school achievement and mathematical difficulties: Findings from a four-year longitudinal study. Learning and Instruction, 19(6), 513-526.

Lago, R. M. (2007). Examining the psychometrics of number sense among kindergarten students. The Pennsylvania State University.

Lang, K. (2010). Measurement matters: Perspectives on education policy from an economist and school board member. The Journal of Economic Perspectives, 24(3), 167-181.

LeFevre, J. A., Fast, L., Skwarchuk, S. L., Smith-Chant, B. L., Bisanz, J., Kamawar, D., \& Penner-Wilger, M. (2010). Pathways to mathematics: Longitudinal predictors of performance. Child Development, 81(6), 1753-1767.

Lembke, E., \& Foegen, A. (2009). Identifying early numeracy indicators for kindergarten and first-grade students. Learning Disabilities Research \& Practice, 24(1), 12-20.

Locuniak, M. N., \& Jordan, N. C. (2008). Using kindergarten number sense to predict calculation fluency in second grade. Journal of Learning Disabilities, 41(5), 451-459.

Luyten, H., Cremers-Van Wees, L., \& Bosker, R. (2003). The Matthew effect in Dutch primary education: Differences between schools, cohorts and pupils. Research Papers in Education, 18(2), 167-195.

Malofeeva, E., Day, J., Saco, X., Young, L., \& Ciancio, D. (2004). Construction and evaluation of a number sense test with head start children. Journal of Educational Psychology, 96(4), 648-659.

Martikainen, P., Laaksonen, M., Piha, K., \& Lallukka, T. (2007). Does survey non-response bias the association between occupational social class and health? Scandinavian Journal of Public Health, 35(2), 212-215.

Micklewright, J., \& Schnepf, S. V. (2006). Response Bias in England in PISA 2000 and 2003 (Vol. 771): Department for Education and Skills.

Moeller, K., Pixner, S., Klein, E., Cress, U., \& Nuerk, H. (2009). Zahlenverarbeitung ist nicht gleich RechnenEine Beschreibung basisnumerischer Repräsentationen und spezifischer Interventionsansätze. Prävention und Rehabilitation, 21, 121-136.

Muthén, B., \& Muthén, L. (2012). Mplus 7 base program. Los Angeles, CA: Muthén \& Muthén.

National Longitudinal Surveys. (2016). National Longitudinal Survey of Youth 1979. Retrieved from https://www.nlsinfo.org/content/cohorts/nlsy79

Nuerk, H.-C., Geppert, B. E., van Herten, M., \& Willmes, K. (2002). On the impact of different number representations in the number bisection task. Cortex, 38(5), 691-715.

OECD. (2013). PISA 2012 Results: Excellence through Equity: Giving Every Student the Chance to Succeed (Volume II). PISA: OECD Publishing.

Okamoto, Y., \& Case, R. (1996). II. Exploring the microstructure of children's central conceptual structures in the domain of number. Monographs of the Society for Research in Child Development, 61(1-2), 27-58.

Parsons, S., \& Bynner, J. (2005). Does numeracy matter more? London: National Research Development Centre for Adult Literacy and Numeracy (NRDC).

Passolunghi, M. C., \& Lanfranchi, S. (2012). Domain-specific and domain-general precursors of mathematical achievement: A longitudinal study from kindergarten to first grade. British Journal of Educational Psychology, 82(1), 42-63.

Passolunghi, M. C., Vercelloni, B., \& Schadee, H. (2007). The precursors of mathematics learning: Working memory, phonological ability and numerical competence. Cognitive Development, 22(2), 165-184.

Plug, E., \& Vijverberg, W. (2005). Does family income matter for schooling outcomes? Using adoptees as a natural experiment*. The Economic Journal, 115(506), 879-906. 
Polidano, C., Hanel, B., \& Buddelmeyer, H. (2013). Explaining the socio-economic status school completion gap. Education Economics, 21(3), 230-247.

Porter, S. R., \& Whitcomb, M. E. (2005). Non-response in student surveys: The role of demographics, engagement and personality. Research in Higher Education, 46(2), 127-152.

Reijneveld, S., \& Stronks, K. (1999). The impact of response bias on estimates of health care utilization in a metropolitan area: the use of administrative data. International Journal of Epidemiology, 28(6), 11341140.

Riphahn, R. T., \& Serfling, O. (2005). Item non-response on income and wealth questions. Empirical Economics, $30(2), 521-538$.

Sabelhaus, J., Johnson, D., Ash, S., Swanson, D., Garner, T. I., Greenlees, J., . . G Garner, G. (2015). Is the Consumer Expenditure Survey Representative by Income? In C. D. Carroll, T. F. Crossley, \& J. Sabelhaus (Eds.), Improving the Measurement of Consumer Expenditures (Vol. 74, pp. 241-262). Chicago and London: University of Chicago Press.

Sammons, P. (1995). Gender, ethnic and socio-economic differences in attainment and progress: a longitudinal analysis of student achievement over 9 years. British Educational Research Journal, 21(4), 465-485.

Sasanguie, D., Göbel, S. M., Moll, K., Smets, K., \& Reynvoet, B. (2013). Approximate number sense, symbolic number processing, or number-space mappings: What underlies mathematics achievement? Journal of Experimental Child Psychology, 114(3), 418-431.

Schafer, J. L., \& Graham, J. W. (2002). Missing Data: Our View of the State of the Art. Psychological Methods, $7(2), 147-177$.

Schermelleh-Engel, K., Moosbrugger, H., \& Müller, H. (2003). Evaluating the fit of structural equation models: Tests of significance and descriptive goodness-of-fit measures. Methods of Psychological Research Online, 8(2), 23-74.

Schmitt, D. P., Realo, A., Voracek, M., \& Allik, J. (2008). Why Can'ta Man Be More Like a Woman? Sex Differences in Big Five Personality Traits Across 55 Cultures. Journal of Personality and Social Psychology, 94(1), 168-182.

Sims, D. P. (2008). Strategic responses to school accountability measures: It's all in the timing. Economics of Education Review, 27(1), 58-68.

SLO - nationaal expertisecentrum leerplanotwikkeling. (2006). Dutch Core objectives Primary Education.

Søgaard, A. J., Selmer, R., Bjertness, E., \& Thelle, D. (2004). The Oslo Health Study: The impact of self-selection in a large, population-based survey. International Journal for Equity in Health, 3(1), 3.

Statistics Netherlands. (2014). Population dynamics; birth, death and migration per region. Retrieved from http://statline.cbs.nl/StatWeb/publication/?VW=T\&DM=SLEN\&PA=37259eng\&LA=EN

Statistics Netherlands. (2015). Regionale kerncijfers; nationale rekeningen. Retrieved from http://statline.cbs.nl/Statweb/publication/?DM=SLNL\&PA=82801ned\&D1=a\&D2=0,6$17 \& \mathrm{D} 3=\mathrm{a} \& \mathrm{VW}=\mathrm{T}$

Statistics Netherlands. (2016). Regionale kerncijfers Nederland. Retrieved from The Hague, and Heerlen: http://statline.cbs.nl/StatWeb/publication/?VW=T\&DM=SLNL\&PA=70072ned\&LA=NL

Torche, F. (2015). Analyses of Intergenerational Mobility An Interdisciplinary Review. The ANNALS of the American Academy of Political and Social Science, 657(1), 37-62.

TUBS. (2011). Limburg in the Netherlands. Retrieved from https://commons.wikimedia.org/wiki/File:Limburg_in the_Netherlands.svg?uselang=de

Turrell, G., Patterson, C., Oldenburg, B., Gould, T., \& Roy, M.-A. (2003). The socio-economic patterning of survey participation and non-response error in a multilevel study of food purchasing behaviour: area-and individual-level characteristics. Public Health Nutrition, 6(2), 181-189. 


\section{References}

Van Kuyk, J. J. (1997). Leerlingvolgsysteem: Ordenen - Handleiding. Arnhem, Netherlands: Cito.

Washington, E. L. (2008). Female Socialization: How Daughters Affect Their Legislator Fathers' Voting on Women's Issues. American Economic Review, 98(1), 311-332.

Weiß, R. H., \& Osterland, J. (2013). Grundintelligenztest Skala 1: Revision; CFT 1-R: Hogrefe. 


\section{Curriculum Vitae}

Stefa Hirsch was born on April 26, 1986 in Castrop-Rauxel, Germany. She graduated from high school (Gymnasium) at the CJD Christophorusschule Brunswick, Germany, in 2005.

From 2005 until 2011, she studied economics at the University of Mannheim, Germany, specializing in labor economics and behavioral economics. In the academic year 2008/2009, she participated in the $\mathrm{PhD}$ program of the University of California at Berkeley.

In 2012, she started working for a consultancy firm in Cologne, returning to academia to pursue a PhD in the economics of education at Maastricht University in September 2013. The result of her work as a doctoral candidate is compiled in this dissertation. Part of the thesis was written at the Hector Research Institute of Education Sciences and Psychology in Tuebingen, Germany, during a research stay from January until March 2016. She presented her research at international conferences, amongst others annual meetings of the Society of Labor Economists (June 2015, May 2016), the European Society for Population Economics (June 2016) and the European Economic Association (September 2016).

In April 2016, she also completed her Bachelor of Science in psychology. Since October 2016, she holds the position of postdoctoral researcher at the Leibniz-Institut für Wissensmedien (IWM), located in Tuebingen. Concurrently, she works in her own consultancy firm in Berlin. 